Original Research Paper

\title{
Modern Propulsions for the Aerospace Industry
}

\author{
${ }^{1}$ Relly Victoria Virgil Petrescu, ${ }^{2}$ Raffaella Aversa, \\ ${ }^{2}$ Antonio Apicella and ${ }^{1}$ Florian Ion Tiberiu Petrescu \\ ${ }^{I}$ ARoTMM-IFToMM, Bucharest Polytechnic University, Bucharest, (CE), Romania \\ ${ }^{2}$ Department of Architecture and Industrial Design, Advanced Material Lab, \\ Second University of Naples, 81031 Aversa (CE), Italy
}

Article history

Received: 10-03-2018

Revised: 02-04-2018

Accepted: 11-05-2018

Corresponding Author: Florian Ion Tiberiu Petrescu ARoTMM-IFToMM, Bucharest Polytechnic University, Bucharest, (CE), Romania Email: scipub02@gmail.com

\begin{abstract}
This paper aims to contribute to the study of propulsion systems for modern aerospace vehicles with the obvious aim of improving them and to give them the ability to move much faster and easier in any direction, for a very long time, going through huge distances without the need of fuel refueling, as is the case with conventional, chemical propulsion. The work aims to raise the level of protection and safety of the pilots, these wonderful and brave people, who often realize true wonders for humanity without asking for additional rights or bragging with their silent achievements. At the same time, it is desirable to gradually move to new propulsion systems originally intended for spacecraft so that they can then be deployed quickly to conventional aircraft carrying passengers everywhere on our planet. The proposed modern propulsion systems no longer retain anything from the classical chemical technique but are based on a reaction technique in which a new type of fuel will be emitted, namely energy, accelerated particles at very high speeds, energies and impulses, accelerated ions, accelerated electrons, or concentrating photons of the same frequency (LASER).
\end{abstract}

Keywords: Propulsion Systems, Modern Aerospace Vehicles, Energy, Power, Impulses, Accelerated Ions, Accelerated Electrons, Photons, LASER

\section{Introduction}

In August 1884-Alexander Fjodorowitsch Moshaiski carried out the first unplanned (uncontrolled) engine by ramp-launch. On August 14, 1901, Gustav Albin Weisskopf/Whitehead conducted the first international (self-guided) (self-guided), controlled (controlled) motorized flight. On December 17, 1903, the Wright Brothers succeeded in the first controlled flight, a slingshot launch. On March 18, 1906, Traian Vuia had the first detachment of a self-propelled aircraft, Vuia 1. Then on September 12, 1906 - Jacob Christian Hansen Ellehammer, with Ellehammer I, on October 23, 1906 Alberto Santos-Dumont "14bis" on November 12, 1906 Alberto Santos-Dumont "14bis" corps record.

On January 13, 1908, Henri Farman "Voisin-Farman1" performed the first flight recognized by the FIA over a distance of $1 \mathrm{~km}$. He was born on 8th June 1908 - Roe I, then on January 23rd, 1909 - Blériot XI, on April 6, 1909 Henri Farman with Farman III, on 5th June 1909 - Avro Triplane No. 1, on September 13, 1909 - Alberto SantosDumont's with "Demoiselle" (Petrescu and Petrescu, 2012a). On March 28, 1910, the first flight with a Hydroavion Henri Fabre takes place. In April 1910 - Avro Triplane No. 2. Then on June 17, 1910 - Vlaicu I-Aurel Vlaicu. Continue on 24 June 1910 - Avro Triplane No. 3 and on July 30, 1910 - Bristol Boxkite, then immediately on December 16, 1910 - Coanda-1910 Henri Coanda the first tests of a propulsion aircraft (reaction). In April 1911 - Avro Type D, in 19th July 1911 - Avro Curtiss-type, in December 1911 - Duigan Biplane von Avro.

On March 3, 1912 - Avro 500 / Type E, then on May 1, 1912 - Avro Type F, on August 7, 1912 - Avro Type G. In January 1913 - Avro 501, on May 28, 1913 - Avro 503, then in July 1913 - Avro 504, in May 1914 - Avro 514, in April 1915 - Avro 508, on May 21, 1915 - SPAD A 1, on June 1, 1915 - Airco DH2, in April 1916 - SPAD S.VII, on February 22, 1916 - SPAD A 4, May 1916 Avro 523, September 9, 1916 - Bristol F.2A, in 1917 AEG D I and in March 1917 - Avro 529, following in 4. April 1917 - SPAD S.XIII, in Juli 1917 - Airco D.H.9, in Juli 1917 - Avro 530, in 5. Juli 1917 - SPAD S.XII, in April 1918 - Avro 531, in August 7, 1918 - BlériotSPAD S.XX, in 21 August 1918 - Nieuport-Delage NiD 
29, in 4 October 1918 - Curtiss NC, in Dezember 1918 Avro 533, in 1919 - Avro 548, in April 1919 - Avro 536, in April 30, 1919 - Avro 534, in 25 June 1919 - Junkers F.13 (Petrescu and Petrescu, 2012a).

The following flights took place: 1920 - Avro 571, 1920 - Cierva C.1 Autogiro, February 1920 - Avro 547, December 12, 1920 - Blériot-SPAD S.33, March 4, 1921 - Caproni Ca.60, 1921 - Avro 555 Bison, 1921 Cierva C.2 Autogiro, 1922 - Avro 549, 1922 - Cierva C.3 Autogiro, 1923 - Avro 560, 9. January 1923 Cierva C.4 Autogiro, February 1923 - Blériot-SPAD S.56, 29. April 1923 - Boeing Modell 15 / PW-9, May 9, 1923 - Blériot 115, July 1923 - Cierva C.5 Autogiro, October 1923 - Avro 558, 1924 - Avro 562 Avis, May 1924 - Cierva C.6A Autogiro, June 1924 - Avro 561 Andover, 1925 - Avro 563 Andover, February 22, 1925 - de Havilland DH.60 Moth, May 1926 - Blériot 127, 29 July 1926 - Cierva C.6D Autogiro/Avro 587, September 1926 - Avro 581, April 1927 - Avro 594, September 1927 - Avro 576/Cierva C.9 AutogiroAvro 576, Novembrie 1927 - Avro 604 Antelope, December 1927 - counsel, Avro 584, 7 January 1928 - Polikarpow U-2, 9 March 1928 - ACAZ C.2, 11 June 1928 - first human flight in a rocket Lippisch Ente, July 1929 Avro 618, June 1929 - Avro 619, 24 January 1929 Blériot 111, 25 July 1929 - Dornier Do X (List the first flights, From Wikipedia).

Next: May 1930 - Avro 624, June 1930 - Avro 621, 13. October 1930 - Junkers Ju 52/3m W No.4013, D2201, December 21, 1930 - Blériot 137, March 9, 1931 Blériot 125, October 17, 1931 - Dornier Y, October 26, 1931 - by Havilland DH.82A Tiger Moth, 4. November 1932 - Beech Model 17 Staggerwing, February 1933 Boeing Model 247, April 28, 1933 - Fiat CR.32, July 1, 1933 - Douglas DC-1, December 31, 1933 - Polikarpow I-16 Rates (ZKB-12), November 4, 1934 - Junkers Ju 86, later V-1 Wnr.4901, D-AHEH, November 17, 1934 Heinkel He 111, later V-1 Wnr.713, D-ADAP, November 23, 1934 - Dornier Do 17 C, later V-1 Wnr.256, D-AJUN, March 28, 1935 - Consolidated XP3Y-1, April 1, 1935 - North American NA-16, April 15, 1935 - Douglas TBD-1 Devastator Prototype als XTBD-1), May 28, 1935 - Messerschmitt Bf 109 V-1 Wnr.758, D-IABI, 15 July 1935 - Dornier Do 18 A, later V-1 Wnr.253, D-AHIS, 28. July 1935 - Boeing Model 299 (B-17 Flying Fortress), September 17, 1935 Junkers Ju 87 V-1 Wnr.4921, October 5, 1935 - Nieuport 160 (1.Prototype named later Nieuport 161), November 8, 1935 - Hawker Hurricane, December 17, 1935 Douglas DC-3 (as Douglas Sleeper Transport/DST) February 1936 - Fiat BR.20, March 1936 - Nieuport 161, March 4, 1936 - Zeppelin LZ 129 Hindenburg, March 5, 1936 - Supermarine Type 300 Spitfire (K5054), May 10, 1936 - Fieseler Fi 156 V-1 Wnr. 601, D-IBXY, 3 July 1936 - Short S.23 Empire (C.23), 28 September 1936 -
Dornier Do 14 Wnr.234, D-AGON, 21 October 1936 Junkers Ju 88 V-1 Wnr.4941, D-AQEN, October 30, 1936 - Dornier Do 19 V-1 Wnr.701, D-AGAI, January 15, 1937 - Beechcraft Model 18, February 9, 1937 Blackburn B-24 Skua, March 4, 1937 - Junkers EF 61 E1 Wnr.4931, April 11, 1937 - Junkers Ju 89 V-1 Wnr.4911, D-AFIT, May 7, 1937 - Lockheed XC-35, 16 June 1937 - Airspeed AS 10 Oxford, July 5, 1937 Dornier Do 24 V-3 Wnr.761, D-ADLP, July 27, 1937 Focke-Wulf Fw 200, August 28, 1937 - Junkers Ju 90 V1 Wnr.4913, D-ALUU, October 16, 1937 - Short S.25 Sunderland (K4774), January 10, 1938 - Dornier Do 24 V-1 Wnr.760, D-AIBE, October 2, 1938 - Dewoitine D. 5 May 1939 - Mitsubishi A6M "Zero", May 7, 1939 Petljakow WI-100 (Prototype of Pe-3, later Pe-2), May 14, 1939 - Short Stirling, 1. June 1939 - Finke-Wulf Fw 190 V-1, 20. June 1939 - Heinkel He 176 (missile plane), 27.August 1939 - Heinkel He 178 (Erstflug first flight with propulsion and turbine aircraft), 25 October 1939 - Handley Page HP57, December 3, 1939 - Bloch 155, December 29, 1939 - Consolidated XB-24 Liberator, December 30, 1939 - Iljuschin BSch-2 (ZKB55) IL-2), (List the first flights, From Wikipedia).

The following were followed: 29. May 1940 Vought XF4U-1/F4U Corsair (with the corresponding prototype), September 7, 1940 - Blohm \& Voss BV 222, October 27, 1940 - Airspeed AS 39 Fleet Shadower, American NA-73 (Prototype for P-51 Mustang Series), November 25, 1940 - de Havilland DH.98 Mosquito (W4050) (Prototype), November 25, 1940 - Martin B-26 Marauder (40-1361) November 1940 - Junkers Ju 288 V1 Wnr.0001, D-AACS, January 9, 1941 - Avro Manchester III (BT308) (Prototype), March 30, 1941 Heinkel He 280 V-2 with two non, 18. April 1941 Messerschmitt Me 262 V-1, May 15, 1941 - Gloster E.28/39 (the first British propelled airplane), June 27, 1941 - Douglas XB-19, July 9, 1941 - Fieseler Fi 256 V 1 Wnr.001, 1 August 1941 - Grumman XTBF-1 Avenger, 13 August 1941 - Messerschmitt Me 163A Komet, 12 September 1941 - Airspeed AS 51 Horsa, 22 December 1941 - Fairey Firefly (Z1826), 14. January 1942 - Sikorsky XR-4, March 1942 - Bloch 157, 19. April 1942 - Macchi MC.205, April 30, 1942 - Gumman XF6F-3 Helicat (02982), July 16, 1942 - Junkers Ju 290 V-1 Wnr.0001, BD + TX, September 21, 1942 - Boeing B -29 (Aus 345 / XB-29), September 7, 1942 Consolidated B-32, October 1, 1942 - Bell XP-59A Airacomet (erstes Strahlflugzeug der USA), November 15, 1942 - Heinkel He 219 Uhu, 9 January 1943 Lockheed L-049 Constellation, March 5, 1943 - Gloster Meteor (DG206) (1.Prototyp mit Halford H.1 Motoren), April 1943 - Nakajima Ki-84, 15th June 1943 - Arado Ar 234V-1 Blitz, October 20, 1943 - Junkers Ju 390 V-1 Wnr.0001, GH + UK, January 9, 1944 - Lockheed XP80 Shooting Star (44-83020), March 11, 1944 - Blohm 
and Voss BV 238, July 12, 1944 - Focke-Wulf Ta 152 H, 28 July 1944 - by Havilland Hornet (RR915), August 21, 1944 - Grumman F8F, September 10, 1944 - Fairchild XC-82 Packet (43-13202), December 8, 1945 - Bell 47, April 24, 1946 - Jakowlew Jak-15, April 24, 1946 Mikoyan-Gurewitsch MiG-9 (Prototype named as I300), 22 May 1946 - de Havilland Canada DHC-1 Chipmunk, June 1946 - Northrop YB-35, August 8, 1946 - Convair XB-36, July 16, 1947 - Saunders-Roe SR.A/1, 31. August 1947 - Antonow An-2 (Prototype named as SKh-1), October 1, 1947 - North American F-86 Saber (1.Prototype named as NA-140 (XP-86) Hughes H-4, November 23, 1947 - Convair XC-99, December 17, 1947 - Boeing B-47 (Prototype als XB-47, 46-065), December 30, 1947 - Mikoyan-Gurewitsch MiG- as I310 (Type'S 1/ S-01)), 16th July 1948 - Vickers Viscount, August 16, 1948 - Northrop F-89 Scorpion (1Prootype named as N-24 (XP-89)). September 1948 - Saab 29 Tunnan, May 1949 - English Electric/BAC Canberra (1.Prototype named as VN799), July 27, 1949 - de Havilland DH.106 Comet I, September 4, 1949 - Bristol Brabazon I, 19th September 1949 - Fairey Gannet, 10 November 1949 - Sikorsky S-55 (List the first flights, From Wikipedia; Chen and Patton, 1999; Fernandez et al., 2005; Fonod et al., 2015; Lu et al., 2015; 2016; Murray et al., 2010; Palumbo et al., 2012; Patre and Joshi, 2011; Sevil and Dogan, 2015; Sun and Joshi, 2009; Crickmore, 1997; Donald, 2003; Goodall, 2003; Graham, 2002; Jenkins, 2001; Landis and Dennis, 2005; Clément, Wikipedia; Cayley, Wikipedia; Coandă, Wikipedia; Gunston, 2010; Laming, 2000; Norris, 2010; Goddard, 1916; Kaufman, 1959; Oberth, 1955; Cataldo, 2006; Gruener, 2006; Sherson et al., 2006; Williams, 1995; Venkataraman, 1992; Oppenheimer and Volkoff, 1939; Michell, 1784; Droste, 1915; Finkelstein, 1958; Gorder, 2015; Hewish, 1970). Today, airplane flights are becoming more and more often used, becoming a routine and managing to develop and conquer a very large market segment, to the detriment of public transport by rail or by water. Many travelers choose to travel by air rather than by train or boat, due to the shorter travel time and the more enjoyable way to travel in flight under conditions of safety and comfort.

There is a fierce competition between aircraft and train journeys, permanent train managers seeking to improve the train travel conditions and considerably increase the speed of travel by introducing Maglev (magnetic levitation) type trains, or classic trains with increased mobility capabilities.

If to the large or very large airplanes, have been introduced for passenger some cinemas for a long time ago and newer laptops and individual gagets for all their passengers, to have the opportunity to play a game or watch a TV, some desired film, or simply sail on a personal computer during the trip, today and the trains have started to introduce such modern means of spending time for their travelers.

The introduction of the modern propulsions and to the trains was not only a fad or a necessity to respond to the big competition made with the modern passenger aircraft, but rather constituted a need to restructure a major segment of rail passenger transport, by fast and modern means of national and international rail transport and aircraft have now increased both travel speeds and unobstructed spaces realized, from the need to earn a major transportation segment. However, there is still a need for new aerospace concepts to implement new propulsion concepts that can move the aircraft much faster with increased safety and comfort and much longer distances without stopping for refueling (Ward, 2010).

This paper attempts to propose such concepts and from respect to our wonderful pilots, but also with the conviction that humanity period in galactic and universal expansion has already begun (Frăţilă et al., 2011; Pelecudi, 1967; Antonescu, 2000; Comănescu et al., 2010; Aversa et al., 2016a; 2016b; 2016c; 2016d; 2017a; 2017b; 2017c; 2017d; 2017e; Mirsayar et al., 2017; Cao et al., 2013; Dong et al., 2013; De Melo et al., 2012; Garcia et al., 2007; Garcia-Murillo et al., 2013; He et al., 2013; Lee, 2013; Lin et al., 2013; Liu et al., 2013; Padula and Perdereau, 2013; Perumaal and Jawahar, 2013; Petrescu and Petrescu, 1995a; $1995 \mathrm{~b} ; 1997 \mathrm{a} ; 1997 \mathrm{~b} ; 1997 \mathrm{c} ; 2000 \mathrm{a} ; 2000 \mathrm{~b} ; 2002 \mathrm{a}$; $2002 \mathrm{~b}$; 2003; 2005a; 2005b; 2005c; 2005d; 2005e, 2016a; 2016b; 2016c; 2016d; 2016e; 2013; 2012a; 2012b; 2011; Petrescu et al., 2009; 2016a; 2016b; 2016c; 2016d; 2016e; 2017a; 2017b; 2017c; 2017d; $2017 \mathrm{e} ; 2017 \mathrm{f} ; 2017 \mathrm{~g} ; 2017 \mathrm{~h} ; 2017 \mathrm{i} ; 2017 \mathrm{j} ; 2017 \mathrm{k}$; 2017l; 2017m; 2017n; 2017o; 2017p; 2017q; 2017r; $2017 \mathrm{~s} ; 2017 \mathrm{t} ; 2017 \mathrm{u} ; 2017 \mathrm{v} ; 2017 \mathrm{w} ; 2017 \mathrm{x} ; 2017 \mathrm{y}$; 2017z; 2017aa; 2017ab; 2017ac; 2017ad; 2017ae; Petrescu and Calautit, 2016a; 2016b; Reddy et al., 2012; Tabaković et al., 2013; Tang et al., 2013; Tong et al., 2013; Wang et al., 2013; Wen et al., 2012; Antonescu and Petrescu, 1985; 1989; Antonescu et al., $1985 \mathrm{a} ; 1985 \mathrm{~b} ; 1986 ; 1987 ; 1988 ; 1994 ; 1997 ; 2000 \mathrm{a}$; 2000b; 2001).

\section{Materials and Methods}

An ion propellant (Fig. 1) is an electrical propulsion form used to propel the spacecraft that creates force by accelerating the ions. Ion extinguishers are classified as they accelerate ions using electrostatic or electromagnetic force. Electrostatic ion propulsion engines use the Coulomb force and accelerate the ions in the direction of the electric field. Electromagnetic ion gates use the Lorentz force to accelerate the ions. The term "propellant ionizer" typically designates chips or electrostatic networks. 


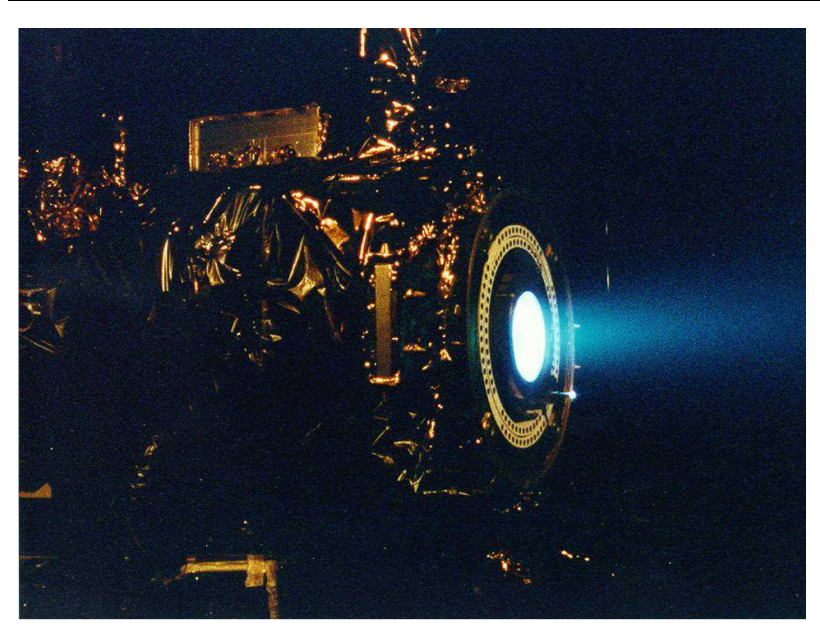

Fig. 1:NASA's $2.3 \mathrm{~kW}$ NSTAR ion thruster during a hot fire test at the Jet Propulsion Laboratory on the Deep Space 1 spacecraft

The propulsion created in ionic propellants is very small compared to conventional chemical missiles, but a specific impulse or very high propulsion power is obtained. This high fuel efficiency is achieved through the fuel efficiency of the propulsion system. However, they use a large amount of energy and, in use, their performance is limited to power (while normal chemical fuels are limited energies). Considering the practical weight of suitable power supplies, the accelerations given by these types of propellers are in the order of 1000 standard weights (The Future of Aircraft Propulsion is Electric, NASA).

Due to the relatively high power requirements, given the specific power of the power supplies and the need for a medium space of other ionized particles, ionic propulsion is currently only feasible beyond the planetary atmosphere.

The official father of the concept of electric propulsion is Konstantin Tsiolkovsky, who published for the first time a reference to this idea in 1911. However, the first documented example of the possibility of electric propulsion can be found in Robert H Goddard's book, September 1906 Experiments ionic propulsion were performed by Goddard at Clark University during 1916-1917.

The technique has been recommended for vacuum conditions near high altitude, but the force has been demonstrated with atmospheric pressure ionized air flows. The idea came back to Hermann Oberth from Wege zur Raumschiffahrt, published in 1923, explaining his thoughts on the massive propulsion economy, predicting its use in spacecraft propulsion and attitude control and leaving the gas loaded with electrostatic acceleration.

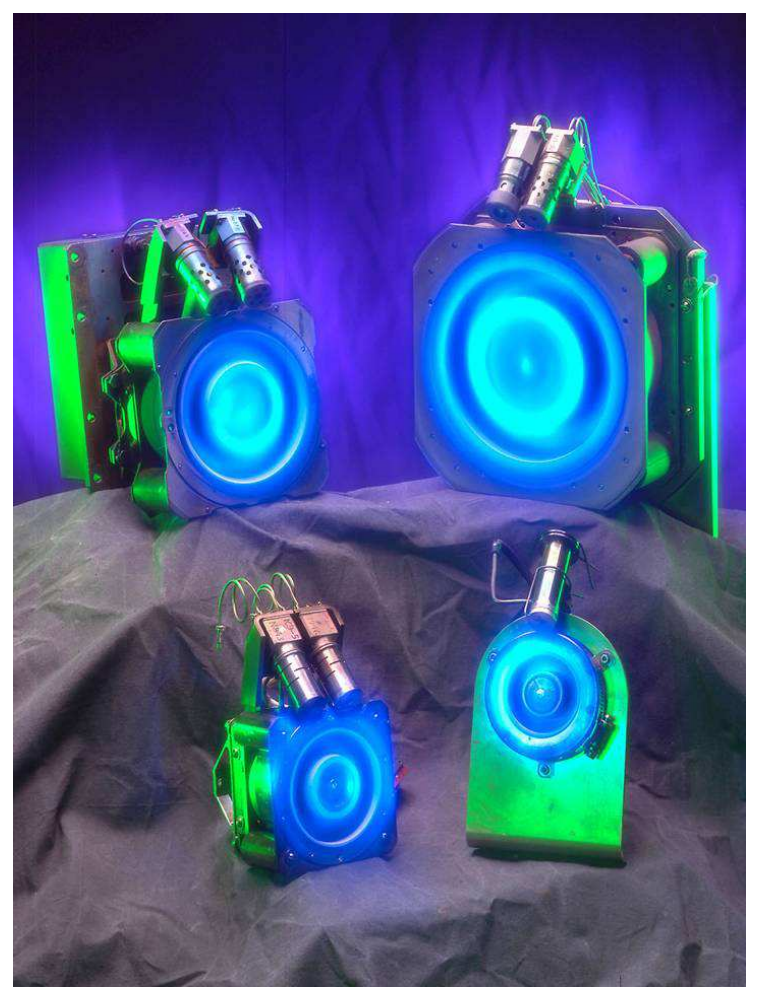

Fig. 2: Soviet and Russian Hall effect thrusters

An ionic propellant was built by Kaufman (1959) at the headquarters of the NASA Glenn Research Center. It was similar to the general design of an electrostatic gaseous propellant with mercury as a fuel. The suborbital tests of the engine followed in the 1960s and in 1964 the engine was sent on a suborbital flight aboard the Space Electric Rocket Test 1 (SERT 1) test. He worked successfully with planning 31 minutes before returning to Earth.

The effect of the Hall effect was independently studied in the US and USSR in the 1950s and 1960s (Fig. 2). However, Hall's propulsion concept has only been developed in an efficient Soviet Union propulsion system, while in the US, scientists have instead focused on the development of the ionic propellant. Projectors with Hall Effects have been operated on Soviet satellites since 1972. By the 1990s they were mainly used for satellite stabilization in the North-South and West-West directions. Some 100-200 engines completed their mission on Russian and Soviet satellites by the end of the 1990s. The Soviet pilot project was introduced in the West in 1992, after a team of electric propulsion specialists with the support of the Missile Defense Organization Bălţi, visited the Soviet laboratories.

Ionic advances use ionic beams (electrically charged atoms or molecules) to create a push in line with pulse preservation (Larson, 2015). 
The ion accelerating method varies, but all models take advantage of the charge/mass ratio of the ions.

This ratio means that relatively small potential differences can create very good evacuation speeds.

This reduces the amount of reaction mass or fuel required, but increases the amount of specific power required as compared to chemical missiles.

The ionic bands are thus able to obtain extremely high specific pulses.

The disadvantage of low pushing is the accelerated acceleration of the spacecraft as the mass of the current electric units is directly correlated with the amount of energy given.

This reduced push causes propellers not to be suitable for launching spacecraft in orbit, but they are ideal for space applications.

The various ionic propulsors have been designed and generally fall into two categories: Electrostatic or electromagnetic.

The main difference is how the ions are accelerating.

The electrostatic propulsion engines use the Coulomb force and are classified as acceleration ions in the direction of the electric field.

Electromagnetic ion gates use the Lorentz force to accelerate the ions.

Power sources for ion-powered motors are usually solar panels, but at a distance away from the sun, nuclear power is used.

In each case, the power supply is essentially proportional to the peak power that can be supplied and both provide essentially no power limit for this application.

\section{Electrostatic Electromotors}

\section{Propulsion Bullets with Electrostatic Ion}

Electrostatic ion propulsion jets typically use xenon gas (Fig. 3).

This gas has no charge and is ionized bombarding it with energetic electrons.

These electrons can be fed from a filament with a hot cathode and accelerated into the cathode's electric field, which enters the anode (Kaufman type propellant).

Alternatively, the electrons can be accelerated by the oscillating electric field induced by an alternating magnetic field of a coil, resulting in self-sustaining discharge and omitting any cathode (ionic radiofrequency propellant).

Positively charged ions are extracted through a 2 or 3 grate extraction system.

After entering the network system through the plasma sheath, the ions are accelerated due to the potential difference between the first network and the second potential (the screen called the acceleration grid) to the final ionic energy of $1-2 \mathrm{keV}$, generating the pulling force.

The propulsion ion only emits a positively charged xenon beam.

To avoid charging the spacecraft, another cathode is placed next to the electron-emitting engine (basically the electron flow is the same as the ion flux) in the ion beam.

This also prevents the return of the ion beam to spacecraft and, therefore, the cancellation of force.

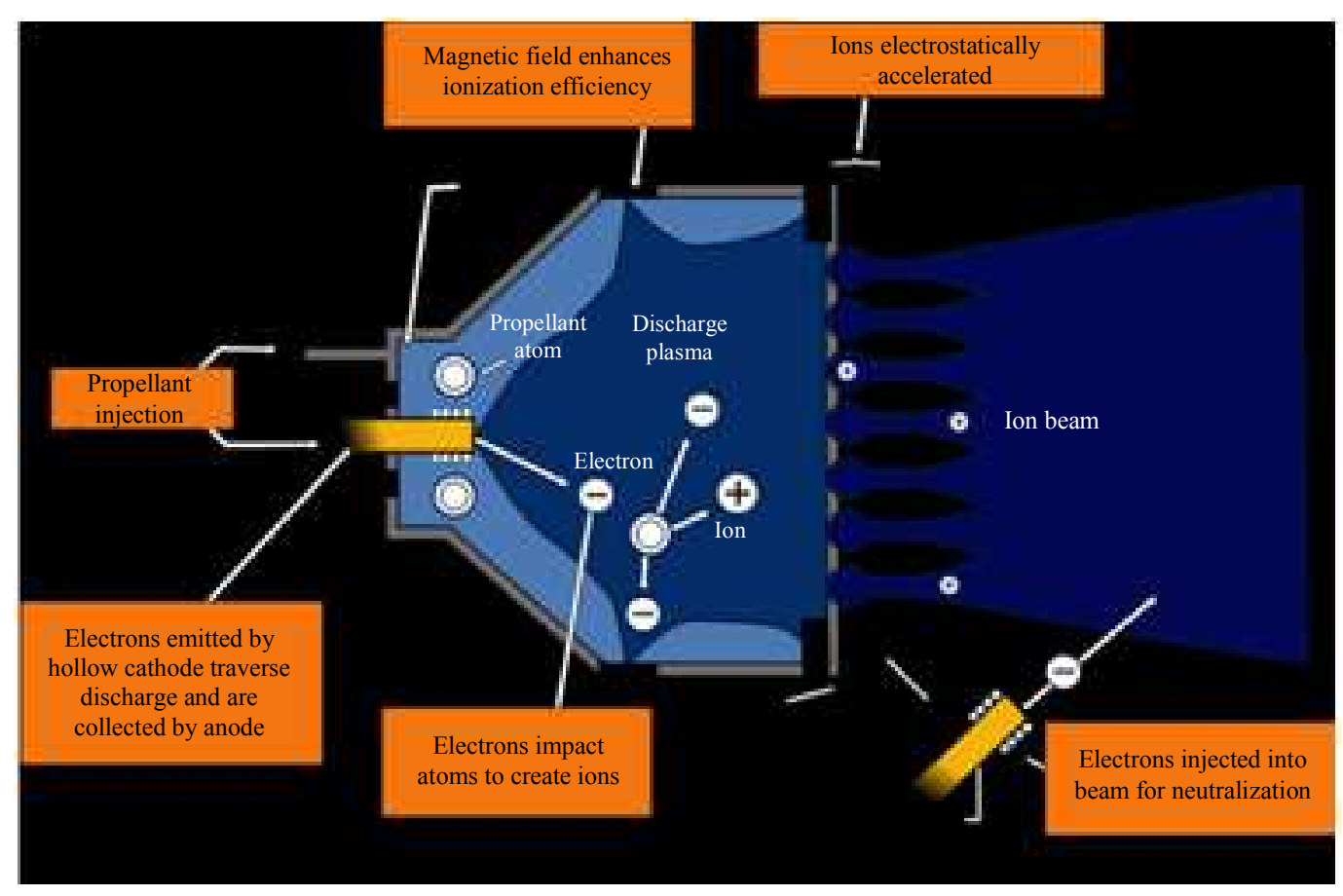

Fig. 3: A diagram of how a gridded electrostatic ion engine (Kaufman type) works 


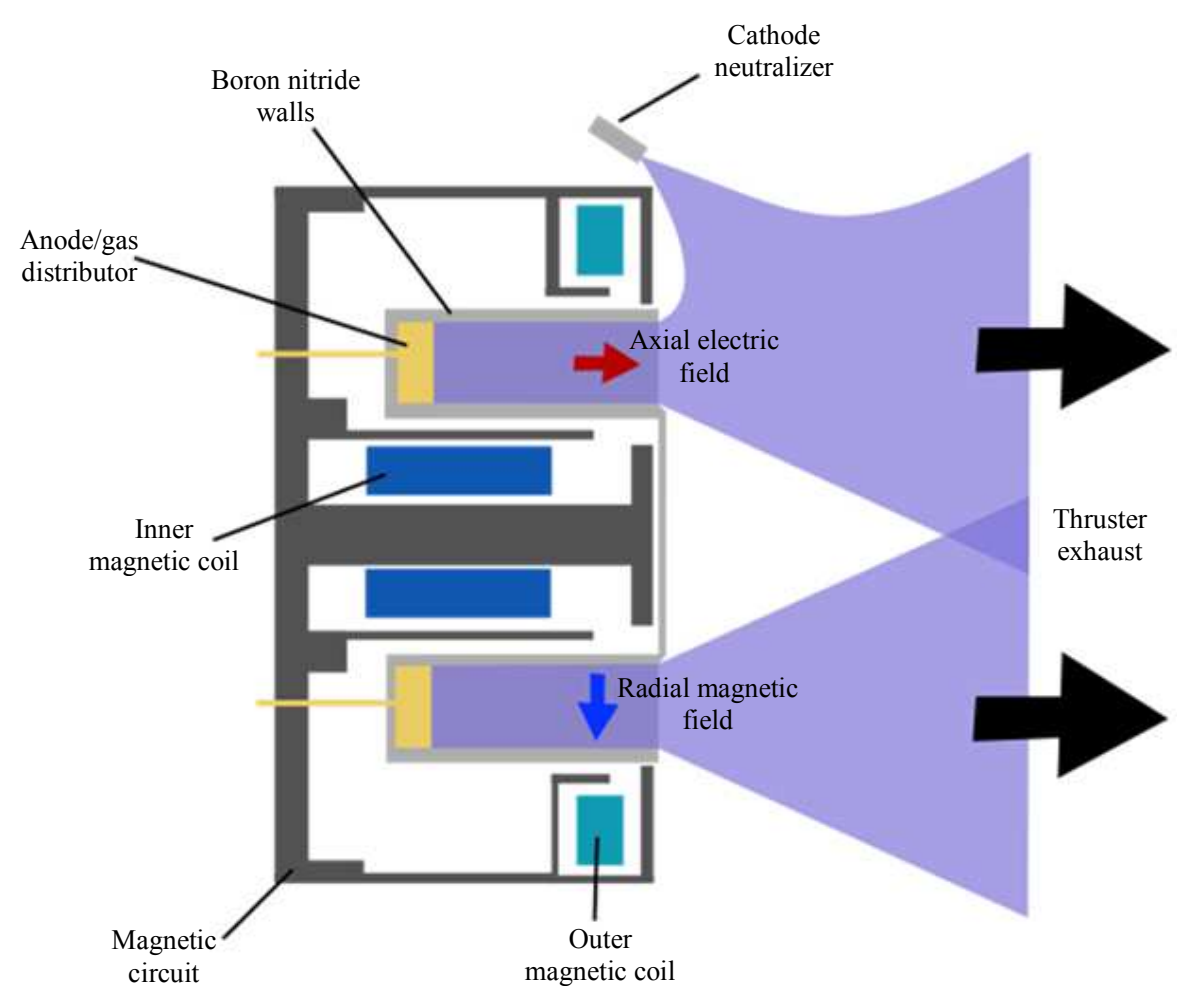

Fig. 4: Schematic of a hall thruster

Analysis of the electrostatic ion propulsion group (past/present):

- $\quad$ NASA Solar Propulsion Technology (NSTAR)

- Development of NASA's evolutionary xenon (NEXT)

- $\quad$ Nuclear Xenon System (NEXIS)

- High power electric propulsion (HiPEP)

- EADS with radio frequency radio transmission (RIT)

- $\quad$ Dual-Stage 4-Grid (DS4G)

\section{Effect Hall Effect}

The greenhouse projectors (Fig. 4) accelerate the ions by means of an electrical potential maintained between a cylindrical anode and a negatively charged plasma forming the cathode.

The majority of the propeller (usually xenon gas) is introduced near the anode where it becomes ionized and the ions are attracted to the cathode, accelerates in and through it, collects electrons, allowing them to neutralize the beam and let it go at high speed.

The anode is at one end of the cylindrical tube and in the center is a tip that is wrapped to produce a radial magnetic field between it and the surrounding tube.

Ions are largely unaffected by the magnetic field because they are too massive.
However, electrons produced near the tip of the peak to create the cathode are much more affected and are trapped by the magnetic field and are held in place by their attraction to the anode. Some of the electrons spiral at the anode, circulating around the peak of a current.

When they reach the anode, they affect the uncharged propellant and cause it to be ionized before finally reaching the anode and closing the circuit.

\section{Propulsion of Electric Field Emissions}

Electric Propulsion (FEEP) uses a very simple system to accelerate liquid metal ions to create force. Most models use either cesium or indium as fuel.

The project consists of a small fuel tank that stores liquid metal, a very small slit on which the fluid flows, then the throttle ring. Cesium and Indian are used because of their high atomic weights, low ionization potentials and low melting points. Once the liquid metal reaches inside the transmitter slot, an electric field applied between the transmitter and the accelerator ring determines the instability of the liquid metal and its ionization. This creates a positive ion, which can then be accelerated in the field created by the transmitter and the throttle ring. These positively charged ions are then neutralized by an external electron source to prevent the spacecraft from being loaded. 


\section{Electromagnetic Handle}

\section{Pulsed Inductive Thruster (PIT)}

Pulsed Inductive Thruster (PIT) use push pulses instead of continuous force and are capable of operating at Megawatts (MW) power levels.

PITs consist of a large coil surrounding a coneshaped tube that emits propellant gas, as shown in the diagram. Ammonia is the gas frequently used in PIT engines. For each pulse imposed by PIT, a large load is first accumulated in a capacitor group behind the coil and then released. This creates a current that moves circularly in the direction of $j$.

The current then creates a magnetic field in the outer radial direction $(\mathrm{Br})$, which then creates a current in the ammonia gas that has just been released in the opposite direction to the original current. This opposite stream ionizes ammonia and these positive charges are accelerated by the PIT engine due to the electric field $\mathrm{j}$ passing through the magnetic field $\mathrm{Br}$ due to the Lorentz force.

\section{Magnetoplasmadynamic (MPD)/Lorentz Force Strength Accelerator (LiLFA)}

LNT (LLT) Lorentz (LLT) engines from LNT (LLT) and Lirentz (LiLFA) engines use almost the same idea as building a LiLFA propeller outside the MPD propeller.

Hydrogen, argon, ammonia and nitrogen gas can be used as a fuel. In a special configuration, ambient air in Low Earth Orbit (LEO) can be used as a propulsion agent (Staelin, 2008).

The gas first enters the main room where it is ionized in plasma from the electric field between the anode and the cathode. This plasma then drives the electricity between the anode and the cathode. This new current creates a magnetic field around the cathode, which traverses the electric field, thus accelerating the plasma due to the Lorentz force.

The LiLFA unit uses the same general idea as the MPD propeller, except for two main differences. The first difference is that LiLFA uses lithium vapors, which has the advantage of being stored as a solid.

The other difference is that the cathode is replaced with a few cathodes loaded into the cathode tube. The MPD cathode is readily corroded due to contact with the plasma constant. In LiLFA, lithium vapors are injected into the naked cathode and are not ionized in their plastic form/corroding the cathode rods until they leave the tube. Plasma is then accelerated using the same Lorentz force.

\section{$M P D=$ Magnetoplasmadynamic. MPDT = Magneto Plasma Dynamic Thruster}

MPDT is a power supply powered by an electric motor using the Lorentz force (the force resulting from the interaction between a magnetic field and an electric current) for a generated traction force. Force-induced electric and magnetic fields (Fig. 5a; Staelin, 2008). Magnetoplasmadynamic Unit (MPD, Fig. 5b) (MPDT) It is sometimes called Lorntz Force Accelerator (LFA) or (especially in Japan) MPD arcjet.

Generally, a gaseous fuel is ionized and introduced into an acceleration chamber, where the magnetic and electric fields are created using an energy source.

The particles are then propelled by the Lorentz force resulting from the interaction between the plasma flow current and the magnetic field (which is either externally applied or induced by the current) through the exhaust chamber. Unlike chemical propulsion, there is no combustion of fuel. As with other power transmission variations, the pulse force and traction force increase with the input power, while the tensile force per watt decreases.

There are two main MPD propeller types, the field applied and the field itself (Fig. 6). Field propulsion devices have magnetic rings that surround the exhaust chamber to produce the magnetic field, while the field propulsions have a cathode that extends through the middle of the chamber. Applied fields are required at low power levels where field configurations are too weak. Various propellants such as xenon, neon, argon, hydrazine and lithium were used, lithium being generally the most efficient.

VASIMR is a completely different type of engine that attempts to provide the same level of performance as the MPD but works on a completely different principle: It is an electrothermal device in which the energy is first applied to the propeller to increase its energy (temperature) VASIMR, the propeller is heated by RF and then part of the propellant's thermal energy content is converted to direct kinetic energy using a suitable nozzle, in this case a magnetic nozzle. The details of this engine can be found in the pulse of the main pulse with magnetoplasm.

In theory, MPDs could produce extremely high pulses (Isp) with an exhaust speed of up to and over $110,000 \mathrm{~m} / \mathrm{s}$, triple xenon propulsion and about 20 times better than liquid rockets.

MPD technology also has the potential to reach voltages up to 200 newton (45 lbf), by far the highest for any form of electric propulsion and almost as large as many interplanetary chemical missiles.

This would allow the use of electric propulsion on missions that require fast delta-v maneuvers (such as orbit capture around another planet), but with much greater fuel efficiency.

MPD technology has been explored from an academic point of view, but commercial interest has been reduced due to several remaining issues. A big problem is that power requirements of the order of hundreds of kilowatts are needed for optimal performance. Current systems of interplanetary spacecraft (such as Radioisotope Thermoelectric Generators (RTG)) and solar networks are not capable of producing so much power. 


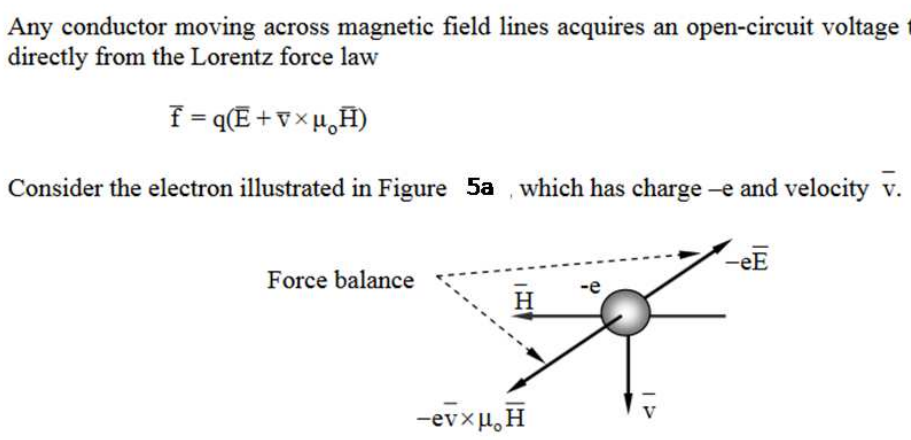

(a)

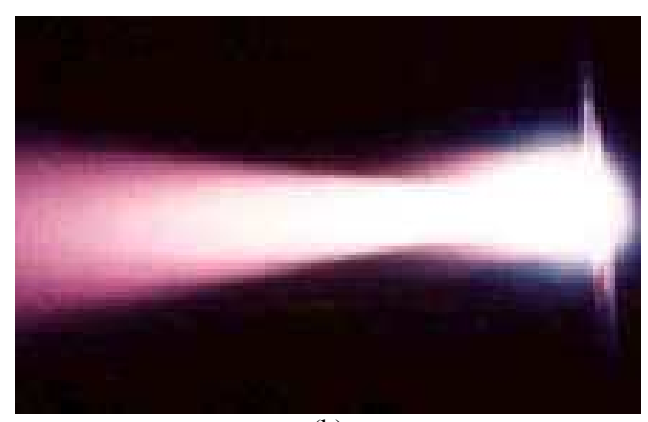

(b)

Fig. 5: An MPD thruster during test firing

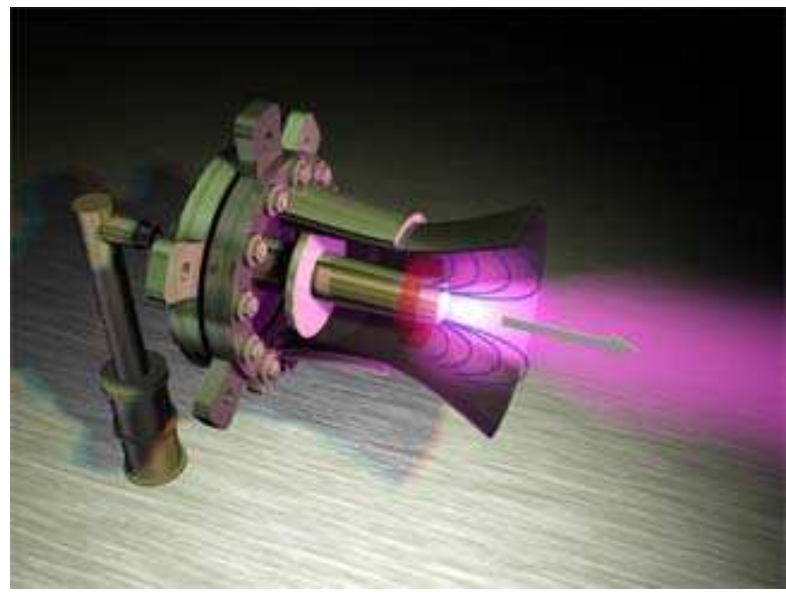

Fig. 6: CGI rendering of Princeton self-field MPD thruster (from Popular Mechanics magazine)

NASA's "Prometheus" project would generate energy in hundreds of kilowatts but was discontinued in 2005.

A project to produce a space nuclear reactor designed to generate 600 kilowatts of electricity began in 1963 and began most of the 1960s in the USSR.

It was to lead a communications satellite, which was not finally approved.

Nuclear reactors delivering electricity (ten times higher than current $\mathrm{X}$ energy sources) were in orbit by the USSR: RORSAT and TOPAZ.
Plans for the development of a large scale nuclear reactor for use on a spacecraft were announced in 2009 by the Kurchatov Institute in Russia, the Roscosmos National Agency and confirmed by the President of Russia in November 2009.

Another plan, proposed by Bradley C. Edwards, is to transmit power from the ground.

This plan uses $5,200 \mathrm{~kW}$ at 0,84 microns with Field Adaptive Optics to transmit the power of the spacecraft powered by MPD where it transforms into GaAs photovoltaic energy.

Adjusting the laser wavelength of 0.840 microns (1.48 $\mathrm{eV}$ per photon) and the $1.43 \mathrm{eV}$ photovoltaic panel together generate an estimated conversion efficiency of $59 \%$ and an estimated power density of up to $540 \mathrm{~kW} / \mathrm{m}^{2}$.

This would be enough to drive a larger MPD, probably to raise the satellites from LEO to GEO.

Another problem with MPD technology was degradation of cathodes due to evaporation due to high current densities (above $100 \mathrm{amp} / \mathrm{cm}^{2}$ ).

The use of lithium carbide and barium carbide blends and multi-channel channel cathodes has been demonstrated in the laboratory as a promising solution to the cathode erosion problem.

Variable Pulse Magnetoplasm (VASIMR) is an electromagnetic propulsion propulsion of the spacecraft. Use radio waves to ionize and heat a propeller and magnetic fields to accelerate the resulting plasma to 
generate the force. It is one of several types of electric propulsion systems for spacecraft.

The plasma heating method used in VASIMR was originally developed as a result of nuclear fusion research. VASIMR is designed to reduce the gap between high voltage and low voltage pulse systems and high voltage high voltage pulse systems.

VASIMR is capable of working both ways. The Costa Rican researcher and former astronaut Franklin Chang-Diaz created the VASIMR concept and is working on its development in 1977 (Fig. 7).

Variable magnetoplastic pulse, sometimes called a plasma electrothermal propellant or magnetoplastic electrothermal rocket, uses radio waves to magnetize and magnetize ionization and heat the magnetic field, accelerating the result of forced plasma constraint.

This type of engine is non-electric and is therefore part of the same electric propulsion family (as it differs in the plasma acceleration method), such as electric plasma propulsion, microwave arc, or inductive pulse class.

It can also be seen as a non-electric version of an arc capable of reaching a higher propulsion temperature by limiting the heat flow from plasma to structure. No engine type has any electrode.

The main advantage of these models is the elimination of the erosion problems of the electrodes, which cause rival models of ion-filled ejectors using electrodes to have a short life expectancy. In addition, since each component of a VASIMR engine is magnetically shielded and does not come into direct contact with plasma, the potential durability of this engine design is greater than other ion/plasma engine designs.

The engine design consists of three parts: plasma gas transformation via helicon RF antennas; energizing the plasma by further heating the RF in a cyclic ionic resonance amplifier (ICRF); and using electromagnets to create a magnetic nozzle to convert the constructed thermal energy of the plasma into kinetic force (Fig. 8).

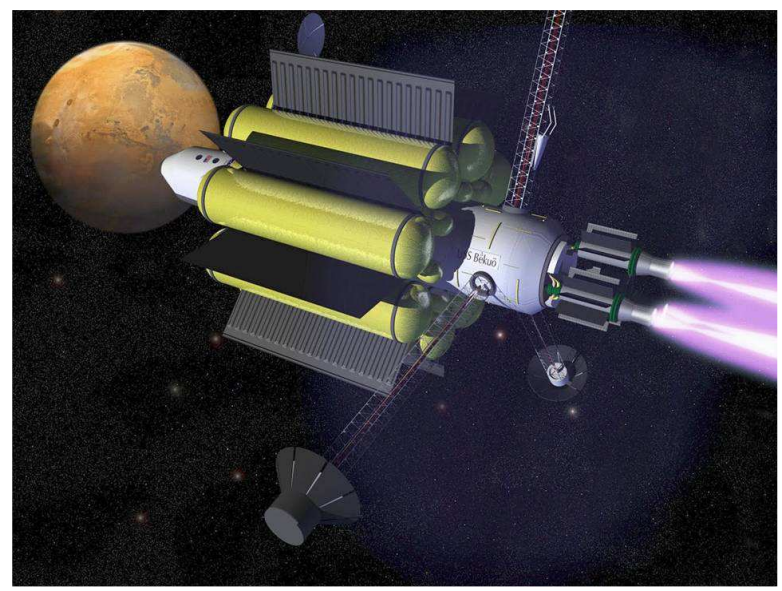

Fig. 7: Several VASIMR engines propelling a craft through space

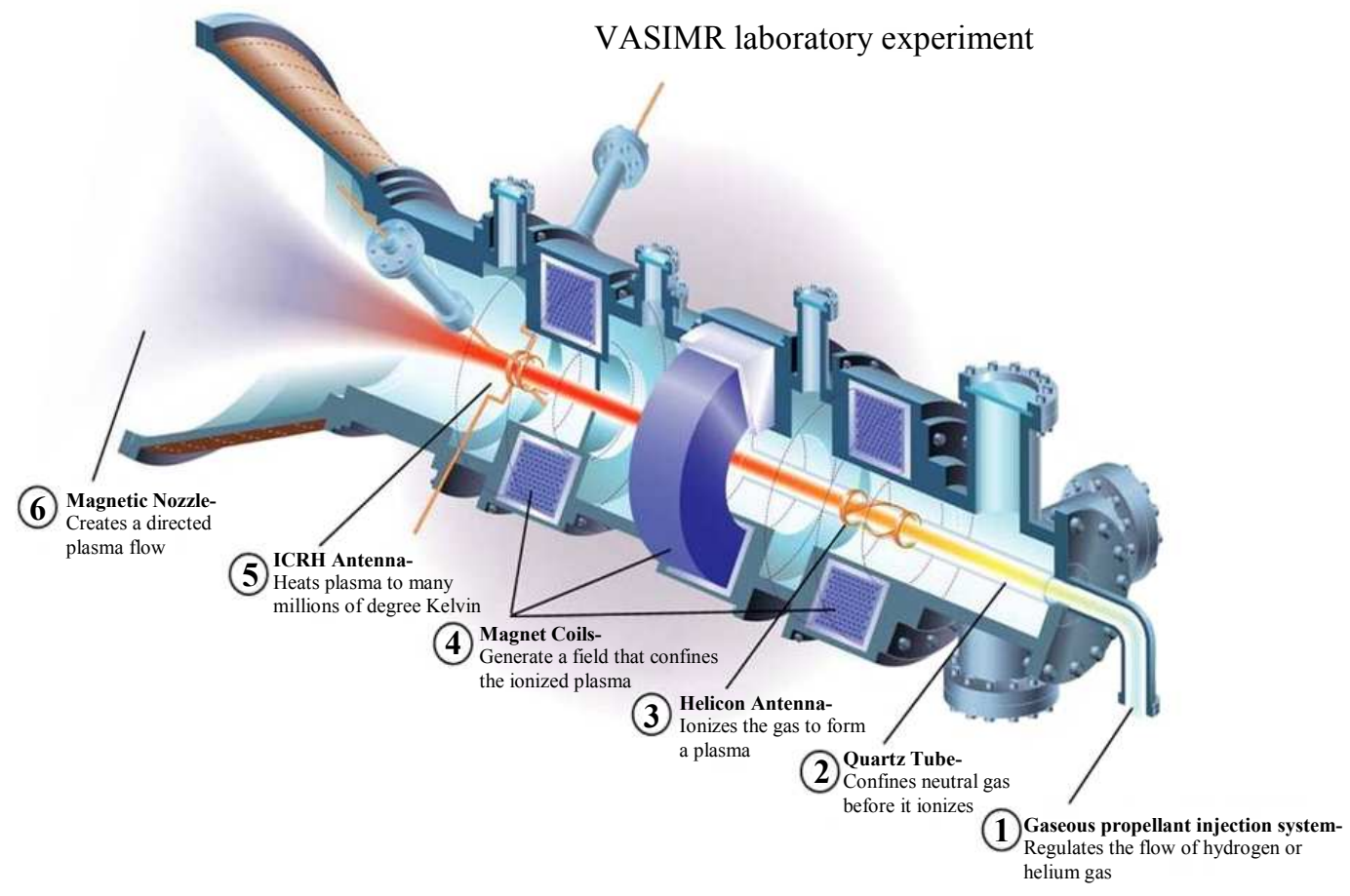

Fig. 8: Several VASIMR engines propelling a craft through space 
By varying the amount of energy for RF heating and the amount of fuel delivered for plasma generation, VASIMR can generate low emissions, high specificities, or pulse emissions relatively high at a certain pulse rate.

Unlike regular cyclotron resonance heating processes, in VASIMR, the ions are immediately discharged through the magnetic nozzle before having time to obtain a thermal distribution.

Based on a new theoretical work done in 2004 by Arefiev and Breizman at UT-Austin, almost all of the energy in the cyclotron ion is uniformly transferred into the ionized plasma in a single-pass cyclotron absorption process.

This allows the ions to leave the magnetic nozzle with a very low energy distribution and significantly arrange the magnets in the engine.

VASIMR does not use electrodes and protects plasma from most hardware, eliminating electrode erosion, a major source of wear in ion engines.

Compared to traditional engines with very complex sanitary systems, high-performance valves, actuators and turbocharger units, VASIMR virtually eliminates all moving parts (except small ones such as gas valves), maximizing long-term durability.

However, some new problems arise as interaction with strong magnetic fields and thermal management.

The relatively high power at which VASIMR works generates a large amount of residual heat that must be channeled without creating thermal overload and excessive heat demand for the materials used.

Strong superconducting electromagnets, used to contain hot plasma, generate tesla magnetic fields.

They may present problems with other devices on board and may also interact negatively with Earth's magnetosphere.

To counteract this last effect, the VF-200 will consist of two $100 \mathrm{~kW}$ propulsion units packed together with the magnetic field of each propeller oriented in opposite directions to produce a zero torque magnetic quadrapol.

After years of research into the NASA concept, Franklin Chang-Diaz set up Ad Astra Rocket in January 2005 to begin developing the VASIMR engine.

Later that year, the company signed a space agreement with NASA and took control of the Advanced Space Propulsion Laboratory.

In this laboratory, a $50 \mathrm{~kW}$ prototype was built and tested in a vacuum chamber. Subsequently, a $100 \mathrm{~kW}$ version was developed, followed by a prototype of 200 $\mathrm{kW}$. After a rigorous testing period in a $150 \mathrm{cc}$ vacuum chamber, the most recent configuration was considered a spacecraft and it was announced that the company had an engine test agreement at the International Space Station on or before 2013 .

The first VASIMR VX-50 engine model proved to be capable of a power of 0.5 Newton $(0.1 \mathrm{lbf})$.
Published data on the VX-50 engine capable of processing $50 \mathrm{~kW}$ of total RF power showed that the propellant efficiency was $59 \%$ calculated as: $90 \%$ coupling efficiency NA $\times 65 \%$

It was hoped that the overall efficiency of the engine could be increased by scaling the power levels.

The VX-100 was expected to have a propulsion efficiency of $72 \%$ by improving the efficiency of the NB ion to $80 \%$.

However, there have been additional (lower) efficiency losses related to the conversion of the DC current to radio frequency power and also to the energy consumption of auxiliary equipment of superconducting magnets.

By comparison, 2009's state-of-the-art engines, such as HiPEP from NASA, operated at a total energy efficiency of up to $80 \% /$ PPU.

On October 24, 2008, the company announced that generation of plasma generations VX-200 - the first propulsion step or a high-frequency power transmitter has reached its operating state.

DC-RF solid state-of-the-art technology has become very efficient, reaching an efficiency of up to $98 \%$.

Helicon's release uses $30 \mathrm{kWe}$ of radio waves to convert argon gas to plasma.

The remaining $170 \mathrm{kWe}$ of energy is allocated to the energy transfer and the acceleration of the second part of the engine by the resonance with the cyclotron ion.

Based on the previous VX-100 test data, the VX-200 was expected to have a system efficiency of $60-65 \%$ and a $5 \mathrm{~N}$ force.

The optimal optimal impulse seemed to be around 5,000 years, using an inexpensive propulsion agent with argon.

Specific power estimated at $1.5 \mathrm{~kg} / \mathrm{kW}$ meant that this version of the VASIMR engine would weigh only about $300 \mathrm{~kg}$.

One of the untested issues was potential transposition into reality; that is, if the hot plasma is detached from the rocket. Another problem was waste management $(60 \%$ efficiency means about $100-60 \% / 100 \% * 200 \mathrm{~kW}=80$ $\mathrm{kW}$ of unnecessary heat) critical to allow continuous operation of the VASIMR engine.

Between April and September 2009 tests were carried out on the VX-200 prototype with two fully integrated Tesla superconducting magnets.

They have successfully extended the VASIMR power range to a capacity of $200 \mathrm{~kW}$.

In November 2010, long-term tests with maximum power were performed, with the VX-200 engine reaching steady state for $25 \mathrm{sec}$, validating the basic features of the design.

The results presented at NASA and in the scientific field in January 2011 confirmed that the design point for optimal efficiency at the VX-200 is $50 \mathrm{~km} / \mathrm{s}$ or $5000 \mathrm{rpm}$.

Based on these data, Ad Astra believes that $70 \%$ driver efficiency is possible, generating a total system 
efficiency of $60 \%$ (DC power to RF with an efficiency of over $95 \%$ ).

On December 8, 2008, Ad Astra signed an agreement with NASA to organize the placement and testing of a VASIMR, VF-200 flight variant on the International Space Station (ISS).

Starting in February 2011, its launch is expected to be in 2014, although it may be later.

Taurus II was reported as the "top rider" of the launch vehicle.

As the available power from the ISS is less than 200 $\mathrm{kW}$, the ISS VASIMR will include a loadable battery system that allows 15 -minute pulse charging.

Engine testing on ISS is valuable because it is in orbit at a relatively low altitude and has a fairly high level of atmospheric traction, which makes it necessary to periodically increase the altitude. At present, recovery of chemical launchers fulfills this requirement.

If the SAS reabsorption tests performed by VASIMR are carried out in accordance with the plan, the increase in the specific impulse could mean that the cost of the fuel for altitude reduction will be twenty-one of the current annual cost of $\$ 210$ million. Hydrogen is generated by ISS as a by-product, which is currently ventilated in space, will be redirected to VASMIR to act as fuel instead of current argon.

The VF-200 consists of two $100 \mathrm{kV}$ VASIMR units with opposite magnetic dipoles so that no torque is directed to the space station when combustion combs are burned. The VF-200-1 is the first flight unit and will be tested in space attached to the ISS (Fig. 9).

Since February 2011, NASA has 100 people designated to work with Ad Astra to integrate the VF200 into the space station.

VASIMR is not suitable for launching beneficial loads on the Earth's surface due to the low thrust rate and the need for vacuum operation.

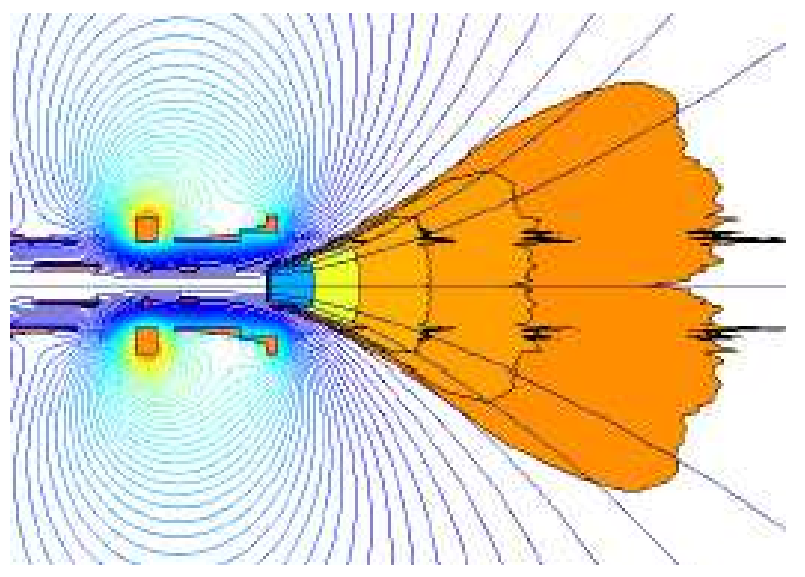

Fig. 9: VASIMR magnetic field
Instead, it would function as a higher stage for load, reducing the need for fuel for space transportation. The engine is expected to perform the following functions at a fraction of the cost of chemical technologies:

- Drag space station compensation

- Monthly delivery of the cargo

- The transfer of the satellite

- Renewal, maintenance and satellite repairs

- In the recovery of space resources

- Ultra-fast robotic space missions

Other applications for VASIMR, such as fast human transport on Mars, would require a very low energy source, such as a nuclear reactor (see the nuclear electric missile).

NASA Administrator Charles Bolden said VASIMR technology could be a revolutionary technology that would reduce travel time on a mission on Mars from Monday to days.

In August 2008, Ad Astra's development director, Tim Glover, publicly stated that the first planned VASIM engine "delivers non-human loads from the Earth's orbit to a smaller orbit," supporting NASA's return to the moon's efforts.

The most important future application of spacecraft powered by VASIMR is freight transport.

Numerous studies have shown that, despite longer transit times, spacecraft powered by VASIMR will be much more effective than traditional chemical missiles integrated into space-related goods.

An OVT - essentially a "space trailer" - powered by a single VF-200 engine could carry about 7 metric tons of freight from Low Earth Orbit (LO).

NASA is considering delivering about 34 metric tons of LLO load to a propelled chemical.

To make this trip, it would burn about 60 tons of LOX-LH2 fuel.

A comparable OTV should use 5 VF-200 motors powered by a $1 \mathrm{MW}$ solar array.

To do the same, OTV should only spend about 8 metric tons of argon propellant.

The total mass of such an OTV would be in the range of $49 \mathrm{t}$ (output and return fuel: $9 \mathrm{t}$, hardware: $6 \mathrm{t}$, load 34 t). OTV transit times can be reduced by making lighter loads and/or by extending the VASIMR arc to the lower level of the Isp.

For example, an empty OTV on the Earth's return journey covers the distance in approximately 23 days at an optimum optimum pulse of $5,000 \mathrm{~s}(50 \mathrm{kN} \cdot \mathrm{s} / \mathrm{kg})$ or about 14 days at $3.35 \mathrm{~s}$ Isp ( $30 \mathrm{kN} \bullet \mathrm{skg})$.

The total mass of NASA specifications "OTV (including structure, solar matrix, fuel tank, avionics, fuel and cargo) was estimated at 100 tonnes (98.4 tons long, 110 tons shorter) capable of delivering $2 \mathrm{MW}$. 
Starting in October 2010, Ad Astra Rocket strives to use VASIMR for space mission missions to help "clean up the growing problem of space garbage." They hope to have a first-generation commercial offer by 2014.

\section{Plasma Without Electrodes}

Plasma without electrodes has two unique characteristics: The removal of anodic and cathode electrodes and the ability to accelerate the engine. Removal of electrodes eliminates the erosion factor, which limits the life of other ionic engines. The neutral gas is first ionized by electromagnetic waves and then transferred to another room where it is accelerated by an electric and magnetic oscillating field, also known as the ponderomotive force. This separation of the ionization and acceleration phase gives the engine the ability to accelerate the propeller flow, which then changes the thrust magnitude and the specific pulse values.

\section{Thermal Electric Handle}

The electrothermal leads use electricity to accelerate the propeller. There are several types:

1. Resistojet

2. Arcjet

3. Microwave electrothermal

4. Cyclotron Ion Propulsion (VASIMR)

\section{Helicon Tripolar}

Dual helix propulsion is a type of plasma propellant that provides high-speed ionized gases to provide a spacecraft. In this propeller model, the gas is injected into a tubular chamber (source tube) with an open end. The radio frequency (at $13.56 \mathrm{MHz}$ in the prototype design) is coupled to a special antenna wrapped around the camera.

The electromagnetic wave emitted by the antenna causes the gas to decompose and form a plasma. The antenna then excites a wave of Helicon in the plasma, which further warms the plasma. The device has an approximately constant magnetic field in the source tube (provided by the solenoid prototype), but the magnetic field deviates and falls rapidly in magnitude away from the source region and can be considered a type of magnetic nozzle.

During operation, there is a severe limit between high-density plasma in the source region and low-density plasma in the exhaust gases, which is associated with a sudden change in the electrical potential. Plasma properties change rapidly beyond this limit, known as a current double layer.

The electrical potential is much larger inside the source region than in the exhaust and this serves both to limit most of the electrons and to accelerate the ions away from the source region. Enough of electrons get rid of the source region to make sure the plasma in the exhaust is neutral as a whole.

A major limiting factor for ionic propellants is their small thrust; however, it is generated at a high propellant efficiency (mass use, specific impulse). Efficiency comes from a high evacuation speed, which in turn requires high energy and performance is ultimately limited by the available ship power.

The low pulling force requires ionic propulsion to provide a continuous force for a long time to achieve the desired displacement velocity (delta-v) for a particular mission. In order to produce sufficient pulse changes, ion-fueled motors are designed to last for weeks or years.

In practice, the life of propellants with electrostatic ion is limited by several processes:

When designing electrostatic ion propulsion, the charge exchange ions produced by the beam's ions with the neutral gas flow can be accelerated to the negative negative grid of the accelerator and can cause network erosion. The end of life is reached when either a structural failure of the grid occurs or the holes in the acceleration grid become so large that the ion extraction is severely impaired (for example by blocking the electrons).

Network erosion cannot be avoided and is the major factor in reducing lifespan. Through a detailed grid and material selection project, it has a lifetime of 20,000 hours and a much larger distance, which is enough to reach the current space missions.

A NASA (NSTAR) solar energy test determined 30,472 $\mathrm{h}$ (about 3.5 years) of continuous power to the peak.

The test was completed before any malfunction and the test results showed that the engine was not approaching the failure.

Hall-type projectors have a very strong erosion of the ceramic discharge chamber.

Due to high discharge voltages, power ions up to $1000 \mathrm{~V}$ can influence the walls of the camera and can erode the material. Hours of life of several thousand hours are attained.

Ionizing energy is a very high percentage of the energy required to drive the ions. Ideal propulsion for ion propulsion is thus a propellant molecule or a slightly ionized atom having a high mass/ionization ratio. In addition, the propulsion agent must not cause the propellant to erode to allow for a long service life; and should not contaminate the vehicle.

Many of the current models use xenon gas because it is easy to ionize, has a fairly large number of atoms, inert nature and low erosion. However, xenon is global and very expensive.

Older projects use mercury, but are toxic and expensive, tend to contaminate the vehicle with metal and it was difficult to feed it with precision. 
Other propellers, such as bismuth, have promises and are areas of research, especially for models that are not connected to the grid, such as Hall-effect engines.

The design of VASIMR (and other plasma engines) is theoretically able to use virtually any propelling material. However, in current tests, the most practical propulsion agent is argon, which is a relatively abundant and inexpensive gas.

Ionic protocols are frequently quoted with an efficiency metric. This efficiency is the kinetic energy of the jet emitted per second divided by the electrical power of the device.

The current energy efficiency of the system in use is determined by propulsion efficiency, which depends on vehicle speed and exhaust speed.

Some propellers may vary depending on the exhaust speed, but they can all be designed with different exhaust speeds.

At the lower end of the Isps system, overall efficiency decreases because ionization occupies a higher percentage of energy and high propulsion efficiency is reduced.

Optimal efficiencies and evacuation rates can thus be calculated for any given mission to provide minimum total costs.

Ionic prototypes have many applications for space propulsion. The best applications of propellers use long lifetimes when no significant force is required.

These include orbital transfers, attitude adjustments, traction compensation for terrestrial orbit, freight transport, such as chemical fuels between fuel depots and ultra-fine adjustments for more scientific tasks.

Ionic advances can also be used for interplanetary and space missions, where time is not critical. The error continues for a very long period can generate a higher speed than traditional chemical rockets.

From electric propulsion, ion propulsion was considered the most commercial and academic academic in search of interplanetary missions and maneuvering orbits. Ionic engines are considered the best solution for these missions because they require a very large change in overall speed that can be built over long periods of time.

Several spacecraft have worked with this technology.

\section{SERT}

Ion propulsion systems have been demonstrated for the first time in space by NASA Lewis (now Glenn Research Center) Electric Electric Rocket Test (SERT) I and II. The first was SERT-1, launched on July 20, 1964, which successfully demonstrated that the technology works as intended in space. They were propelled with electrostatic ion using mercury and cesium as the reaction mass. The second test, SERT-II, launched on February 3, 1970, verified the operation of two mercuryion engines for thousands of hours of operation.

\section{Deep Space 1}

NASA has developed an ionic propellant called NSTAR for use in their interplanetary science missions in the late 1990s. This xenon ion propellant was first tested in the space of the highly successful Deep Space 1 probe launched in 1998. This was the first propulsion propulsion as an interplanetary propulsion system on a scientific mission. Based on this technology developed by NASA, the contractor, Hughes, has developed the Xenon Ion Propulsion System (XPS) to drive geosynchronous satellites.

\section{Artemis}

On July 12, 2001, the European Space Agency did not launch the Artemis telecommunication satellite at the desired altitude and left it in a fallen orbit.

The fuel supply of the satellite was sufficient to transfer to semi-stable orbit and the RIT-10 propulsion system (dedicated only to stations and maneuvers) was used over the next 18 months to transfer a geostationary orbit.

\section{Hayabusa}

Hayabusa, the Japanese space agency, launched in 2003 and reunited with Itokawa 25493 asteroids and left in the immediate vicinity for several months to collect evidence and information, was propelled by four xenon ion engines. He used xenonic ions generated by the cyclonic resonance of microwaves and a carbon / carbon composite (which is erodible) for the accelerator grid. Although the Hayabusa engines had some technical difficulties, the reconfiguration during the flight allowed one of the four engines to be repaired and allowed the mission to return to Earth.

\section{Smart 1}

Hall Effect propulsion is a type of ionic propulsion used by the Soviet Union for decades and is also applied in the West: Space Spatial Space launched in 2003 (Snecma PPS-1350 G). This satellite ended the mission on September 3, 2006, in a controlled collision on the Moon, after a deviation of the trajectory so that the scientist could see the impact of the 3-meter crater on the visible side of the Moon.

\section{Goce}

The gravity of the ESA and the Stacy-State Ocean Circulation Explorer were launched on March 16, 2009. It will continue to use ion propulsion for more than twenty months of mission to combat the air that lives in its low orbit.

\section{BepiColombo}

ESA will launch BepiColombo's mission to Mercury in 2014. It uses reactive propulsion engines 
to reach Mercury where a chemical launcher for orbit will be launched.

\section{LISA Pathfinder}

LISA Pathfinder is an ESA spacecraft that will be launched in 2013. It will not use ion propulsion as the main propulsion system but will use both colloidal and FEEP for very precise altitude control - the reduced forces of these propulsion devices make it possible to increase the incremental distances of the spacecraft are very precise. It's a test for the possible LISA mission.

\section{International Space Station}

Starting in February 2010, a 2011/2012 launch of a $200 \mathrm{~kW}$ VASIMR Ad Astra VF-200 electromagnetic propulsion for placement and testing on the international space station. The VF-200 is a VX-200 flight version (although it may be later). As the available power from the ISS is less than $200 \mathrm{~kW}$, the ISS VASIMR will include a loadable battery system that allows $15 \mathrm{~min}$ pulse charging. ISS engine testing is valuable because ISS orbits at a relatively low altitude and records relatively high levels of atmospheric traction, which makes it necessary to periodically increase the altitude. At present, recovery of chemical launchers fulfills this requirement. If the SAS reabsorption tests performed by VASIMR are carried out in accordance with the plan, the increase in the specific impulse could mean that the cost of the fuel for altitude reduction will be twenty-one of the current annual cost of \$ 210 million. Hydrogen is generated by ISS as a byproduct, which is currently ventilated in space.

\section{Engine Motor or Ionic Engine}

Through this section, the authors propose a new impulse motor that works with beam or beam pulses (ion beam).

With a new ionic engine, a new aircraft is built (a new ship).

The main feature of this type of engine is the high power (energy) that accelerates the beam to very high energy, in circular accelerators, in modern linear accelerators (LINAC) or both.

You can use accelerators similar to static accelerators of physics (synchrotron, syncrocyclotron or cyclotron isocron).

The ionic engine (the ionic propellant, which accelerates the positive ions through a potential difference) is about 10 times more efficient than the classic combustion-based system.

We can still improve efficiency by 10-50 times if positive accelerated ions are used in a cyclotron mounted on the ship; efficiency can easily increase 1000 times if the positive ions are accelerated in a syncytronron syncytronron or isocron cyclotron (1-100 GeV).

The future (ionic) motor will necessarily have a circular particle accelerator (high or very high energy,
Fig. 11). Of course, the difficulties will come from the project, but they need to be solved step by step.

Thus, we can increase the speed and autonomy of the ship using a smaller amount of fuel.

It can use synchrotron radiation (synchrotron light, high intensity beams), such as high-intensity radiation (X-rays or Gamma rays). In this case, it will be a beam motor (not an ionic engine).

A linear particle accelerator (also called LINAC) is an electric device for acceleration of subatomic particles. This type of particle accelerator has many applications.

Recently, he used an injector in a higher energy synchrotron in an experimental laboratory dedicated to particle physics. In this sense, the large classic synchrotron is reduced to an annular surface (magnetic core).

The design of a LINAC depends on the type of particles that accelerate: Electron, proton or ion.

It is proposed to use a strong LINAC at the output of synchrotron (especially when electrons accelerate) to avoid energy loss by premature emission of photons (Fig. 11).

A LINAC can be used in the Synchrotron input and one at the output (Fig. 10). To use a slight LINAC entry, between it and the synchrotron, take an extra step in a stadium shape (Fig. 10).

The last LINAC can be reduced if multiple LINACs are placed. See the diagram below (Fig. 10).

This paper (shortly) presents the current ionic engines (called ionic propulsion) and the new ionic (impulsive) motors proposed by the authors.

The ionic engine (the ionic propellant, which accelerates the positive ions through a potential difference) is about 10 times more efficient than the classic combustion-based system.

We can still improve efficiency by 10-50 times if accelerated ionic impulses are used in a marine cyclotron; the efficiency can easily increase 1000 times if the positive ions are accelerated to a syncytrronron sincytronic or isocron cyclotron $(1-100 \mathrm{GeV})$.

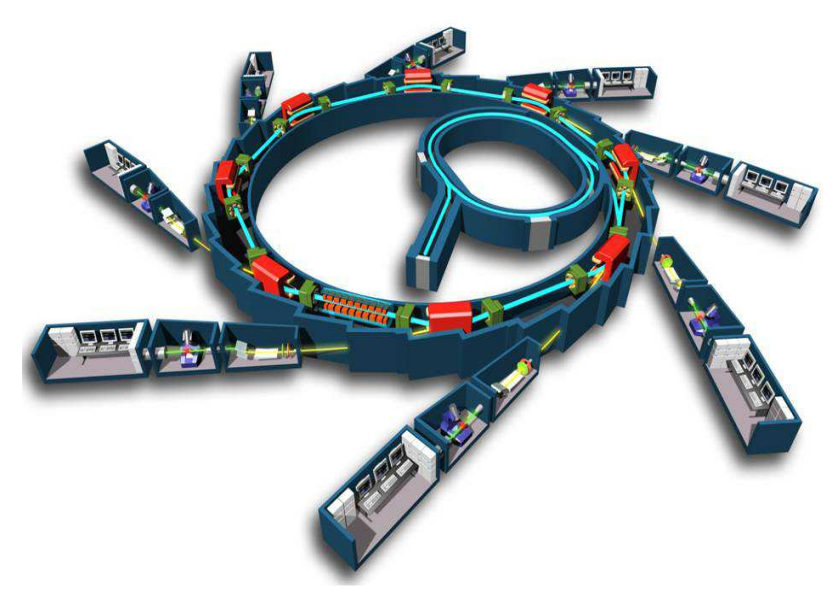

Fig. 10: A high energy synchrotron schema 


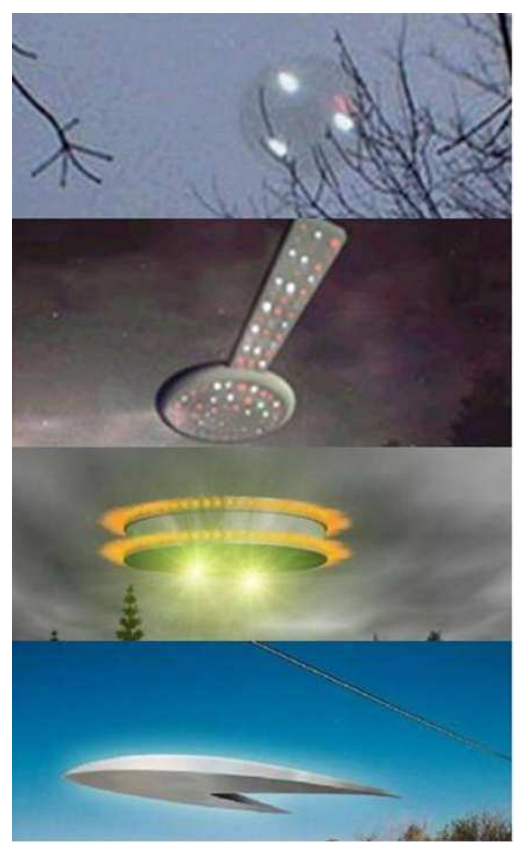

This ship has a circular particle accelerator (a synchrotron)

This ship has first a circular particle accelerator (a synchrotron) and at the end a big linear particle accelerator (a big LINAC)

This ship has two circular particle accelerators (two synchrotrons)

This ship has first a circular particle accelerator (a synchrotron) and at the end two big linear particle accelerators (two big LINAC)

Fig. 11: Some flying synchrotron prototypes

The future (ionic) motor will necessarily have a circular particle accelerator (high or very high energy).

Thus, we can increase the speed and autonomy of the ship using a smaller amount of fuel and power. Synchrotron radiation (synchrotron light, high intensity beams), such as high-intensity radiation (X-rays or gamma rays), could be used. In this case, it will be a beam engine (not an ionic motor), it will only use energy (energy, which can be solar energy, nuclear power, or both) and thus we will eliminate the fuel.

A linear particle accelerator (also called LINAC) is an electric device for acceleration of subatomic particles. This type of particle accelerator has many applications. Recently, he used an injector in a higher energy synchrotron in an experimental laboratory dedicated to particle physics. In this sense, the large classic synchrotron is reduced to an annular surface (magnetic core).

The design of a LINAC depends on the type of particles that accelerate: Electron, proton or ion.

It is proposed to use a strong LINAC at the output of synchrotron (especially when electrons accelerate) to avoid energy loss by premature emission of photons (Fig. 11).

A LINAC can be used in the Synchrotron input and one at the output (Fig. 10). To use a slight LINAC entry, between it and the synchrotron, take an extra step in a stadium shape (Fig. 10).

With a new ionic engine, a new aircraft is built that can travel through the water.

This new aircraft can accelerate directly without an additional combustion engine and no gravitational assistance from other planets.
The compact engine, tightly closed, requires no air (oxygen).

The ship passes through dust clouds without any problems.

The transition from air to water and vice versa can be quiet or even accelerated without any problems.

The ionic engine (ionic propellant) has 2 major advantages (a) and 2 disadvantages (b) compared to chemical propulsion; (a) the impulse and energy per unit of fuel used is much higher; 1 - Increasing the impulse generates a higher velocity (speed so that we can go for longer distances in a short time); 2 - High energy reduces fuel consumption and increases ship's autonomy; (b) force generation and acceleration are very low; we can not overcome the sedimentary forces through the atmosphere and we have no chance of overcoming the gravitational forces - the ship will not leave a planet (or it will not fall on it) using the ionic unit (requires an extra motor). Acceleration of the ship is possible, but only with very low acceleration.

Increasing several energies (and pulses) can reach the required forces and accelerations (increase will be very high, 100-1000 PeV).

Increasing particle energy can be done with circular or modern linear accelerators. The increase in particle energy will be enormous and, in addition, the accelerated particulate stream will have to increase (and the torque diameter, if the flow is high enough, the required energy will be less, $10 \mathrm{GeV}-10 \mathrm{TeV}$ ).

We can increase the number of particles per impulse, the number of pulses per second and the particle energy. 
The immediate consequence of increasing particle energy will be to increase the speed and autonomy of the ship. Now we can get huge speeds in a very short time. The ship will pass through any atmosphere (including water) with great ease. The ship can take off or land directly.

Originally it can be used to hunt old (old) shapes that adapt and accelerator (s).

This idea was presented by the author in 1996, but was published and protected by copyright in 2009 .

Although the deployment stage is probably a bit more advanced, it cannot exceed the limits of the current accelerators.

\section{Particle Accelerator}

A particle accelerator is a device that uses electromagnetic fields to propel charged particles at high speeds and to contain them in well-defined beams (Fig. 12).

A set of regular CRT TVs is a simple form of accelerator.

There are two basic types: Electrostatic and oscillating field accelerators.

At the beginning of the twentieth century, cyclotrons were commonly referred to as "atoms".

Despite the fact that modern collisions propel the subatomic particles - the atoms themselves being relatively easy to disassemble without an accelerator the term persists in popular use when referring to particle accelerators in general.

Large particle beams are useful for both fundamental and applied research in science (Fig. 13), as well as in many technical and industrial fields that are not related to fundamental research. It is estimated that there are about 26000 global accelerators. Of these, only about $1 \%$ are research cars with energies greater than $1 \mathrm{GeV}$ of the kind covered by this article. Otherwise, about $44 \%$ are for radiotherapy, $41 \%$ for ion implantation, $9 \%$ for industrial processing and research and $4 \%$ for biomedical research and other low energy research.

For fundamental research into the dynamics and structure of matter, space and time, physics seeks the simplest types of interactions to the highest possible energies.

They usually involve the energy of many $\mathrm{GeV}$ particles and interactions between the simplest types of particles: Lepton (for example, electrons and positrons) and matrices of matter or photons and gluons for the sum of the field. Since isolated quarks are experimentally unavailable due to color closure, the simplest available experiments involve interactions between leptons with each other and nucleons with nucleons, which are composed of quarks and gluons. For a quark collision study, scientists use collisions of nucleons that can be considered useful as essential interactions with two cucumbers and gluons, of which they are compounds. Thus, elemental particle physicists tend to use electron generating machines, positrons, protons and antiprotons interacting with each other or with the simplest nuclei (e.g., hydrogen or deuterium) at the highest possible energies, $\mathrm{GeV}$ or more.

Physical physical atomic range can be used to investigate the structure, interactions and properties of the core itself and condensed matter at extremely high temperatures and densities, as it did in the early moments of the Big Bang.

These investigations often involve collisions of heavy nuclei - atoms, such as iron or gold - to the energies of several GeVs on the nucleon. For smaller energies, accelerated nucleus beams are also used in medicine as well as in cancer treatment.

Besides the fundamental interest, high-power electrons can be combined into extremely bright and consistent radiation of high-powered photon photons and synchrotron photons, which have many uses in the study of atomic spectral structure, chemistry, biology and technology.

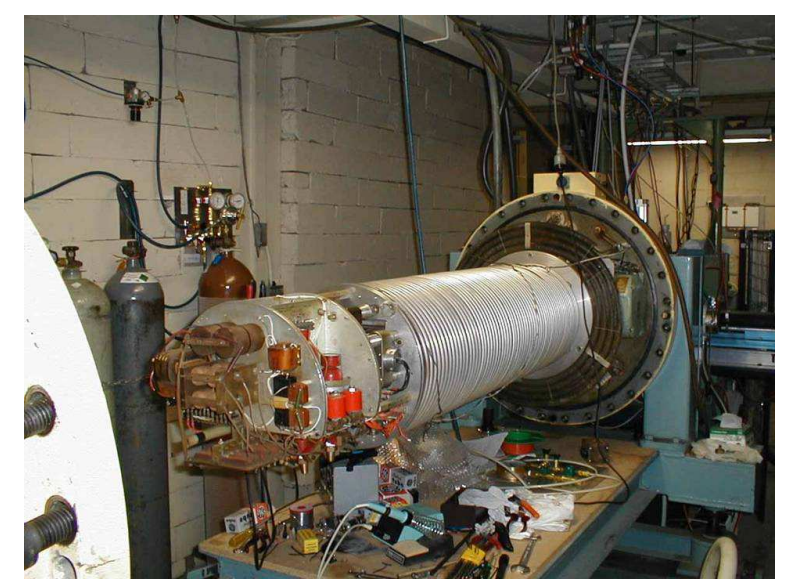

Fig. 12: A 1960s single stage $2 \mathrm{MeV}$ linear Van de Graaff accelerator, here opened for maintenance

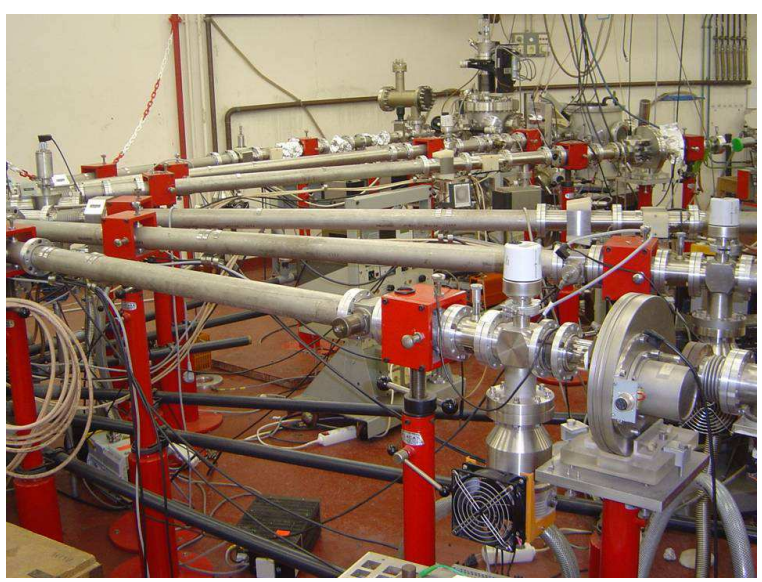

Fig. 13: Beamlines leading from the Van de Graaff accelerator to various experiments, in the basement of the Jussieu Campus in Paris 
Examples include ESRF in Europe, which were recently used to extract detailed three-dimensional images of amber insects.

Thus, there is a great demand for moderate energy accelerators $(\mathrm{GeV})$ and high intensity.

\section{Low Energy Consumption Machines}

Daily examples of particle accelerators are cathode ray tubes on TV sets and X-ray generators. These intensive accelerators use a single pair of electrodes with a voltage of several thousand volts DC between them. In an X-ray generator, the target itself is one of the electrodes. A low energy particle accelerator called ion implanter is used in the manufacture of integrated circuits.

\section{High Power Machines}

Types of DC accelerators capable of accelerating particles at speeds sufficient to cause nuclear reactions are Cockcroft-Walton generators or voltage multipliers (Fig. 14) which convert static wear belts from DC or DC DC generators.

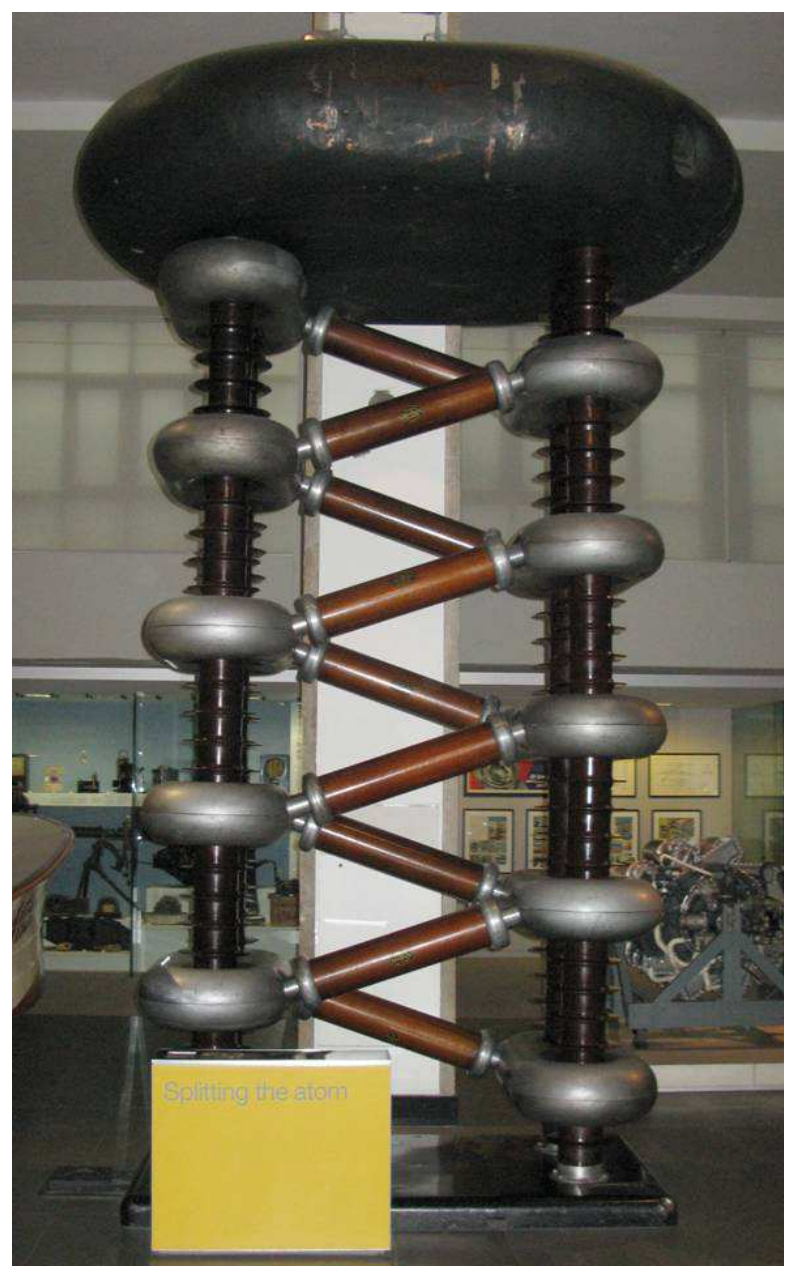

Fig. 14: In early particle accelerators a Cockcroft-Walton
The largest and most powerful particle accelerator at present is CERN, RHIC, Large Hadron Collider (LHC) (Fig. 15) and Tevatron (Fig. 16) used for experimental particle physics.

Tevatron is a circular particle accelerator in the United States at the Accelerator Fermi National Laboratory, east of Batavia, Illinois and is the second particle shaker after LHC, Fig. 16.

Tevatron is a synchrotron that accelerates protons and antiprotons in a ring of $6.28 \mathrm{~km}$ (3.90 miles) to energies of up to $1 \mathrm{TeV}$, hence the name.

Tevatron was completed in 1983 at a cost of $\$ 120$ million (\$265 million today) and has been regularly updated since then. ("Energy Doubler", as it was known then, produced its first accelerated beam - $512 \mathrm{GeV}$ - on July 3, 1983). The main injector was the most important plus, built over five years in 1994 at a cost of \$ 290 million, to $\$ 639$ million today).

On January 10, 2011, it was announced that Tevatron will cease operations at the end of September 2011 as it was overtaken by the LHC, which began operating in early 2010.

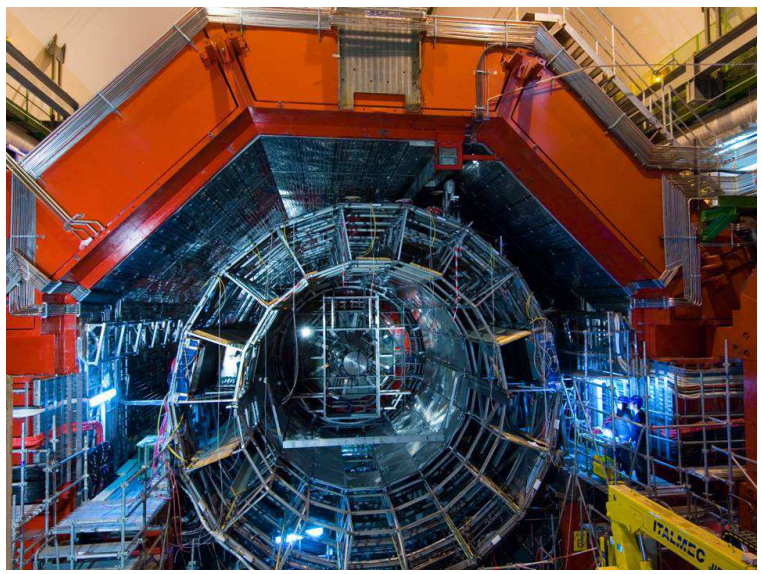

Fig. 15: The Large Hadron Collider (LHC) at CERN

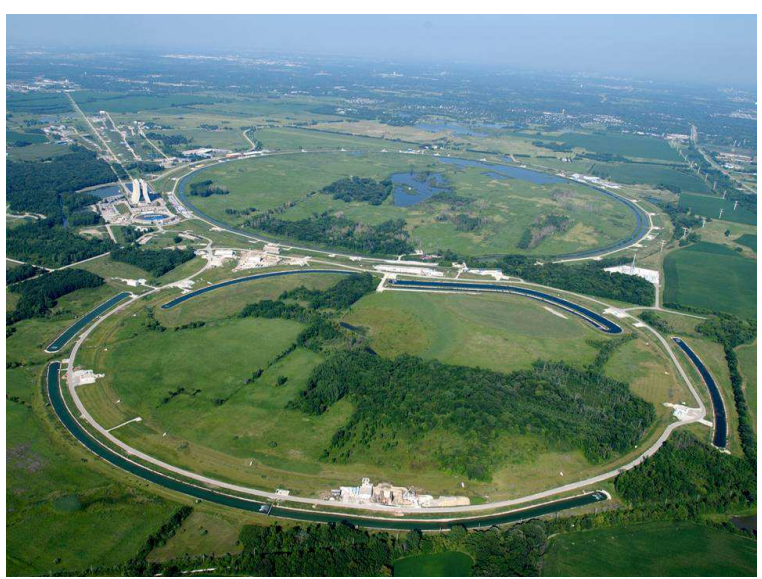

Fig. 16: The Tevatron (background) and Main Injector rings 


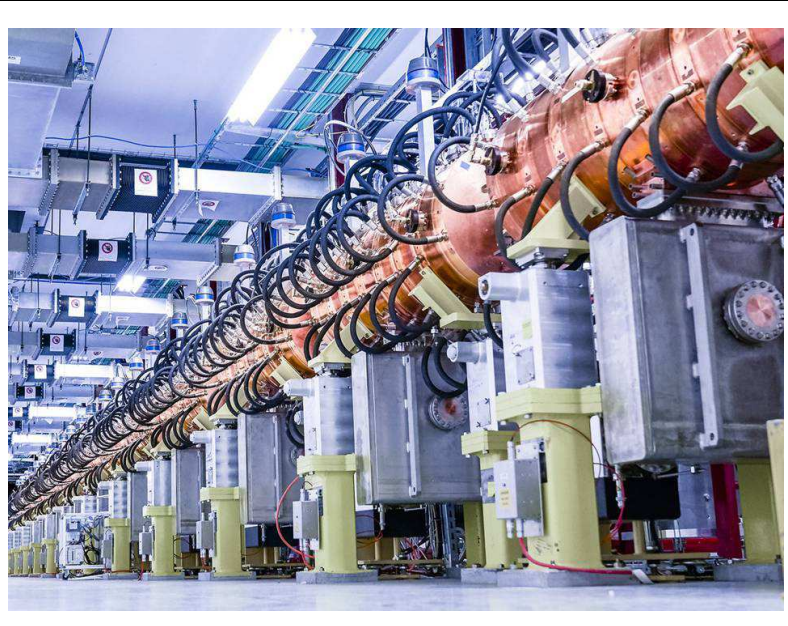

Fig. 17: Los Alamos Linear Accelerator (LINAC)

Tevatron's main ring will probably be reused in future experiments and its components can be transferred to other particle accelerators.

Particle accelerators can also produce proton beams that can produce proton-rich medical isotopes or research, as opposed to those rich in neutrons, manufactured in fission reactors; however, recent works have shown how to make $99 \mathrm{Mo}$, usually made in reactors, by accelerating hydrogen isotopes, although this method still requires a reactor to produce tritium. An example of this type of car is LANSCE at Los Alamos (Fig. 17).

Los Alamos the Neutron Science Center (LANSCE) is the signature of the experimental scientific facility at the Los Alamos National Laboratory. Built 30 years ago, LANSCE was an innovative accelerator project designed by Manhattan Louis Rosen scientist as a world-class neutron dispersion facility. To complement the studies on the nature of elemental particles carried out in other institutions in the 1970s, the new unit would produce the fastest proton beam in the world to explore the fundamental forces of nature in the medium energies.

The variety of research activities offered by LANSCE is created by few plants around the world LANSCE helps scientists solve the problems of biological science in the science of materials in fundamental physics.

A unique attribute of LANSCE is that the five main facilities (Lujan Neutron Dispersion Center, Defense Neutron Research Faculty, Proton Radiography Facility, Isotopic Production Facility and Ultracold Neutron Source) can work simultaneously.

Continuing research at LANSCE includes medical applications, semiconductor development, nuclear deterrence and energy security.

The basic LANSCE facility (Fig. 17) is one of the nation's most prominent linear proton accelerators or LINAC. The 800 mega-electron line $(800 \mathrm{MeV})$ offers the simultaneous power of five major facilities with unique capabilities: Proton Radiology Facility (pRad) that supports NNSA Defense (DP) missions; The Neutron Research Center for Weapons (WNR), which supports DP missions; Lujan Neutron Dispersion Center, supporting DP missions and DOE Office of Science (SC); - Isotopic Production Facility (IPF) supporting the CS Nuclear Physics Office; and the Ultra-cold Neutrons (UCN) facility that supports SC missions.

LINAC at LANSCE has served the nation since 1972, providing the current beam required for all experimental areas supporting NNSA-DP and other DOE missions. LINAC's ability to reliably deliver beam current is the key to LANSCE's ability to conduct research - and thus the key to delivering the NNSA and DOE mission results.

\section{Electrostatic Particle Accelerators}

From a historical point of view, the first accelerators used a simple single-phase static voltage technology to accelerate charged particles. Although this method is still very popular today with electrostatic accelerators that enumerate completely any other type, they are more suitable for lower energy studies due to a practical voltage limit of about $30 \mathrm{MV}$ (when the accelerator is placed in a dielectric gas force, sulfur hexafluoride, which allows a high voltage). The same high voltage can be used twice in a tandem accelerator if the particle loading can be reversed while inside the terminal; this is possible by accelerating the atomic nuclei by first adding an additional electron or by forming an anionic chemical compound (negative charge) and then placing the beam through a thin foil to detach the electrons inside the high voltage conduction terminal, positive load.

Although electrostatic accelerators accelerate the particles along a straight line, the term linear accelerator is more often associated with accelerators using oscillating electric fields, rather than static electric fields. Thus, many accelerators arranged in a straight line are not referred to as "linear accelerators", but rather "electrostatic accelerators" to differentiate the two cases.

\section{Field acceleration Oscillators}

Due to the high voltage required by the electric discharge, to accelerate the particles at higher energies, techniques involving several low voltage but high voltage sources are used. The electrodes can be arranged to accelerate the particles in a line or circle, depending on whether the particles are subjected to a magnetic field while they are accelerated, determining their arc trajectories.

\section{Linear Particle Accelerators}

In a linear accelerator (bond), the particles are accelerated in a straight line with an objective of interest 
at one end. They are often used to provide a reduced impact of the original particles before being injected into the circular accelerators.

The longest line in the world is the SLAC Linear Stanford Accelerator, which is $3 \mathrm{~km}$ long. SLAC is a positive descent of electrons.

High power linear accelerators use a linear array of plates (or bypass tubes) to which a large alternating energy field is applied. As the particles approach a plate, they are accelerated to a load with the opposite polarity applied to the plate.

As they pass through a hole in the plate, the polarity is switched so that the plates reject them now and are now accelerated to the next plate.

Normally, a stream of particle "beams" is accelerated so that carefully controlled AC voltage is applied to each plate to continuously repeat this process for each group.

As the particles approach the speed of light, the switching speed of the electric fields becomes so high that they operate at microwave frequencies, so RF cavity resonators are used in machines with a higher power than plain plates.

Linear accelerators are also widely used in medicine, radiotherapy and radiosurgery. The LINAC line accelerates electrons with a lever and a complex bending magnet arrangement that produces a power range of between 6 and 30 million volts $(\mathrm{MeV})$.

The electrons can be used directly or they can collide with a target to produce an X-ray. The reliability, flexibility and precision of the radiation beam produced largely replaced the older use of Cobalt-60 therapy as a treatment tool.

\section{Circular or Cyclic Accelerators}

In a circular accelerator, the particles rotate in a circle several times until they reach a sufficient amount of energy. The particle trace is usually bent into a circle using electromagnets.

The advantage of circular accelerators (linacs) is that the ring topology allows for continuous acceleration, because particles can move to infinity if we do not take into account certain barriers (limits) that can occur especially to electrons, which at a certain energy reached in circular accelerators can no longer store yet another extra energy and break their circular trajectory which they leave by eventually transforming into an energetic photon and eventually into a limited energy electron, that is, many cyclic rotating particles for acceleration at a certain level of energy emit energy particles, for example photons, which happens especially with electrons at circular aceleration. The energy increase of an electron to even higher energies can instead be experienced in linear accelerators, with the disadvantage of using a much larger space and more materials to achieve it.

Another advantage is that a circular accelerator is smaller than a comparable linear accelerator of power (i.e., a connection must be extremely long to have the equivalent power of a circular accelerator).

Depending on the energy and the particle that is accelerated, the circular accelerators suffer a disadvantage in that the particles emit synchrotron radiation.

When any charged particle is accelerated, it emits electromagnetic radiation and secondary emissions. Because a particle circulating in a circle always accelerates towards the center of the circle, it continuously emits the tangent of the circle. This radiation is called synchrotron light and depends very much on the particle mass of the particle and the particle type. For this reason, many high-power electronic accelerators are created by connections. To make good use of this effect, some accelerators (synchrotrons) are specially designed to produce synchrotron light (X-rays).

Because the special theory of relativity requires matter to travel always slower than the speed of light in a vacuum in high power accelerators, because energy increases the particle speed approaching the speed of light as a limit but without ever touching it.

Consequently, particle physicists do not generally think of speed, but rather of the energy or impulse of a particle, usually measured in electron volts $(\mathrm{eV})$.

An important principle for circular accelerators and particle beams in general is that the particle trajectory curvature is proportional to particle loading and magnetic field, but inversely proportional to the impulse (typically relativistic).

\section{Cyclotrons}

The earliest circular accelerators were cyclotrons, invented in 1929 by Ernest O. Lawrence (Fig. 18) at the University of California, Berkeley.

Cyclotrons have a single pair of D-shaped plates to accelerate particles and a unique maritime dipole to bend their path into an orbital circle (Fig. 18).

It is a characteristic feature of charged particles in a uniform and constant magnetic field $\mathrm{B}$ that orbits with a constant period at a frequency called cyclotron frequency as long as their speed is small compared to the speed of light $\mathrm{c}$.

This means that the cyclotron $\mathrm{D}$ acceleration can be driven at a frequency constant by an accelerator frequency (RF) energy source as the beam rotates continuously outward.

The particles are injected into the center of the magnet and pulled to the outer edge at the maximum energy (Fig. 19).

Cyclotrons reach an energy limit due to relativistic effects, by which particles become more massive, so that their cyclotron frequency drops from synchronization with RF acceleration. 


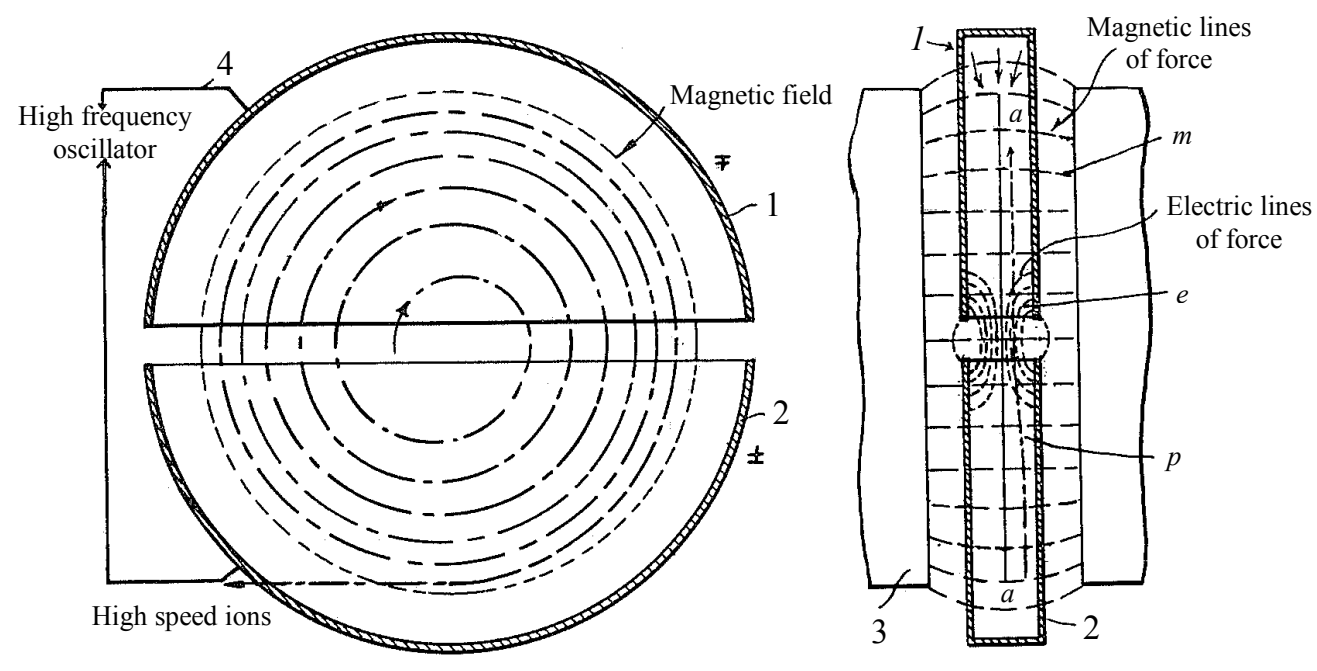

Fig. 18: Diagram of cyclotron operation from Lawrence's 1934 patent

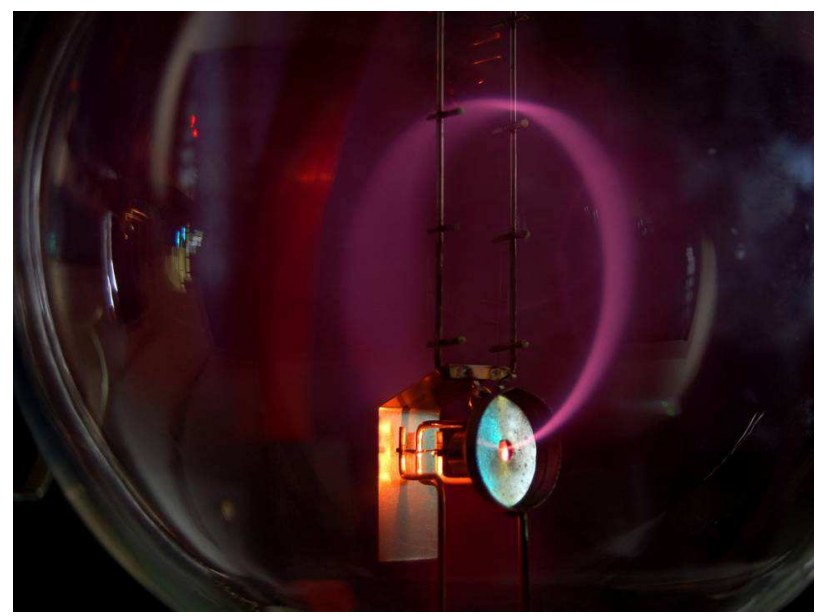

Fig. 19: Beam of electrons moving in a circle. Lighting is caused by excitation of gas atoms in a bulb

Therefore, simple cyclotrons can accelerate protons with only 15 million electrons $(15 \mathrm{MeV}$, corresponding to a rate of about $10 \%$ of $\mathrm{c}$ ), as protons go out of the field with the electric field.

If it continues to accelerate, the beam will continue to spiral at a larger radius, but the particles would not have enough speed to complement the larger circle in step with the RF acceleration. Cyclotrons are, however, useful for low energy applications (Fig. 20).

\section{Synchrocyclotrons and Isochronic Cyclotrons}

There are ways to change the classic cyclotron to increase the energy limit.

This can be done in constant constant constant constant by shaping the pole magnet to increase the magnetic field with the radius.

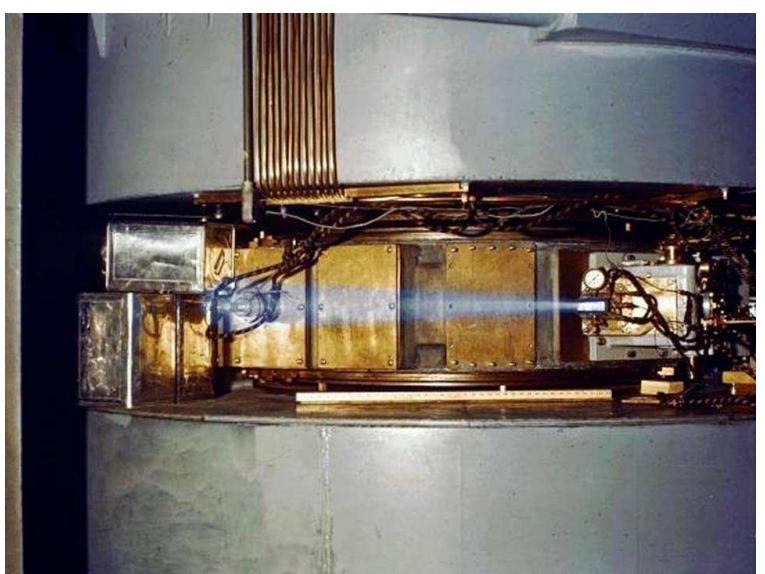

Fig. 20: 60-inch cyclotron, circa 1939, showing a beam of accelerated ions (likely protons or deuterons) escaping the accelerator and ionizing the surrounding air causing a blue glow

Then the larger energy particles move a smaller distance in each orbit than otherwise and can remain in the acceleration phase. Such machines are called isochronic cyclones. Their advantage is that they can deliver continuous beams with a higher average intensity, which is useful for some applications.

The main drawbacks are the size and cost of the large magnet and the difficulty of obtaining the larger field required at the outer edge. Another possibility, the synchrocyclotron (Fig. 21), accelerates the particles into beams in a constant B field, but reduces the frequency of the RF acceleration field so as to keep the particles in step as they spiral outwards.

This approach suffers from short beam intensity due to agglomeration and, again, the need for a high magnet and a constant field on a higher energy orbit. 


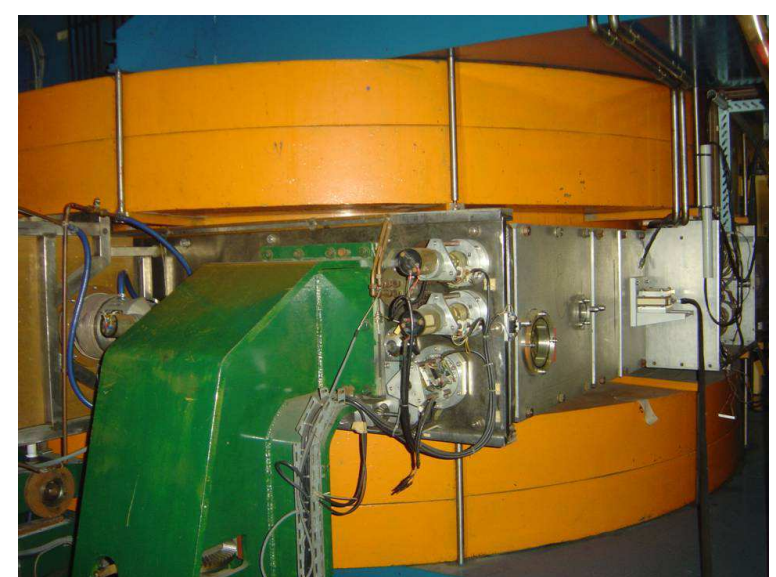

Fig. 21: A magnet in the synchrocyclotron at the Orsay proton therapy center

\section{Betatrons}

Another type of circular accelerator, invented in 1940 to accelerate electrons, is Betatron, a concept that eventually comes from Norwegian-German counterpart Rolf Widerøe.

These machines, such as synchrotrons, use an annular magnet (see below) with an increasingly cyclic B field but accelerate the particles by induction from the magnetic field as if they were at the secondary coil in a transformer, changing magnetic flux on orbit.

Making a constant orbit beam while providing the appropriate accelerator field requires that the magnetic flux that connects the orbit is somewhat independent of the magnetic field in the orbit, bending the particles over a constant radius of the ray.

These machines were virtually limited by the very large electron radiation losses moving almost at the speed of light in a relatively small orbit (Fig. 22).

\section{Synchrotrons}

To reach even higher energies, with relativistic mass approaching or exceeding the particle mass (for protons, billions of electrons or $\mathrm{GeVs}$ ), it is necessary to use a synchrotron (Fig. 23). This is an accelerator in which the particles are accelerated into a constant-radius ring. An immediate advantage over cyclotrons is that the magnetic field must be present only in the real region of particle orbits, which is much narrower than the diameter of the ring. (The largest cyclotron built in the US had a magnet pole of $184 \mathrm{~cm}(4.7 \mathrm{~m})$, while the LEP and LHC diameter is about $10 \mathrm{~km}$. The diaphragm of the two LHC beams is one millimeter.)

However, as the particle impulse increases during acceleration, it is necessary to return the magnetic field $\mathrm{B}$ in proportion to maintaining the constant curvature of the orbit.

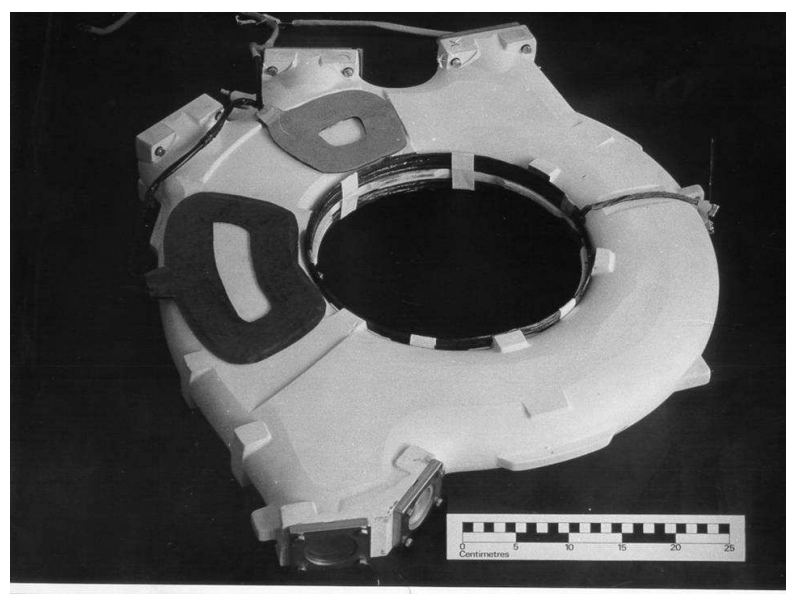

Fig. 22: A Betatron

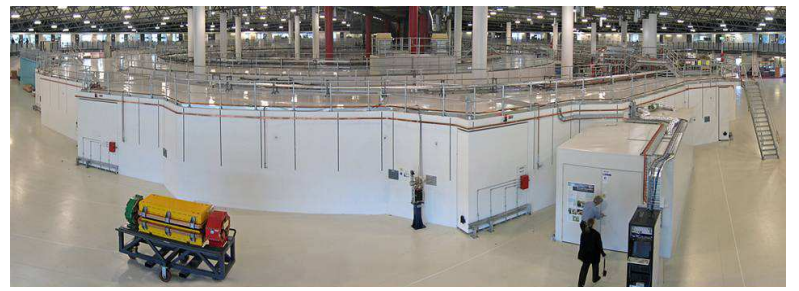

Fig. 23: The interior of the Australian Synchrotron facility. Dominating the image is the storage ring, showing the optical diagnostic beamline at front right. In the middle of the storage ring is the booster synchrotron and linac

Consequently, synchrotrons cannot accelerate the particles continuously, such as cyclotrons, but must operate cyclically, providing particles in groups that are delivered to a target or to an external beam, frequently every few seconds.

Since high-power syncroton performs most of its work on particles that are already moving near the speed of light c, the time to complete an orbit on the ring is almost constant, just like the frequency of resonances of the RF cavity used to accelerate.

Note also an additional point about modern synchronous thrones: Because the diaphragm is small and the magnetic field does not cover the entire area of particle orbit, as in the case of a cyclotron, several functions can be separated.

Instead of a huge magnet, one has a line of hundreds of bending magnets that close (or are closed) vacuum tubes. The synchrotron design was revolutionized in the early 1950 s with the discovery of the strong focus concept.

The focusing of the beam is performed independently of specialized quadrupole magnets, while the acceleration itself is performed in separate RF sections similar to short linear accelerators. Also, it is not necessary for the circular machines to be circular, but rather the beam conduit may have straight sections 
between the magnets in which the beams may collide, they may cool, etc. It evolved into a whole separate subject called Physical Physical Physics. Complex complex synchrons, such as Tevatron, LEP and LHC, can provide particle bundles in B-shaped magnet storage rings where they can continue to orbit for long periods of time to experiment or accelerate.

Larger energy cells, such as Tevatron and LHC, are in fact acceleration complexes with a cascade of seriesspecific elements, including beam accelerations with beam initiation beam, one or more low energy synchrotrons reaches the necessary intermediate magnet and allows focus approach, see beam cooling) and a last great ring for final acceleration and experimentation.

The particles are injected into the main ring in substantial energies either by a linear accelerator or by an intermediate synchrotron which is in turn fed by a linear accelerator.

The line is, in turn, fed by the accelerated energy to the intermediate energy through a high-voltage power supply, usually a Cockcroft-Walton generator.

Starting at an appropriate initial velocity determined by the injection rate, the magnetic field is then increased. The particles pass through an electrostatic accelerator driven by a high alternating voltage.

At particle speeds that are not near the speed of light, the frequency of the acceleration voltage may be proportional to the current in the bending magnets.

Better frequency control is performed by a servo loop that responds to detecting the passage of the moving group of particles.

At particle speeds approaching the speed of light, the frequency becomes more constant, while the current in the bending magnets continues to increase.

The maximum energy that can be applied to the particles (for a certain ring size and magnet number) is determined by the saturation of the bending magnets (the point where the growth current does not produce additional magnetic field).

One way to get extra power is to make the torus larger and add additional bending magnets.

This allows the redirection of saturation to be smaller and so the particles can be stronger. Another means of achieving greater power is the use of superconducting magnets, which is not limited to basic saturation.

\section{Large Synchrotrons}

One of the first synchrotrons, now withdrawn, is Bevatron, built in 1950 at Lawrence Berkeley's lab.

The name of this proton accelerator comes from its power in the range of $6.3 \mathrm{GeV}$ (called $\mathrm{BeV}$ for billions of volts, the name preceding the adoption of the giga SI prefix).

A series of heavy elements, unseen in the natural world, were created with this car.
This site is also the site of one of the first large bubble rooms used to examine the results of the atomic collisions produced here.

Another big synchrotron is Cosmotron built at the Brookhaven National Laboratory, which reached 3.3 $\mathrm{GeV}$ in 1953.

Until August 2008, the world's largest synchrotron of energy was Tevatron, the Fermi Accelerator Laboratory in the United States.

Accelerates protons and antiprotons to less than $1 \mathrm{TeV}$ of kinetic energy and collates them together (Fig. 16).

Large-scale ink (LHC, Fig. 15), built at the European High Energy Physics Laboratory (CERN), has about seven times this energy (so proton-proton collision takes place at about $14 \mathrm{TeV}$ ).

It is housed in the $27 \mathrm{~km}$ tunnel, which previously housed the Large Electron Positron (LEP) probe, so it will maintain the claim as the largest scientific device ever built.

The LHC will also accelerate heavy ions (such as lead) to a $1.15 \mathrm{PeV}$ energy.

The largest proposed device of this type was the Superconducting Super Collider (SSC) to be built in the United States.

This design, like others, has used surviving magnets that allow the creation of intense magnetic fields without limiting central saturation.

With the construction started, the project was canceled in 1994, citing excessive budget overruns - due to problems of estimating naïve costs and economic management problems, rather than design deficiencies.

It can also be argued that the end of the Cold War led to a change in the scientific funding priorities that contributed to the final cancellation.

Although there is still potential for proton cyclic accelerators and stronger weights, it seems that the next step of electron beam energy should avoid synchrotrophic radiation loss. This will require a return to the linear accelerator, but with devices far longer than those currently used.

At present, there is a major effort to design and build a Linear International Collator (ILC), which will consist of two opposite linear accelerators, one for electrons and one for positrons.

They will collide at a total mass center of $0.5 \mathrm{TeV}$.

However, synchrotronics also has a wide range of applications (see synchrotronics light) and many second generation synchrotrons and the third was built specifically to exploit them.

The third-generation synchronous source is the European Synchronous Radiation System (ESRF) in Grenoble, France, Advanced Photon Source (APS) near Chicago, USA and SPring-8 in Japan, accelerating electrons up to 6,7 and $\mathrm{GeV}$. Synchrotrons that are useful for top research are large-scale machines that cost 
tens or hundreds of millions of dollars to build and each beam (which can be from 20 to 50 at a high synchrotron), two or three million USD.

These facilities are mainly built by government agencies to finance governments in developed countries or through collaborations between several countries in a region and act as infrastructure facilities at the disposal of scientists from universities and research organizations across the country.

Several compact models, such as the compact light source, have been developed. SOLEIL ("Sun" in French) is a synchrotron plant near Paris, France. She made the first electronic acceleration on May 14, 2006. The SOLEIL name is an advantage for LURE, LURE, which means Laboratoire for electromagnetic reasoning.

The facility is run by a civil society owned by the French National Center for Scientific Research (CNRS) and the Commissariat à l'Énergie Atomique (CEA), two French national research agencies. It is located in SaintAubin, in the department of Essonne, a south-western suburb in Paris near Gif-sur-Yvette and Saclay, which houses other facilities for nuclear physics and particle physics (Fig. 24).

Advanced Photon Source (APS) from the Argonne National Laboratory (Argonne, IL, USA, Fig. 25) is a US national research facility for synchrotron radiation light sources funded by the United States Department of Energy. The Argonne National Laboratory is administered by UChicago Argonne LLC and is composed of the University of Chicago and Jacobs Engineering Group, Inc.

Using high-brilliant X-rays in the APS, members of the international research community in the field of synchronous radiation carry out fundamental and applied research in the field of material science and biological science; physics and chemistry; ecological, geophysical and scientific planetary; and innovative $\mathrm{X}$-ray tools.

ISIS is a pulsed neutron source and a mion. He is at the Rutherford Appleton Laboratory at the Harwell Science and Innovation Campus in Oxfordshire, UK and is part of the Scientific and Technological Council (Fig. 26). It uses spectroscopy and spectroscopy techniques of the muon to investigate the structure and dynamics of condensed matter on a microscopic scale, ranging from subatomic to macromolecular.

Hundreds of experiments are organized annually at ISIS, visiting researchers from around the world in various fields of science such as physics, chemistry, materials engineering, earth sciences, biology and archeology.

Neutrons are constituents of uncharged atoms and penetrate materials well, deflecting only from the nuclei of atoms.

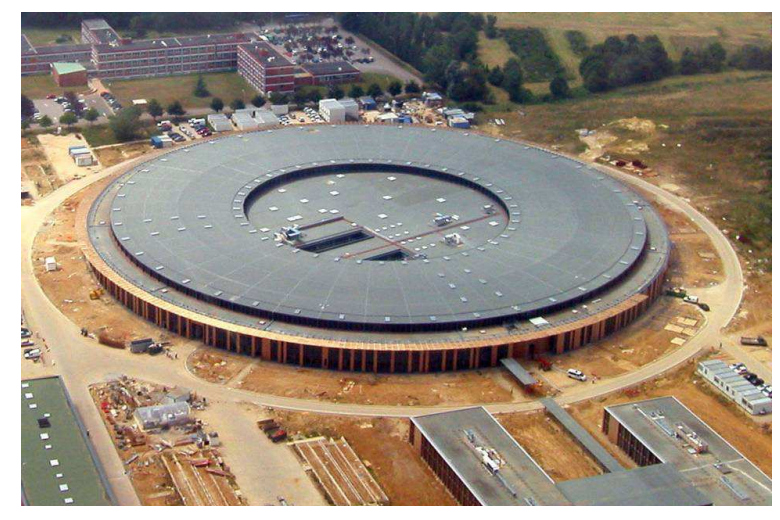

Fig. 24: Modern industrial-scale synchrotrons can be very large (here, Soleil near Paris)

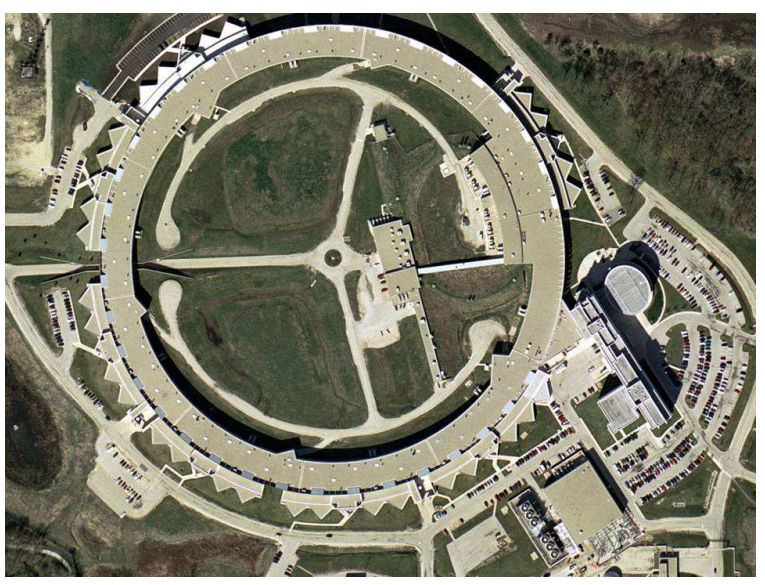

Fig. 25: The Advanced Photon Source (APS) at Argonne National Laboratory (in Argonne, IL, USA) is a national synchrotron-radiation light source research facility funded by the United States Department of Energy Office of Science

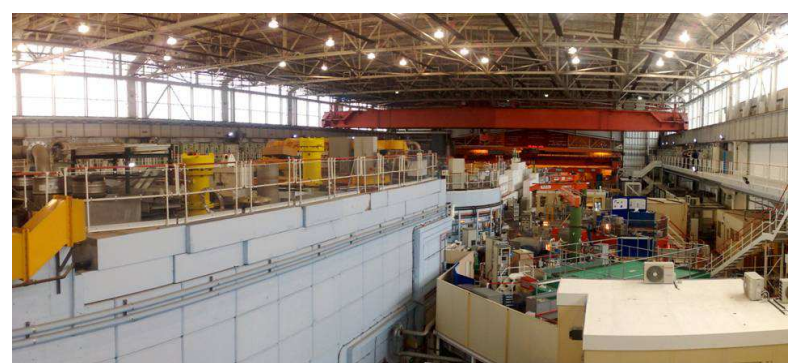

Fig. 26: Another view of the ISIS experimental hall for Target Station 1

The statistical accumulation of neutrons deflected at different locations beyond the sample can be used to find the structure of a material and the loss or gain of energy by the neutrons can reveal the dynamic behavior of the pieces in a sample, the dissemination of the soil in the process. 
In ISIS, neutrons are created by accelerating the proton beam in a synchrotron, then colliding with a heavy metal tungsten target under a constant cooling load to dissipate the heat from the $160 \mathrm{~kW}$ proton.

Impacts lead to the neutralization of tungsten atoms and neutrons are guided through guides or beams to about 20 individually optimized instruments to study different types of matter.

The target station and most of the instruments are located in a large room.

Neutrons are a dangerous form of radiation, so the targets and beams are highly protected with concrete.

ISIS produces moths by collision of a fraction of target graphite proton beams, producing rapid degradation pioneers in muons, delivered in a polarized ray through sampling stations.

The National Laboratory of Luz Sincrotron (LNLS) is the Brazilian national synchrotron light laboratory (Fig. 27), a research institution in physics, chemistry, material science and life sciences. It is in the Campinas sub-district of Barão Geraldo, São Paulo, Brazil. The center, operated by the Association of Light Technologists at Synchrotron in Brazil (ABTLuS), based on a contract with $\mathrm{CNPq}$ and the Brazilian Ministry of Science and Technology, has the only particle accelerator (a synchrotron) of physicists, technicians and engineers.

Bevatron was a historical particle accelerator especially a weakly concentrated proton synchrotron - at Lawrence Berkeley National Laboratory, which began operating in 1954 (Fig. 28).

Antiproton was discovered there in 1955, resulting in the Nobel Prize for Physics in 1959 for Emilio Segrè and Owen Chamberlain.

She accelerated protons to a fixed target and was named for her ability to divide billions of eV energy. (Billions of Synchrotron eV).

At the time when the Bevatron project was designed, it was strongly suspected, but it is not known that each particle has a counterpart corresponding to the opposite load, identical in all other respects, to a property known as the symmetry of the load. The anti-electron or positron was first observed in the early 1930s and theoretically understood as a consequence of the Dirac equation at about the same time.

As a result of the Second World War, positive and negative patches were observed in the cosmic ray interactions observed in cloud rooms and photomicrotic emulsion stacks. Bevatron was built to be energetic enough to create antiprotons and thus test the hypothesis that each particle has a suitable antiparticle. Antineutron was soon discovered by Oreste Piccioni and his colleagues, also at Bevatron. Confirmation of the symmetrical fiscal hypothesis of 1955 led to the Nobel Prize for Physics Emilio Segrè and Owen Chamberlain in 1960.

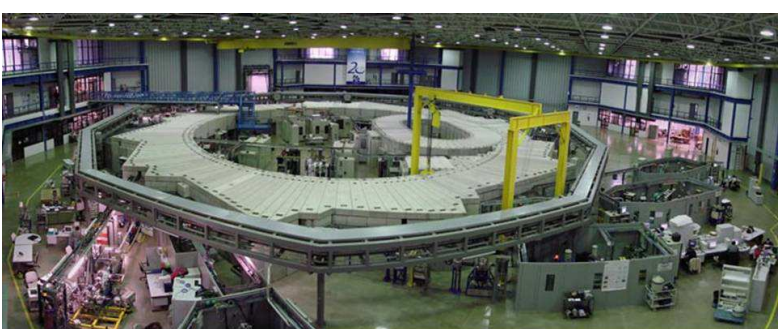

Fig. 27:Laboratório Nacional de Luz Síncrotron (LNLS) is the Brazilian National Laboratory of Synchrotron Light

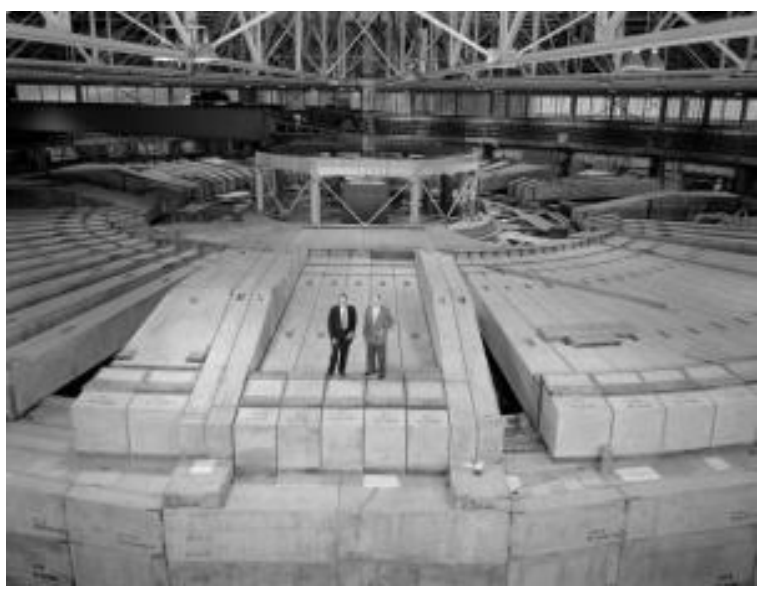

Fig. 28: Edwin McMillan and Edward Lofgren on the shielding of the Bevatron. The shielding was only added later, after initial operations

Shortly after Bevatron entered into use, it was recognized that parity was not kept in the weak interactions, which led to solving the father's puzzle, understanding the oddity and establishing the CPT symmetry as an elemental element of the relativistic theory of the song.

To create antiprotons (mass $\sim 938 \mathrm{MeV} / \mathrm{c} 2$ ) in collisions with nucleons in a stationary target, maintaining energy and impulse, a proton beam energy of about $6.2 \mathrm{GeV}$ is required. At the time it was built, there was no known way of limiting a particle beam into a narrow opening, so that the space of the beams would be about four square feet in cross-section. The combination of diaphragm and energy requires a huge 10,000-ton magnet and a very high vacuum system.

A large engine/generator system was used to raise the magnetic field for each acceleration cycle. At the end of each cycle, after the phase was used or extracted, the energy of the large magnetic field was returned to start the engine, which was then used as a generator to feed the next cycle, conserving energy; the whole process lasted about five seconds. The rising character, the fall, the cry, the sound of the engine generation system could be heard throughout the complex when the car was in operation. 
In the years that followed the discovery of the antiproton, many pioneering works were made using proton beads extracted from the accelerator itself to hit the targets and generate secondary beams of elemental particles not only of protons but also of neutrons, steps, strange particles.

Granules extracted from the particles, both primary and secondary protons, can be passed for further studies through different targets and specialized detectors, especially the liquid air bubble chamber. Many thousands of particle interactions or "events" have been photographed, measured and studied in detail using a large-scale automated system (known as the "Frankensteins") that allows human operator particles (usually spouses) and their coordinates. Plate plates were then analyzed by early generation computers that reconstructed the three-dimensional paths through the magnetic fields and calculated the impulse and energy of the particles. Extremely complex computer programs for their time have mounted route data associated with a particular event to estimate the energies, masses and identities of the produced particles (Fig. 29).

The next generation of accelerators used "strong focusing" and required much smaller openings and thus much cheaper magnets. The AGS (Brookhaven Gradient Alternator) was the first machine with an order of magnitude smaller than the cross section, which reaches the passage and energy of the $30 \mathrm{GeV}$ proton but with the smallest massive magnet. For comparison, Bevatron's largest and largest descendant (about 11,000 times the bulb's intensity) is limited to a cross-section of $1 \mathrm{~mm}$ and concentrates up to 16 microns in junction collision zones and bent magnetism five times more.

The demolition was made in 2009 by Clauss Construction in Lakeside CA by 2011.

The Advanced Light Source (ALS) of Lawrence Berkeley National Laboratory in Berkeley, California, is a synchrotron light source, built between 1987 and 1993, employing 210 scientists and staff. Part of the building where it was hosted was completed in 1942 for a 4.67 meter biker designed by Arthur Brown, designed by the Coit Tower in San Francisco and built by Ernest O. Lawrence. Today, the expanded building hosts ALS and the US Department of Energy user unit, which attracts scientists from around the world.

ALS is a national feature of a use that generates an intense light for scientific and technological research. Being one of the brightest sources of ultraviolet and soft radiation and the third-generation synchrotron light source in the world, ALS makes it impossible to study. The annual faculty hosts 2000 researchers from universities, industries and governmental laboratories around the world. It is funded by the Department of Energy of the Office of Energy Sciences.

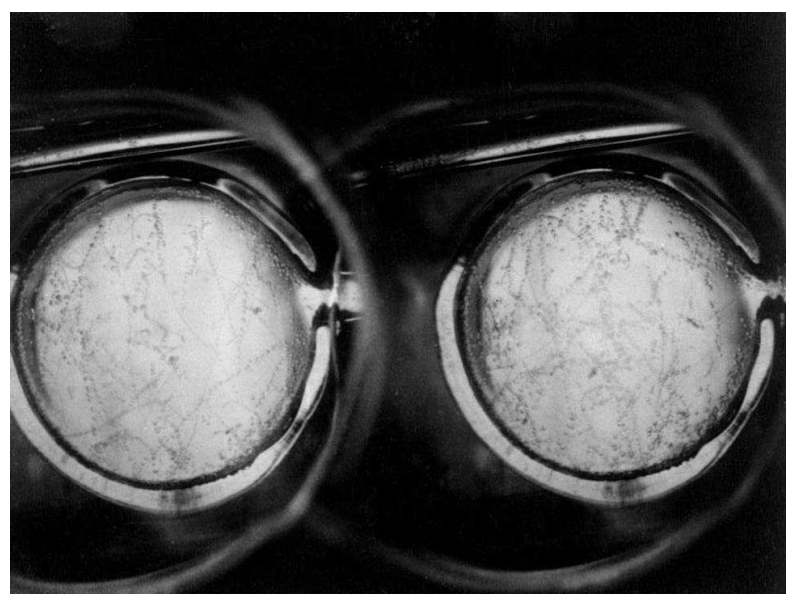

Fig. 29: First tracks observed in liquid hydrogen bubble chamber at the Bevatron

ALS have over 40 beams, simultaneously realizing a wide range of sciences. Any qualified scientist may suggest using the ALS beam.

Proposals are examined by colleagues and high level colleagues are distributed over time. ALS does not charge for transmission time, if user research is not of its own nature (results are published in open literature).

Cosmotron was a particle accelerator, especially a proton synchrotron, at the Brookhaven National Laboratory.

The construction was approved by the United States Atomic Energy Commission. In 1948, it reached its full energy in 1953 and continued to function until 1968.

This was the first particle accelerator that supplied the kinetic energy from the $\mathrm{GeV}$ range to a single particle, accelerating the protons to $3.3 \mathrm{GeV}$.

It was also the first accelerator to extract the particle beam for experiments physically located outside the accelerator.

It was used to observe a number of mesons previously seen in cosmic rays and to cope with the first discoveries of heavy and unstable particles (called V particles at that time).

Source Source Sinkrotron National Source (NSLS) The Brookhaven National Laboratory (BNL) in Upton, New York, is a national research facility used by the United States Department of Energy (DOE). NSLS is considered a second-generation synchrotron and was built from 1978 and finished in 1984 (Fig. 30).

The NSLS experimental floor consists of two electronic storage rings: An X-ray ring and a VUV ring (Vacuum Ultra Violet) provide intense concentrated light covering the electromagnetic spectrum from X-ray infrared radiation. The properties of these beams are designed for light and special posts allow scientists in many research fields to perform experiments that are not otherwise possible in their own laboratories. 


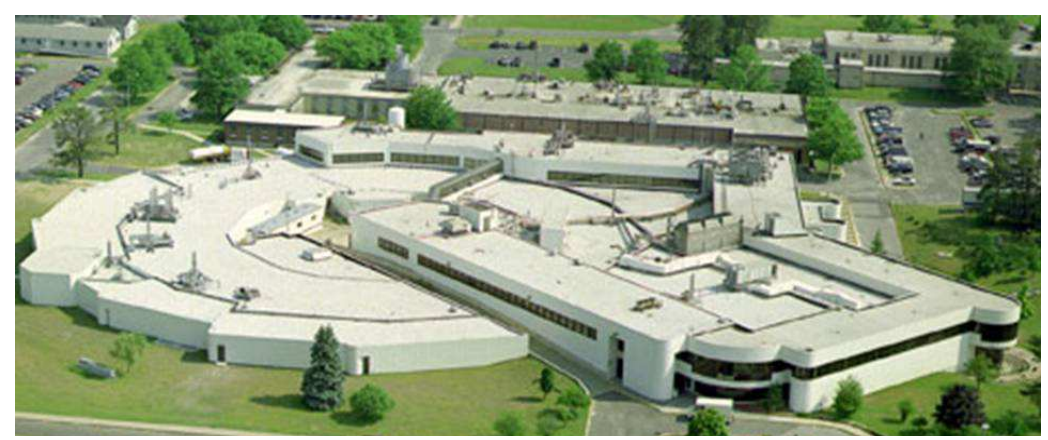

Fig. 30: Aerial view of the NSLS

Stanford Synchrotron Radiation Lightsource (former Stanford Synchrotron Radiation Laboratory), a division of the National SLAC Accelerator Laboratory, is operated by Stanford University for the Department of Energy. SSRL is a national instrument that provides synchrotron radiation, a name given to X-ray electromagnetic radiation produced by ultra-violet, visible and infrared electrons, which circulate in a SPEAR near the speed of light. These extremely bright x-rays can be used to investigate different forms of matter, from atomic and molecular objects to man-made materials with unusual properties. The information and knowledge gained are of great value to society, impacting on areas such as the environment, future technologies, health and education. SSRL provides experimental facilities for 2,000 academic and industrial scientists working in such diverse fields as drug design, environmental cleanup, electronics and X-ray imaging. It is located in the south of San Mateo, just off the park Menlo.

In 1972, the first X-ray beam was built by Ingolf Lindau and Piero Pianetta as literally a "hole in the wall" that extended from the Stanford Positron Electron Ring Asymmetric. At that time, the SPEAR was built during a period of particle collisions, where physicists were more interested in crushing particles together hoping to uncover antimatter, then use X-rays for solid physics and chemistry. From these weak beginnings, the Synchrotron Stanford Radiation Project (SSRP) began. In a short period of time, SSRP had five experimental carts that share the radiation of only a few centimeters of the SPEAR curved dipole magnets. Each of these stations was equipped with a monochrome to select radiations of interest and the experiments would bring samples and final stations around the world to study the unique effects obtained only by synchrotron radiation. Today, the SPEAR storage ring is entirely dedicated to Stanford Synchrotron Radiation Lightsource as part of the SLAC National Accelerator. The SSRL currently operates 24 hours a day for approximately nine months in a year; remaining time is used for maintenance and major upgrades requiring direct access to the storage ring. There are over 30 unique experimental stations that are made available to users in universities, governmental laboratories and industry around the world.

Proton Synchrotron (PS) is the first major particle accelerator at CERN, built as a $28 \mathrm{GeV}$ proton accelerator in the late 1950s and put into operation in 1959. Proton Synchrotron Booster Protons are required for a kinetic energy of 1, $4 \mathrm{GeV}$ and Low LEIR) to $72 \mathrm{MeV}$ per nucleon. It has been operated as Interchangeable Injector (ISR), Synchrotron Super Proton (SPS) and Light Electronics Positron (LEP). Since November 2009, PS has been carrying protons and will supply lead ions for the Large Hadron Coordination Leader (LHC). It has also been used as a source of particles for other experiments, such as the Gargamelle bubble chamber, for which it supplied a beam of neutrinos. This led to the discovery of the weak neutral current in 1974.

The PS machine is a circular accelerator with a circumference of $628.3 \mathrm{~m}$. It is a versatile machine that accelerated protons, antiprotons, electrons, positrons and ionic species. Major updates have improved performance by more than a factor of 1,000 since 1959 . The only major components left behind by the initial installation 50 years ago are magnets and bent buildings.

The Swiss light source is a synchrotron at the Paul Scherrer Institute in Switzerland and is intended for the production of high-luminous electromagnetic radiation (Fig. 31). Its planning began in 1991, the project was approved in 1997 and its first operation took place on December 15, 2000. The experiments started in June 2001, being used especially for research in materials science, biology and chemistry.

The Sincrotron Radiation Sources (SRS) from Daresbury Laboratory in Cheshire, England, was the first generation of second-generation synchrotron radiation producing X-rays.

The research facility provided synchrotron radiation at a large number (at a point 38 ) experimental stations and had an operating cost of about $£ 20$ million per year.

SRS was operated by the Council for Science and Technology. The SRS was closed in August 2008 after 28 years of operation and is currently decommissioned without major plans for re-use of the existing building. 


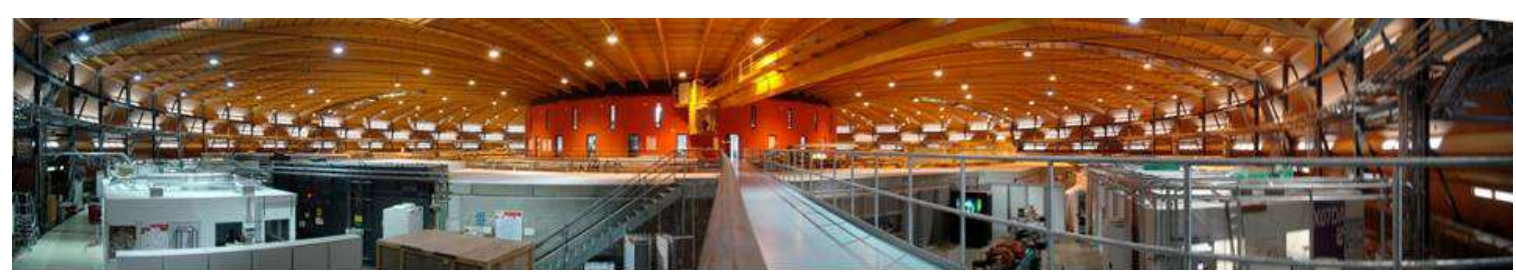

Fig. 31: Panorama of the SLS

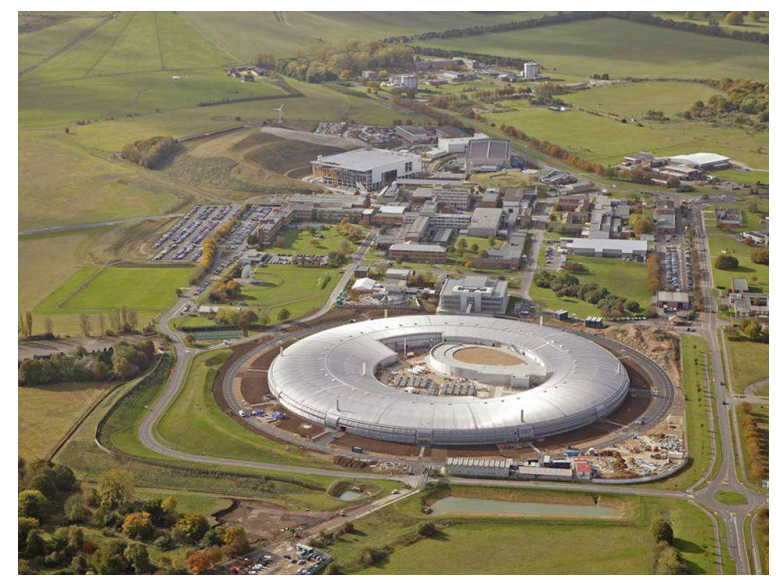

Fig. 32: Aerial view of The Diamond Synchrotron

The diamond light source is a synchrotron unit located in Oxfordshire, United Kingdom (Fig. 32).

Its purpose is to produce intense luminous beams whose special features are useful in many areas of scientific research.

In particular, it can be used to investigate the structure and properties of a wide range of materials (e.g., proteins).

The diamond generates synchrotrotic light at wavelength ranging from X-rays to infrared. It is also known as synchrotron radiation and is the electromagnetic radiation emitted by charged particles traveling near the speed of light. It is used in a wide variety of experiments to study the structure and behavior of many different types of matter.

The particles used by diamonds are electrons traveling with a rounded energy of $3 \mathrm{GeV}$ on a circumferential storage ring of $561.6 \mathrm{~m}$.

The ring is not circular but has the shape of a twentyfour point polygon. As the electrons pass through magnets specially designed at each peak, their sudden change of direction causes them to emit a particularly bright beam of radiation. This is the synchrotron light used for experiments.

Electrons reach this high energy through a series of pre-accelerator steps before being injected into the storage ring:

- An electron gun

- A $100 \mathrm{MeV}$ linear accelerator

\section{- A $100 \mathrm{MeV}-3 \mathrm{GeV}$ booster synchrotron}

Diamond is housed in a toroidal silver building with a circumference of $738 \mathrm{~m}$, covering an area of over 43,300 square meters or an area over six international football fields.

It contains the storage ring and a number of beams with the linear accelerator and the booster syncrotron located at the center of the ring.

These are experimental stations where interaction with synchrotron light with matter is used for research purposes. Seven were available when Diamond entered service in 2007, intending to build another fifteen years between 2011 and 2011 at an additional cost of $£ 120$ million. Since December 2010, there have been eighteen more and more in construction.

The seven available at Diamond opening were:

- Extreme beam conditions to study materials at intense temperatures and pressures

- Materials and magnetism beam, mounted on electronic probes and magnetic materials at atomic level

- Three macromolecular crystallography lines to decode the structure of complex biological samples, such as proteins. Spectroscopy Microfocus Spectroscopy, capable of regulating the chemical composition of complex materials such as moon stones and geological samples. Nanoscience for the beam line, capable of imaging structures and nanometer devices (millions of millimeters)

The diamond is ultimately destined to accommodate up to forty beams, supporting life, physical and environmental sciences.

On September 13, 2007, researchers at the University of Cardiff, led by Professor Tim Wess, discovered that Diamond Synchronotron can be used to uncover the hidden content of ancient documents through light without opening them (penetrative layers of parchment).

A synchrotron like this, the size of a stadium (Fig. 32 ), built as a flying ship, could carry from 30,000 to 50,000 passengers!

\section{Storage Rings}

For some applications, it is useful to store high energy particle beams for a certain amount of time (with 
modern high vacuum technology up to several hours) without additional acceleration.

This is particularly true for beam collision accelerators, in which two strips moving in opposite directions collide with one another with a high gain in effective collision energy.

Since there is a relatively small collision at each intersection of the two beams, the beam acceleration energy is a common destination and then stored in the storage rings, which are essentially synchrotron magnets that accelerate the power.

A storage ring is a type of circular particle accelerator in which a continuous or pulsating particle beam can be kept in circulation for a long time, up to several hours. The storage of a particular particle depends on the mass, energy and the usual load of the stored particles. Most often, storage rings are to store electrons, positrons or protons.

The most common application of storage rings is the storage of electrons that then radiate synchrotron radiation.

There are over 50 facilities based on electronic storage rings in today's world, used for a variety of studies in chemistry and biology.

Storage rings are used to produce high polarized electron beams through the Sokolov-Ternov effect.

Obviously, the best known use of storage rings is their use in particle accelerators and particle collisions, in which two counter-rotating particle particles collide in discrete places, the results of the subatomic interactions being studied in a particle of the clean detector.

Examples of such facilities are LHC, LEP, PEP-II, KEKB, RHIC, Tevatron and HERA.

From a technical point of view, a storage ring is a type of synchrotron. However, a conventional synchrotron serves to accelerate low energy particles at sea through radio frequency accelerators; a storage ring, as the name suggests, keeps the particles stored at a constant energy and the radio frequency cavities are used only to replace the lost energy by synchrotron radiation and other processes.

Gerard K. O'Neill proposed the use of storage rings as building blocks for a cage in 1956. A key advantage of storage rings in this context is that the storage ring can accumulate a large acceleration of the injection beam at a much higher rate bigger.

A force must be applied to the particles in such a way as to move in a circular path.

This can be done either using electrostatic or dipolar dipole magnetic fields, but because most of the storage rings store relativistic loaded particles, it seems very useful to use magnetic fields produced by dipole magnets (Fig. 33).

However, electrostatic accelerators have been built to store very low energy particles and quadrupole fields can be used for unused storage (neutrons); these are relatively rare, however.

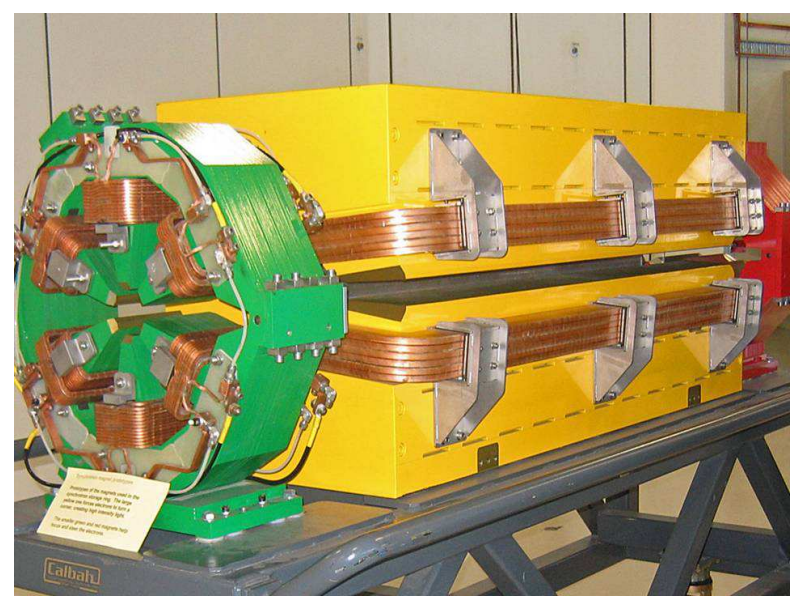

Fig. 33: Different types of magnets used in the storage ring of the Australian Synchrotron. The larger yellow (white) one is a dipole magnet used to bend the electron beam and produce the synchrotron radiation. The green one is a sextupole magnet, the red one (at back) a quadrupole magnet - these are used to focus and steer the electron beam

Diploid magnets offer only a weak focus and a storage ring composed only of these types of magnetic elements produces particles with a large beam size.

For this reason, the dipole magnets intertwine with an appropriate arrangement of quadrupole and sextuples magnets, providing a powerful focusing system that can donate a much smaller beam.

The FODO and Chasman-Green lattice structures are simple examples of powerful focusing systems, but there are many others.

Quadrupoli dipoles and magnets deflect different particle energies in different amounts, a property called chromaticity by analogy with physical optics.

Spreading the energies present inherently in any stored particle beam will in practice lead to a spread of transverse and longitudinal focusing as well as contributing to various particle beam instabilities.

Sextuple magnets (and larger magnets) are used to correct this phenomenon, but this gives rise to a nonlinear motion, which is one of the main problems faced by designers of storage rings.

Because groups will travel a few million kilometers (because they will move near the speed of light for several hours), any residual gas in the beam will lead to many collisions.

This will increase the size of the gram and increase the spread of energy. Therefore, a better vacuum gives a better beam dynamics.

Also, single wide angle dispersion events, either from residual gas or from other particles in the dump (Touschek dispersion), can remove particles large enough to lose them on the walls of the acceleration vessel. 
This gradual loss of particles is called the life of the beam and means that the storage rings must be injected periodically with a new particle supplement.

Particulate injection into a storage ring can be performed in several ways, depending on the application of the storage ring.

The easiest method uses one or more impulses (magnet with kicker for injection) to direct a particle train that enters the beam path; the kicker magnets are stopped before the stored train returns to the injection point, resulting in a stored beam.

This method is sometimes called a single injection.

Multi-stroke injection allows multiple trains to accrue, for example if a high current is required. For particles such as protons without significant beam damping, each injected pulse is placed at a certain point in the transverse or longitudinal space of the beams with stored beams, taking care not to drain the previously injected trains using careful deformation of the device and coinciding with stored.

If there is a significant damping of the beam, for example with the damping electron beam due to synchrotron radiation, an injected pulse can be placed on the edge of the phase space and then allowed to depreciate in the stored stock stored before the injection for another moment. Typical damping times from synchrotronics are tens of milliseconds, allowing for more pulses per second.

If particle extraction is required (e.g., in an acceleration chain), then a single extraction can be performed similarly to the injection. Also, resonance extraction can be used.

A storage ring can be a very useful component of a flying ship!

This vessel (UFO) has two circular accelerators (see picture below, Fig. 34).

An accelerator is used permanently and the second can only be used for large loads. Generally it acts as a storage ring.

\section{Electron Synchrotron}

The first synchrotron electron accelerator was Cornell Electron Synchrotron, designed and produced in the late 1960s, followed by many other high-power circular accelerators designed for particle physics culminating in the CERN LEP.

Electronic syncroctrons have been installed over the past two decades, specializing in sources of synchrotron light, ultraviolet light and X-rays.

\section{Source of Synchrotron Radiation}

Synchrotron light and radiation generators are light sources with X-ray syncroctrons, such as the diamond built at the Rutherford Appleton Laboratory in England or Argonne Advanced Photon Source Laboratory National in Illinois America.

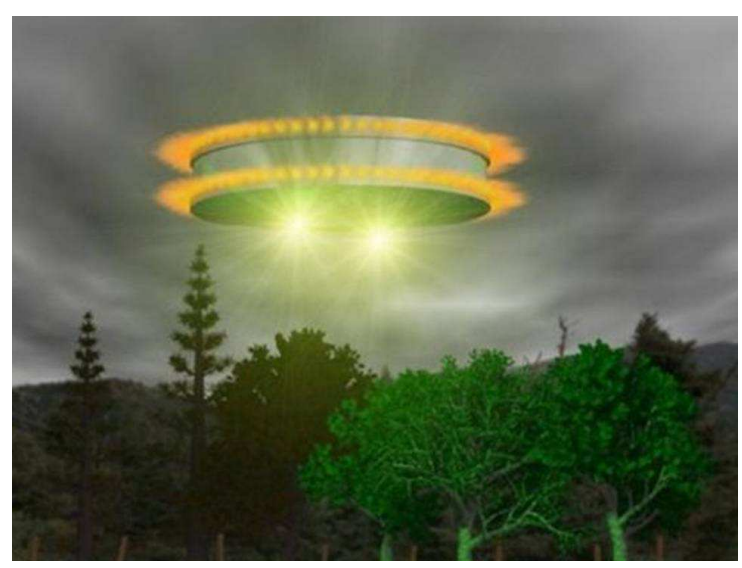

Fig. 34: This ship (UFO) has two circular accelerators

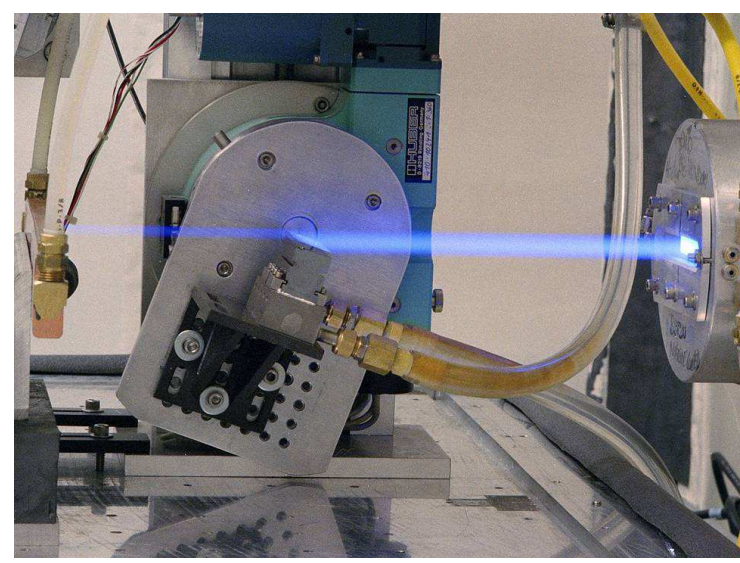

Fig. 35: Synchrotron radiation emerging from a beam port. The blue colour comes from oxygen and nitrogen atoms in the air, ionised by the X-rays

High energy X rays are useful, for example, for X-ray absorption (XAFS) (Fig. 35).

Synchrotrotic radiation is most emitted by light particles, which is why these accelerators are invariably electron accelerators. Synchrotrotic radiation generates a better image as studied and developed at SLAC SPEAR.

A synchrotron light source is a source of electromagnetic radiation produced by a synchrotron for scientific and technical purposes by specialized particle accelerators, usually acceleration electrons. Once a highenergy electron beam has been generated, it is directed to auxiliary components, such as bending magnets and induction devices (induction or winding), into free storage rings and electronic lasers. They provide powerful magnetic fields perpendicular to the beam needed to transform the energy of high energy electrons into light or other EM radiation.

\section{Results and Discussion}

Sincrotronics has great advantages with important applications in the fields of condensed matter physics, 
materials science, biology and medicine. Most experiments with synchrotronic light aim to investigate the structure of matter in the microscopic sub-sample, microscopically of micronetry and millimeter, being important in medical imaging. A primary example of industrial application is that of manufacturing microstructures through the LIGA process.

Synchrotrotic radiation may appear in the accelerator either as an obstacle, resulting in unwanted energy losses in the context of particle physics, or as a deliberately generated source of radiation for many laboratory applications. In other words, it is an effect that was initially undesirable, but then it was adapted and used in the production of synchrotronic light, because the electrons are accelerated at high speeds in several stages to get the final energy that is way common in the gigaelectronvolt field. The process forces electrons to travel through a closed path of powerful magnetic fields, similar to a radio antenna, but with the great difference that relativistic speed alters the observed frequency due to the Doppler effect with a factor $\gamma$ and Lorentz's relativistic contraction hinders the frequency with another factor $\mathrm{c}$, multiplying the gigahertz frequency of the resonant cavity that accelerates electrons into X-rays.

In addition, due to the relativity, the radiation pattern is distorted and it is expected to be non-theoretical - a high radiation cone, which causes the synchrotron radiation sources to be the brightest sources of X-rays known so far. On the other hand, the geometry of the acceleration plane causes the radiation to be polarized linearly when viewed in the orbital and circularly polarized plane when viewed at a small angle to this plane.

Today there are several advantages of using synchrotronics for spectroscopy and diffraction. At first, accelerators for particle physics were built, synchrotron radiation emerging spontaneously as a parasitic phenomenon when the magnet bending radius was extracted by drilling additional holes in the radial tubes. The first ring for storing it as a synchrotron light source was Tantalus at the Synchrotron Radiation Center and functioned in 1968. Slowly, synchrotron acceleration radiation became more intense and its more promising applications and devices that improved synchrotron radiation had were integrated into the rings. Third-generation synchrotron radiation sources have been designed and optimized from the very beginning to produce brilliant $\mathrm{x}$-rays. The fourth generation of sources is considered to include more time-consuming impulses for highly demanding and even better-designed experiments.

Bending electromagnets in accelerators were first used to generate radiation, but then other specialized devices, called insertion devices, were used to generate more and more powerful radiation. Actual sources of third and fourth generation synchronous radiation are typically based on these input devices when the straight sections of the storage ring are used to introduce periodic magnetic structures (composed of several magnets having a polar $\mathrm{N}$ line and $\mathrm{S}$ repeat) in a sinusoidal fashion. Thus, instead of a single bend, many tens or hundreds of "wiggles" at precise calculated positions add or multiply the total intensity seen at the end of the straight section. These devices are called wigglers or whirlpools. The main difference between an undulator and a wiggler is the intensity of its magnetic field and the magnitude of the deviation from the straight path of the electrons.

There are openings in the storage ring to let the radiation go out and follow a line of the beam in the vacuum chamber of the experiments. A large number of such beams can arise from modern generation sources of the third generation of synchrotron radiation.

These improvements are more than promising not only for old known and used applications, but also for new ones, with which to build very powerful synchrotron light sources, having an essential role in many industrial fields and which in the future can be also used in the field of aerospace for the propulsion of aerospace vessels, a modern propulsion of the future, propulsion that can generate very high travel speeds and huge spaces traversed by the ship without the need for stops for refueling.

With these new sources of synchrotronics light, the future of modern propulsion for the aerospace industry is still assured.

Synchrotron Light is the brightest X-ray source, allowing detailed molecular structure studies leading to Nobel prizes in many areas (see chronology).

In 1956, two American researchers, Diran Tomboulian and Paul Hartman, were authorized to use the $320 \mathrm{MeV}$ synchrotron from Cornell University. In addition to confirming the spectral and angular distribution of mild synchrotrotizations, the first X-ray spectroscopy study was performed using mild synchrotronics. Five years later, the US National Bureau of Standards modified its $180 \mathrm{MeV}$ machine to allow synchrotronics to gather light for experiments. They became known as first-generation synchrotrons, machines built to destroy the nucleus outdoors using electrons, which were later used for experiments with light synchrotrons.

In the coming decades, as the first generation of synchrotron demand for advanced synchrotron technology, pioneering advances have led to a number of developments, such as storage tools that allow particles to travel to long physicists, synchrotron users. One of the most significant developments occurred in the late 1970s when it plans to build the first Sincrotron X-ray light source in Daresbury, UK. The United States, Japan and others have also built second-generation cars, while other first-generation cars have been upgraded to allow more experiments. 
For scientists performing spectroscopy experiments, the brightness of the beam that reached the sample determined the power to resolve the results. For crystallographers, especially those looking for small, small cellular crystals, high brightness was important to solve very close diffractive stains. As second-generation machines have been optimized to produce more light and the fundamental limit has come close. In order to meet the growing demands of an increasing community of synchrotron users, a new approach was needed: Input devices.

The inserts have magnets placed in the straight sections of the storage ring, which can be downgraded to second-generation machines and will quickly incorporate existing frames. The inserts help create a very intense light beam with a maximum intensity, with a wavelength that can be changed by adjusting the field strength (often the difference between two magnets).

Increased brightness has made data collection faster and adjustable wavelengths have benefited both crystallographers and spectroscopists. In the early 1990s, the first generation of Synchrotron (ESRF) in Grenoble, France, began operating in 1994. Now there are over 50 light sources in the world that combine both generations and X-rays.

The experimental configurations of the different synchrotrons are quite similar. The storage devices in which the light is generated have multiple ports, each opening on a beam radius, where scientists are preparing experiments and collecting data. However, beams can vary greatly in detail, depending on the experimental methods in which they are used. Light Source Oxfordshire Diamond has become a new sinkrotron light system in the UK in 2007 and in August 2008 it was the only source of synchrotron in the UK after the SRS closure. This is the largest scientific investment in the UK for 40 years and will have the capacity to host 40 lines. The light source illuminates a wide range of scientific disciplines such as condensed matter physics, chemistry, nanoscience, structural biology, engineering, environmental science and cultural heritage.

\section{Collimated Light}

Collimated light is a light whose rays are almost parallel and therefore will spread slowly as they propagate. The word is related to "colinear" and involves a light that does not disperse with the distance (ideally) or that will disperse the minimum (in reality). A perfectly collimated beacon, without divergence, cannot be created due to diffraction, but the light can be collimated through a number of processes, for example through a collimator. Collimated light is sometimes thought to be infinitely concentrated. Thus, as the distance from a point source increases, the spherical flank becomes flatter and closer to the flat waves, which are perfectly collimated (Fig. 36).
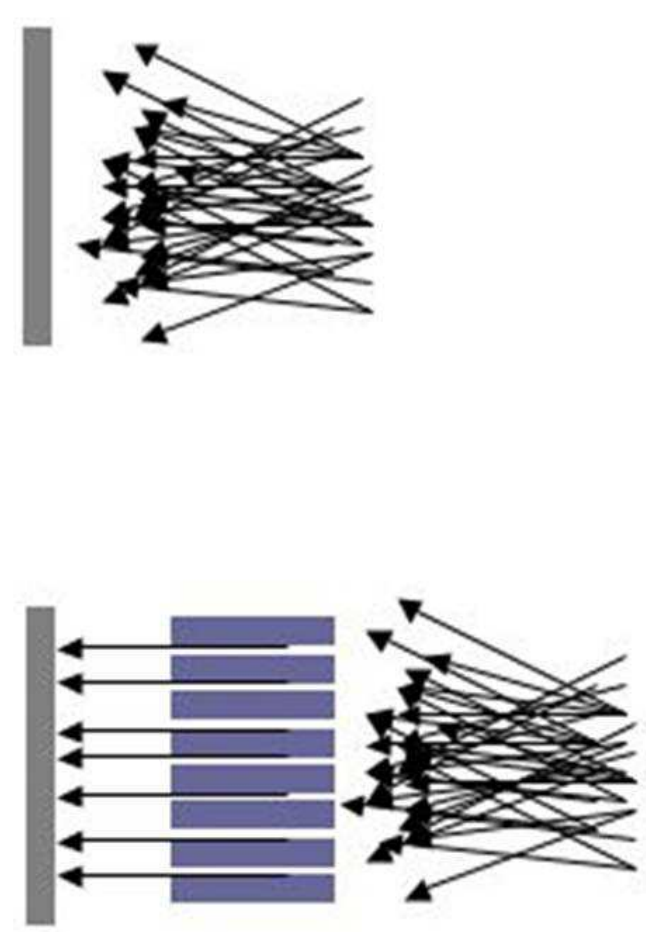

Fig. 36: In the lower picture, the light has been collimated

Synchrotrons produce a unique type of continuous radiation on the spectrum and can be adjusted to the desired wavelength - emitted by electrons accelerated in a magnetic field.

For two decades, the Bureau of Sciences has been the main supporter of sincrotron light sources in the United States.

Currently, there are four, each with unique capabilities, used by a total of over 6,000 academic, governmental and industry researchers.

The four are the Advanced Light Source from Lawrence Berkeley National Laboratory, the Argonne Advanced Probe Laboratory, the Lab Brookhaven Synchronization Laboratory and Stanford Synchrotron Radiation Laboratory at the Stanford Linear Accelerator Center.

The scientists at these sites helped pioneer the many synchrotron innovations used today, including a network of magnets that increased the brightness (photon density) in two magnitude orders; Insertion devices that oscillate the electron beam path to generate X-rays and ultraviolet light with high flux (number of photons) and collimation (parallel alignment of photons); and powerful experimental techniques such as X-ray scattering and Xray microscopy.

The "collimated" light obtained in a synchrotron can be used to move the flying ships.

The energy and pulse of light emitted must be very high. 
We can increase the number of pulses per second and the number of particles per pulse, but we can not increase the velocity of a particle. We are already working with the highest experimentally determined speed, the speed of light.

However, we can increase the energy of photons by increasing the frequency of beam light.

The modular nature of modern synchrotrons means that new technologies can be integrated into existing machines as they arrive.

The use of a strong 4-line linear accelerator line, known as electronic lasers (FEL), can generate a fast femtosecond rate, but at the same intensity at each peak in the sources of the synchrotron emit a second millimeter $\mathrm{x}$ or lighter than the most powerful synchrotron pulses.

A synchrotron light source is a source of electromagnetic radiation produced by a synchrotron, which is artificially produced for scientific and technical purposes by specialized particle accelerators, usually acceleration electrons.

With high energy generation, it addresses auxiliary components, such as bending and insertion devices (induction or doubt), free storage rings and electronic lasers.

They provide powerful magnetic fields perpendicular to the beam needed to transform the energy of high energy electrons into light or other EM radiation.

Any ship engine needs energy (power) and fuel.

A ship with a carrier motor only needs power (power). The ship's fuel is electrons. Energy (which also produces electrons) also confers the role of fuel.

Such a ship requires only a nuclear reactor that supplies energy (energy). Power can be complete with some solar panels or other power supplies. No fuel! The autonomy of vessels increases greatly.

An ion propellant can not take off or land the ship in a gravitational field. Not even a month!

We need very, very big energies! Super LASER can do that. But today and especially tomorrow, we can produce more energy with accelerators, particle accelerators!

We can also use linear accelerators. Or a combination of a circular accelerator and a linear accelerator.

Or, we will accelerate a particle of up to $10-100 \mathrm{PeV}$ or we will increase particle flow per pulse and pulse per second.

\section{Lasers}

The laser is a device that emits light (electromagnetic radiation) through an optical amplification process based on photon-stimulated emission.

The term "laser" appeared as an acronym for the amplification of light by radiation-stimulated emission.

Laser emission lamps are notable for the high degree of spatial and temporal coherence that cannot be achieved by using other technologies.
The consistency space is usually expressed by the exit being a narrow beam that is limited by diffraction, often the so-called "pencil beam".

Laser beams can be focused on very small spots, obtaining very high irradiance. Or they can be launched in a very small divergence beam to concentrate their power at a great distance.

The temporary (or longitudinal) consistency involves a polarized wave at a single frequency whose phase is correlated over a relatively long distance (the length of coherence) along the beam.

A beam produced by a thermal light source or other incoherent source has an amplitude and an instantaneous phase that varies randomly over time and position and therefore a very short coherence length.

The so-called "single-wave laser" actually generates radiation in several ways, with slightly different frequencies (wavelengths), often not in a single polarization.

And although temporal consistency implies monochromaticity, there are even lasers that emit a wide spectrum of light or emit different wavelengths of light simultaneously.

There are some lasers that are not a unique spatial way and therefore their light beams differ far more than is required by the diffraction limit. However, all of these devices are classified as "lasers" based on their method of producing that light: Stimulated emission. Lasers are used in applications where it is not possible to obtain coherent spatial or temporal light using simpler technologies.

The word laser started as an acronym for "amplifying light by radiation-stimulated emission"; Typically, "light" use generally means electromagnetic radiation of any frequency, not only visible light, i.e., infrared laser, ultraviolet laser, X-ray laser and so on. As a microwave oven, the massage room was originally developed, radio and microwave frequencies are called "master", rather than "microwave lasers" or "radio lasers" (Fig. 37).

A laser that produces light through itself is rather an optical oscillator than an optical amplifier as suggested by the acronym.

With the widespread use of the original acronym as a common noun, the current optical amplifiers have come to be called "laser amplifiers", despite the apparent redundancy in that name.

The verb generated back to the lesion is commonly used in the field, which means "producing laser light", especially with regard to the laser environment; when a laser is in operation it is said to be "laser". Subsequent use of laser words and masseur in an extended sense that does not refer to laser technology or devices can be seen in applications such as the astrophysical mask and the atomic laser. 

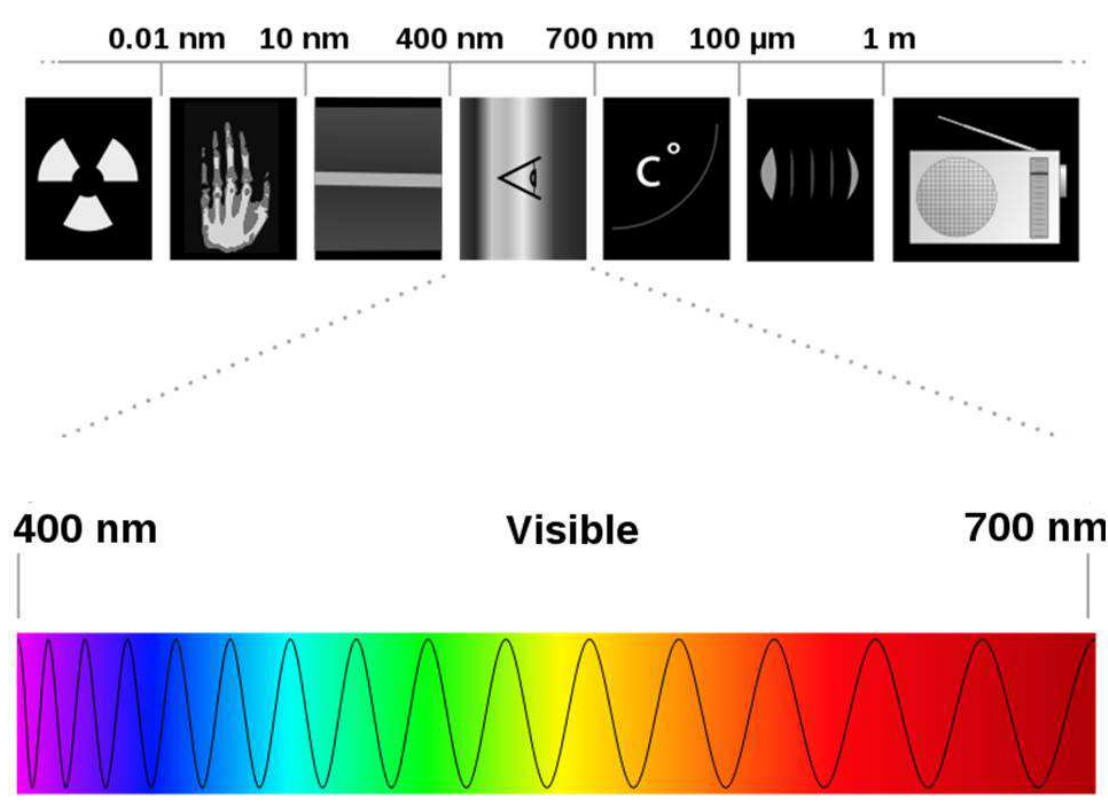

Fig. 37: From left to right: gamma rays, X-rays, ultraviolet rays, visible spectrum, infrared, microwaves, radio waves. Bottom: enlargement of visible spectrum from violet $(400 \mathrm{~nm})$ to red $(700 \mathrm{~nm})$

A laser consists of a winning environment in a very reflexive optical cavity, as well as a means of providing energy to the environment. The gain medium is a material with properties that allow it to amplify light through stimulated emission.

The light of a certain wavelength passing through the gain environment is amplified (increasing power). Mirrors are used around the room to ensure that most of the light makes many passes through the gain medium, thus amplifying it repeatedly.

Part of the light that flips between the mirrors (that is inside the cavity) manages to pass through the transparent partial mirror and escapes like a ray of light.

The process by which the energy needed to amplify is called pumping. Energy is usually supplied as an electric current or light at a different wavelength. Such a light can be provided by a flashlight or even another initial laser.

Most practical lasers contain additional elements that affect the properties, such as the wavelength of the light emitted and the shape of the beam.

The winning environment of a laser is a controlled purity material, size, concentration and shape that amplifies the beam through the stimulated emission process. It can be of any kind: Gas, liquid, solid or plasma.

The amplification medium absorbs the energy of the pump, which raises some electrons into quantum states of higher energy ("excited"). Particles can interact with light either by absorption or by photon emission.

Emissions can be spontaneous or stimulated. In the second case, the photon is emitted in the same direction as the light passing through.
When the number of particles in an excited state exceeds the number of particles in a reduced state of energy, the population reversal is reached and the amount of emission stimulated by the light passing through it is greater than the absorption amount.

Therefore, the light is amplified. By doing so, it is an optical amplifier. When an optical amplifier is placed inside a resonant optical cavity, a laser is obtained.

The light generated by the stimulated emission is very similar to the input signal in terms of wavelength, phase and polarization. This gives laser light consistent consistency and allows it to maintain the uniform polarization and often the monochromaticity determined by the design of the optical cavity.

The optical resonator is sometimes called the "optical cavity", but this is a wrong name: The lasers use open resonators unlike the literal cavity that would be used at microwave frequencies in a masseur.

The resonator typically consists of two mirrors between which a coherent beam of light moves in both directions, reflecting back to itself so that an average photon passes through the gain medium repeatedly before it is emitted from the output or lost to diffraction or absorption.

If the amplification in the medium is greater than the resonator losses, the power of the light recirculator may increase exponentially. But each stimulated emission event returns an atom from its excited state to its basic state, reducing its average gain.

With increased beam power, net gain is reduced to unit and the winning environment is considered saturated. In a Continuous Wave laser $(\mathrm{CW})$, the pump 
power balance against gain saturation and cavity losses produces a laser power value inside the cavity; this balance determines the operating point of the laser. If the applied pump power is too low, the gain will never be enough to overcome the resonator losses and the laser light will not be produced.

The minimum pump power required to start the laser action is called the trigger threshold. The gain medium will amplify any photon that passes through it, regardless of the direction; but only the photons in the resonant space will pass more than once through the medium and receive substantial amplification.

The cavity phase and the laser output beam while moving in a free space (or in a homogeneous environment) instead of wave guides (as in an optical fiber laser) can be approximated as a Gaussian beam in most lasers; such beams have a minimum of divergence for a given diameter.

However, some high-power lasers may be multimodal, with transverse modes often approximated using the Hermite-Gaussian or Laguerre-Gaussian functions. Unstable laser resonances (which are not used by most lasers) have shown that they produce fracture of the beam. Near the "waist" of the beam (or focal region) is very collimated: The wave flank is flat, normal in the direction of propagation, without any divergence of the beam at that point.

However, due to the diffraction, this may be true in Rayleigh. The beam of a single transverse type laser (Gaussian beam) ultimately differentiates at an angle that varies inversely with the diameter of the beam, as required by diffraction. Thus, the "pencil beam" generated directly by a regular helium-neon laser would spread to a magnitude of $500 \mathrm{~km}$ when it will shine on the moon (from the distance of the earth). On the other hand, light from a laser semiconductor usually comes out of the small crystal with great divergence: Up to $50^{\circ}$.

However, even though such a divergent beam can be transformed into a similar collimated beam through a lens system, as always included, for example, in a laser pointer, which comes from a laser diode. This is possible because light is a space mode.

This unique laser lamp property, a spatial coherence, can not be reproduced using a standard light standard (except that it casts much of the light), as can be appreciated by comparing the torch beam or the reflector with any laser.

The mechanism of producing radiation in a laser is based on stimulated emission, where energy is extracted from a transition into an atom or molecule.

This is a phenomenon of quantum discovery by Einstein that provides a derived relationship between the coefficient A describing the spontaneous emission and the coefficient $B$ that applies to the absorbed and emission stimulated.
However, in the case of the free electron laser, the atomic energy levels are not involved; it seems that the operation of this rather exotic device can be explained without reference to quantum mechanics.

A laser may be classified as operating continuously or pulsating, depending on whether the power is essentially continuous over time or whether the output is in the form of pulses of light on a time scale or on another time scale.

Even a laser whose output is normally continuous can be switched on and off intentionally, to a certain extent, to create luminous pulses.

When the modulation speed is much slower than the life of the cavity and the energy storage time in the laser environment or in the pumping mechanism, it is still classified as a "continuous" or "pulsating" wave. Most of the laser diodes used in communications systems fall into this category.

Some laser applications depend on a radius whose output power is constant over time. Such a laser is known as Continuous Wave (CW). Many types of lasers can be made to work continuously to meet such an application.

Many of these lasers are in fact deprived of several longitudinal modes at the same time and the slightly different oscillating oscillations of those oscillations actually generate amplitude variations in time less than the multi-nanosecond take-off time (frequency of reciprocity between modes) or less.

In most cases, these lasers are called "continuous wave" because their output power is constant when they are medium over longer periods of time with very frequent power variations having little or no impact on intentional application. (However, the term does not apply to locked genes in the sense that the intention is to create very short take-off pulses.

For continuous wave operation, the inversion of the winning environmental population must be continually fed by a stable pump source.

In some lasers, this is impossible. In some other lasers, it would be necessary to pump the laser at a very high level of power that would be impossible or would destroy the laser by producing excessive heat. These lasers can not be executed in CW mode.

Laser laser surgery refers to any laser that is not classified as a continuous wave so that the optical power takes place in pulses of a certain duration at a certain repetition rate. It includes a wide range of technologies that address a range of different motivations. Some lasers are simply impulses because they can not be executed continuously.

In other cases, application requires the generation of impulses with as much energy as possible. Since the pulse energy is equal to the average power divided by the repetition rate, this lens can sometimes be satisfied by lowering the pulse frequency so that more energy can 
be built up between the pulses. By laser ablation, for example, a small amount of material on the surface of the workpiece can be evaporated if heated in a very short time while the bird allows the heat to be absorbed in the workpiece volume without reaching a temperature sufficient for to raise a certain point.

Other applications are based on peak pulse power (rather than pulse energy), especially to obtain nonlinear optical effects. For some pulsed energy, it requires pulse generation with the shortest possible duration using techniques such as switching Q.

The optical bandwidth of a pulse may be more limited than the reciprocity of the pulse width. In the case of extremely short pulses, this involves searching for lasers at considerable bandwidth, quite contrary to the very narrow bandwidth limits typical of $\mathrm{CW}$ lasers. The laser environment of dye lasers and solid state lasers produces broadband optical amplification, making it possible to use a laser that can generate light pulses as short as a few femtoseconds $\left(10^{-15} \mathrm{~s}\right)$.

!The propulsion laser has the great advantage of operating with very many pulses per second (high frequency)!

In a $\mathrm{Q}$ switch, population reversal is allowed to accumulate by introducing a loss inside the resonator that exceeds the average gain; this can also be described as a reduction in the quality factor or the "Q" of the cavity. Then, after the stored energy of the pump in the laser environment has reached the maximum possible level, the introduced loss mechanism (often an electrostatic or acoustic optic) is quickly removed (or produced only in a passive device) stored in the winning environment. This results in a short impulse that incorporates that energy and maximum peak power.

A laser lock can emit extremely short pulses in ten thousand seconds in less than ten femtoseconds. These pulses will be repeated at take-off time, ie when light is needed to complete a round trip between the mirrors containing the resonator. Due to the Fourier limit (also known as energy-time uncertainty), the pulse of such a short temporal length has a spectrum spread over considerable bandwidth. Thus, such a gain environment must have a gain bandwidth wide enough to amplify these frequencies. An example of suitable material is doped titanium, titanium sapphire (Ti: Sapphire), which has a very high bandwidth for payload and can produce impulses of only a few femtoseconds.

Such blocked lasers are an extremely versatile tool for investigating processes that occur in extremely short moments (known as femtosecond physics, femtosecond chemistry and ultrafast science) to maximize the effect of nonlinearity in optical materials (for example, when two harmonics are generated, optical oscillator parameters and the like) due to peak power applications and ablation. Again, due to the extremely short pulse duration, such a laser will produce pulses that produce extremely high peak power.

\section{List of Laser Types}

Gas lasers, Chemical lasers, Excimer lasers, Solidstate lasers, Fiber lasers, Photonic crystal lasers, Semiconductor lasers, Dye lasers, Free electron lasers, Biolaser and others.

\section{Positron Annihilation Laser}

In September 2007, BBC News announced that there is some speculation about the possible use of positron annihilation to produce a very strong gamma ray. Dr. David Cassidy of the University of California, Riverside, assumed that such a laser could be used to ignite a nuclear fusion reaction, thus replacing the hundreds of lasers currently used in the fusion initiation experiments.

Radiographs of such lasers pumped by a nuclear explosion were also proposed as antimatter weapons.

\section{Conclusion}

This paper aims to contribute to the study of propulsion systems for modern aerospace vehicles with the obvious aim of improving them and to give them the ability to move much faster and easier in any direction, for a very long time, going through huge distances without the need of fuel refueling, as is the case with conventional, chemical propulsion. The work aims to raise the level of protection and safety of the pilots, these wonderful and brave people, who often realize true wonders for humanity without asking for additional rights or bragging with their silent achievements. At the same time, it is desirable to gradually move to new propulsion systems originally intended for spacecraft so that they can then be deployed quickly to conventional aircraft carrying passengers everywhere on our planet.

The proposed modern propulsion systems no longer retain anything from the classical chemical technique but are based on a reaction technique in which a new type of fuel will be emitted, namely energy, accelerated particles at very high speeds, energies and impulses, accelerated ions, accelerated electrons, or concentrating photons of the same frequency (LASER).

Today, aerospace craft and aircraft have a chance of faster, more modern propulsion by the use of synchrotron beams (light), high-power lasers and, most often, very pulsed, with a frequency of $10^{-15}$ second. That means one can produce virtually $10^{15}$ impulses per second with such a system. Such a system can generate enormous impulse, energy and power, much greater even than the one donated by a very large particle accelerator, due to the large number of pulses produced in one second, even if the power of each is much smaller than that of a pulse donated by a large circular accelerator, but in a quantity of just one pulse per second. 


\section{Final Conclusions and Directions}

This paper aims to propose two new directions for the development of future spacecraft.

1-In order to be able to mount propulsion space jets with accelerated elemental particles jets in circular accelerators mounted directly on ships, a faster development of these systems is needed which at present have reduced capabilities compared to other similar alien systems. This is also due to the fact that investments in this area have not been sufficient, so they should be increased considerably.

2- Until the first directive develops and materializes, we propose the rapid deployment of modern aerospace propulsion solutions based on high power lasers, but especially lasers that have an extremely high frequency.

\section{Acknowledgement}

This text was acknowledged and appreciated by Dr. Veturia CHIROIU Honorific member of Technical Sciences Academy of Romania (ASTR) PhD supervisor in Mechanical Engineering.

\section{Funding Information}

Research contract: Contract number 36-5-4D/1986 from 24IV1985, beneficiary CNST RO (Romanian National Center for Science and Technology) Improving dynamic mechanisms internal combustion engines.

\section{!All these Matters are Copyrighted!}

Copyrights:

1. New Aircraft (New Ionic or Beam Engines): no. 548 of 22-04-2010 [cgiywDssin], Aerospace Engineering

2. Some Few Specifications About the Doppler Effect to the Electromagnetic Waves: 636 of 28-05-2010 [iEtcaouxxA], physics

3. Presenting an Atomic Model and Some Possible Applications in LASER Field: nr. 639 of 29-052010 [yncngrotfo], physics

4. Some Applications in LASER Field: no. 718 of 0907-2010 [xeujouincC], physics

5. The Energies of Today and Tomorrow: nr. 819 of 30-09-2010 [kbHquxwykr], energy engineering;

6. Obtaining Energy by the Annihilation of the Matter with Antimatter - The Battle for Energy: nr. 1068 of 13.03.2011 [GfEqpGDzeh], Energy Engineering

\section{Author's Contributions}

All the authors contributed equally to prepare, develop and carry out this manuscript.

\section{Ethics}

This article is original and contains unpublished material. Authors declare that are not ethical issues and no conflict of interest that may arise after the publication of this manuscript.

\section{References}

Antonescu, P., 2000. Mechanisms and Handlers, Printech Publishing House. Bucharest.

Antonescu, P. and F. Petrescu, 1985. Analytical method of synthesis of cam mechanism and flat stick. Proceedings of the 4th International Symposium on Mechanism Theory and Practice (TPM' 85), Bucharest.

Antonescu, P. and F. Petrescu, 1989. Contributions to cinetoelastodynamic analysis of distribution mechanisms. Bucharest.

Antonescu, P., M. Oprean and F. Petrescu, 1985a. Contributions to the synthesis of oscillating cam mechanism and oscillating flat stick. Proceedings of the 4th International Symposium on Theory and Practice of Mechanisms, (TPM' 85), Bucharest.

Antonescu, P., M. Oprean and F. Petrescu, 1985b. At the projection of the oscillante cams, there are mechanisms and distribution variables. Proceedings of the V-Conference for Engines, Automobiles, Tractors and Agricultural Machines, I-Engines and Automobiles, (AMA’ 85), Brasov.

Antonescu, P., M. Oprean and F. Petrescu, 1986. Projection of the profile of the rotating camshaft acting on the oscillating plate with disengagement. Proceedings of the 3rd National Computer Assisted Designing Symposium in Mechanisms and Machine Bodies, (MOM' 86), Brasov.

Antonescu, P., M. Oprean and F. Petrescu, 1987. Dynamic analysis of the cam distribution mechanisms. Proceedings of the Seventh National Symposium of Industrial Robots and Spatial Mechanisms (IMS' 87), Bucharest,

Antonescu, P., M. Oprean and F. Petrescu, 1988. Analytical synthesis of Kurz profile, rotating flat cam cam. Machine Build. Rev. Bucharest.

Antonescu, P., F. Petrescu and O. Antonescu, 1994. Contributions to the synthesis of the rotating cam mechanism and the tip of the balancing tip. Brasov.

Antonescu, P., F. Petrescu and D. Antonescu, 1997. Geometrical synthesis of the rotary cam and balance tappet mechanism. Bucharest.

Antonescu, P., F. Petrescu and O. Antonescu, 2000a. Contributions to the synthesis of the rotary disc-cam profile. Proceedings of the 8th International Conference on Theory of Machines and Mechanisms, (TMM' 00), Liberec, Czech Republic, pp: 51-56. 
Antonescu, P., F. Petrescu and O. Antonescu, 2000b. Synthesis of the rotary cam profile with balance follower. Proceedings of the 8th Symposium on Mechanisms and Mechanical Transmissions, (MMT'000), Timişoara, pp: 39-44.

Antonescu, P., F. Petrescu and O. Antonescu, 2001. Contributions to the synthesis of mechanisms with rotary disc-cam. Proceedings of the 8th IFToMM International Symposium on Theory of Machines and Mechanisms, (TMM' 01), Bucharest, ROMANIA, pp: 31-36.

Aversa, R., R.V. Petrescu, A. Apicella and F.I.T. Petrescu, 2017a. Nano-diamond hybrid materials for structural biomedical application. Am. J. Biochem. Biotechnol., 13: 34-41. DOI: 10.3844/ajbbsp.2017.34.41

Aversa, R., R.V. Petrescu, B. Akash, R.B. Bucinell and J.M. Corchado et al., 2017b. Kinematics and forces to a new model forging manipulator. Am. J. Applied Sci., 14: 60-80. DOI: 10.3844/ajassp.2017.60.80

Aversa, R., R.V. Petrescu, A. Apicella, F.I.T. Petrescu and J.K. Calautit et al., 2017c. Something about the $\mathrm{V}$ engines design. Am. J. Applied Sci., 14: 34-52. DOI: 10.3844/ajassp.2017.34.52

Aversa, R., D. Parcesepe, R.V. Petrescu, F. Berto and G. Chen et al., 2017d. Processability of bulk metallic glasses. Am. J. Applied Sci., 14: 294-301. DOI: 10.3844/ajassp.2017.294.301

Aversa, R., R.V. Petrescu, A. Apicella and F.I.T. Petrescu, 2017e. Modern transportation and photovoltaic energy for urban ecotourism. Transylvanian Rev. Administrative Sci., 13: 5-20. DOI: $10.24193 /$ tras.SI2017.1

Aversa, R., F.I.T. Petrescu, R.V. Petrescu and A. Apicella, 2016a. Biomimetic FEA bone modeling for customized hybrid biological prostheses development. Am. J. Applied Sci., 13: 1060-1067. DOI: 10.3844/ajassp.2016.1060.1067

Aversa, R., D. Parcesepe, R.V. Petrescu, G. Chen and F.I.T. Petrescu et al., 2016b. Glassy amorphous metal injection molded induced morphological defects. Am. J. Applied Sci., 13: 1476-1482.

DOI: 10.3844/ajassp.2016.1476.1482

Aversa, R., R.V. Petrescu, F.I.T. Petrescu and A. Apicella, 2016c. Smart-factory: Optimization and process control of composite centrifuged pipes. Am. J. Applied Sci., 13: 1330-1341.

DOI: 10.3844 ajassp.2016.1330.1341

Aversa, R., F. Tamburrino, R.V. Petrescu, F.I.T. Petrescu and M. Artur et al., 2016d. Biomechanically inspired shape memory effect machines driven by muscle like acting NiTi alloys. Am. J. Applied Sci., 13: 1264-1271.

DOI: 10.3844/ajassp.2016.1264.1271
Cao, W., H. Ding, Z. Bin and C. Ziming, 2013. New structural representation and digital-analysis platform for symmetrical parallel mechanisms. Int. J. Adv. Robot. Syst. DOI: 10.5772/56380

Cataldo, R., 2006 Overview of planetary power system options for education. ITEA Human Exploration Project Authors, 2006, at Glenn Research Center. Brooke Park, OH.

Cayley George, From Wikipedia. The free encyclopedia. https://en.wikipedia.org/wiki/George_Cayley

Chen, J. and R.J. Patton, 1999. Robust Model-Based Fault Diagnosis for Dynamic Systems. 1st Edn., Kluwer Academic Publisher, Boston.

Clément, A., From Wikipedia. The free encyclopedia. https://en.wikipedia.org/wiki/Cl\%C3\%A9ment_Ader

Coandă-1910, From Wikipedia. The free encyclopedia. https://en.wikipedia.org/wiki/Coand\%C4\%83-1910

Comănescu, A., D. Comănescu, I. Dugăeşescu and A. Boureci, 2010. The Basics of Modeling Mechanisms. 1st Edn., Politehnica Press Publishing House, Bucharest, ISBN-10: 978-606-515-115-4, pp: 274.

Crickmore, P.F., 1997. Lockheed's blackbirds-A-12, YF12 and SR-71A. Wings Fame, 8: 30-93.

Staelin, D.H., 2008. Electromagnetics and applications. Department of Electrical Engineering and Computer Science, Massachusetts Institute of Technology, Cambridge, MA.

Donald, D., 2003. Lockheed's blackbirds: A-12, YF-12 and SR-71". Black Jets. AIRtime.

Dong, H., N. Giakoumidis, N. Figueroa and N. Mavridis, 2013. Approaching behaviour monitor and vibration indication in developing a General Moving Object Alarm System (GMOAS). Int. J. Adv. Robot. Syst. DOI: $10.5772 / 56586$

Droste, J., 1915. On the field of a single centre in Einstein's theory of gravitation. Koninklijke Nederlandsche Akademie van Wetenschappen Proc., 17: 998-1011.

De Melo, L.F., R.A., S.F. Rosário and J.M., Rosário, 2012. Mobile robot navigation modelling, control and applications. Int. Rev. Modell. Simulations, 5: 1059-1068.

Fernandez, V., L.F. Penin, J. Araujo and A. Caramagno, 2005. Modeling and FDI specification of a RLV Reentry for robust estimation of sensor and actuator faults. Proceedings of the AIAA Guidance, Navigation and Control Conference and Exhibit, Aug. 15-18, San Francisco. DOI: 10.2514/6.2005-6254

Finkelstein, D., 1958. Past-future asymmetry of the gravitational field of a point particle. Physical Rev., 110: 965-967.

Fonod, R., D. Henry, C. Charbonnel and E. Bornschlegl, 2015. Position and attitude model-based thruster fault diagnosis: A comparison study. J. Guidance Control Dynam., 38: 1012-1026.

DOI: $10.2514 / 1 . G 000309$ 
Frățilă, G., M. Frăţilă and S. Samoilă, 2011. Automobiles, Construction, Exploitation, Reparation. 10th Edn., EDP, Bucharest, ISBN-13: 978-973-30-2857-4.

Garcia, E., M.A. Jimenez, P.G. De Santos and M. Armada, 2007. The evolution of robotics research. IEEE Robot. Autom. Magaz., 14: 90-103. DOI: 10.1109/MRA.2007.339608

Garcia-Murillo, M., J. Gallardo-Alvarado and E. Castillo-Castaneda, 2013. Finding the generalized forces of a series-parallel manipulator. IJARS. DOI: $10.5772 / 53824$

Goddard, 1916. Rocket apparatus patent December 15, 1916, Smithsonian Institution Archives.

Goodall, J., 2003. Lockheed's SR-71 "Blackbird" Family. Hinckley, UK: Aerofax/Midland Publishing, 2003. (ISBN 1-85780-138-5).

Gorder, P.F., 2015. What's on the surface of a black hole? Not a "firewall"-and the nature of the universe depends on it, a physicist explains.

Graham, R.H., 2002. SR-71 Blackbird: Stories, Tales and Legends. 1st Edn., Zenith Imprint, North Branch, Minnesota, ISBN-10: 1610607503.

Gruener, J.E., 2006. Lunar exploration (Presentation to ITEA Human Exploration Project Authors, November 2006, at Johnson Space Center). Houston, TX.

Gunston, B., 2010. Airbus: The Complete Story. Haynes Publishing UK, Sparkford, ISBN-10: 1844255859, pp: 288 .

He, B., Z. Wang, Q. Li, H. Xie and R. Shen, 2013. An analytic method for the kinematics and dynamics of a multiple-backbone continuum robot. IJARS. DOI: $10.5772 / 54051$

Hewish, A., 1970. Pulsars. Ann. Rev. Astronomy Astrophysics, 8: 265-296.

Jenkins, D.R., 2001. Lockheed Secret Projects: Inside the Skunk Works. 1st Edn., Zenith Imprint, St. Paul, Minnesota: MBI Publishing Company, ISBN-10: 1610607287.

Kaufman, H.R., 1959 Installations at NASA Glenn.

Laming, T., 2000. Airbus A320. 1st Edn., Zenith Press.

Landis, T.R. and D.R. Jenkins, 2005. Lockheed Blackbirds. 1st Edn., Specialty Press, North Branch, ISBN-10: 1580070868, pp: 104.

Larson, G.C., 2015. Electrical power will change the look of aviation. Air and Space Magazine.

Lee, B.J., 2013. Geometrical derivation of differential kinematics to calibrate model parameters of flexible manipulator. Int. J. Adv. Robot. Syst.

DOI: $10.5772 / 55592$

Lin, W., B. Li, X. Yang and D. Zhang, 2013. Modelling and control of inverse dynamics for a 5-DOF parallel kinematic polishing machine. Int. J. Adv. Robot. Syst. DOI: 10.5772/54966

List the first flights, From Wikipedia, free encyclopedia. https://ro.wikipedia.org/wiki/List\%C4\%83_cu prim ele_zboruri
Liu, H., W. Zhou, X. Lai and S. Zhu, 2013. An efficient inverse kinematic algorithm for a PUMA560structured robot manipulator. IJARS. DOI: $10.5772 / 56403$

Lu, P., L. Van Eykeren, E.J. Van Kampen and Q.P. Chu, 2015. Selective-reinitialization multiple-model adaptive estimation for fault detection and diagnosis. J. Guidance Control Dynam., 38: 1409-1424. DOI: $10.2514 / 1 . G 000587$

Lu, P., L. Van Eykeren, E. van Kampen, C. C. de Visser and Q.P. Chu, 2016. Adaptive three-step kalman filter for air data sensor fault detection and diagnosis. J. Guidance Control Dynam., 39: 590-604. DOI: 10.2514/1.G001313

Michell, J., 1784. On the means of discovering the distance, magnitude and c. of the fixed stars, in consequence of the diminution of the velocity of their light, in case such a diminution should be found to take place in any of them and such other data should be procured from observations, as would be farther necessary for that purpose. Philosophical Trans. Royal Society, 74: 35-57.

Mirsayar, M.M., V.A. Joneidi, R.V. Petrescu, F.I.T. Petrescu and F. Berto, 2017. Extended MTSN criterion for fracture analysis of soda lime glass. Eng. Fracture Mechan., 178: 50-59.

DOI: 10.1016/j.engfracmech.2017.04.018

Murray, K., A. Marcos and L.F. Penin, 2010. Development and testing of a GNC-FDI filter for a reusable launch vehicle during ascent. Proceedings of the AIAA Guidance, Navigation and Control Conference, Aug. 2-5, Toronto, Ontario Canada. DOI: $10.2514 / 6.2010-8195$

Norris, G., 2010. Airbus A380: Superjumbo of the 21st Century. 1st Edn., Zenith Press.

Oberth, H., 1955. They come from outer space. Fly. Saucer Rev., 1: 12-14.

Oppenheimer, J.R. and G.M. Volkoff, 1939. On massive neutron cores. Phys. Rev., 55: 374-381.

Padula, F. and V. Perdereau, 2013. An on-line path planner for industrial manipulators. Int. J. Adv. Robot. Syst. DOI: 10.5772/55063

Palumbo, R., G. Morani, M. De Stefano Fumo, C. Richiello and M. Di Donato et al., 2012. Concept study of an atmospheric reentry using a winged unmanned space vehicle. Proceedings of the 18th AIAA/3AF International Space Planes and Hypersonic Systems and Technologies Conference, Sept. 24-28, Tours, France. DOI: 10.2514/6.2012-5857

Patre, P. and S.M. Joshi, 2011. Accommodating sensor bias in MRAC for state tracking. Proceedings of the AIAA Guidance, Navigation and Control Conference, Aug. 8-11, American Inst. of Aeronautics and Astronautics, USA. DOI: 10.2514/6.2011-6605 
Pelecudi, C., 1967. The Basics of mechanism analysis. Publishing house: Academy of the People's Republic of Romania.

Perumaal, S. and N. Jawahar, 2013. Automated trajectory planner of industrial robot for pick-andplace task. IJARS. DOI: 10.5772/53940

Petrescu, F. and R. Petrescu, 1995a. Contributions to optimization of the polynomial motion laws of the stick from the internal combustion engine distribution mechanism. Bucharest.

Petrescu, F. and R. Petrescu, 1995b. Contributions to the synthesis of internal combustion engine distribution mechanisms. Bucharest.

Petrescu, F. and R. Petrescu, 1997a. Dynamics of cam mechanisms (exemplified on the classic distribution mechanism). Bucharest.

Petrescu, F. and R. Petrescu, 1997b. Contributions to the synthesis of the distribution mechanisms of internal combustion engines with Cartesian coordinate method. Bucharest.

Petrescu, F. and R. Petrescu, 1997c. Contributions to maximizing polynomial laws for the active stroke of the distribution mechanism from internal combustion engines. Bucharest.

Petrescu, F. and R. Petrescu, 2000a. Synthesis of distribution mechanisms by the rectangular (cartesian) coordinate method. University of Craiova, Craiova.

Petrescu, F. and R. Petrescu, 2000b. The design (synthesis) of cams using the polar coordinate method (the triangle method). University of Craiova, Craiova.

Petrescu, F. and R. Petrescu, 2002a. Motion laws for cams. Proceedings of the 7 th National Symposium with International Participation Computer Assisted Design, (PAC' 02), Braşov, pp: 321-326.

Petrescu, F. and R. Petrescu, 2002b. Camshaft dynamics elements. Proceedings of the 7 th National Symposium with International Participation Computer Assisted Design, (PAC' 02), Braşov, pp: 327-332.

Petrescu, F. and R. Petrescu, 2003. Some elements regarding the improvement of the engine design. Proceedings of the 8th National Symposium, Descriptive Geometry, Technical Graphics and Design, (GTD’ 03), Braşov, pp: 353-358.

Petrescu, F. and R. Petrescu, 2005a. The cam design for a better efficiency. Proceedings of the International Conference on Engineering Graphics and Design, (EGD’ 05), Bucharest, pp: 245-248.

Petrescu, F. and R. Petrescu, 2005b. Contributions at the dynamics of cams. Proceedings of the 9th IFToMM International Symposium on Theory of Machines and Mechanisms, (TMM' 05), Bucharest, Romania, pp: $123-128$.
Petrescu, F. and R. Petrescu, 2005c. Determining the dynamic efficiency of cams. Proceedings of the 9th IFToMM International Symposium on Theory of Machines and Mechanisms, (TMM' 05), Bucharest, Romania, pp: 129-134.

Petrescu, F. and R. Petrescu, 2005d. An original internal combustion engine. Proceedings of the 9th IFToMM International Symposium on Theory of Machines and Mechanisms, (TMM' 05), Bucharest, Romania, pp: 135-140.

Petrescu, F. and R. Petrescu, 2005e. Determining the mechanical efficiency of Otto engine's mechanism. Proceedings of the 9th IFToMM International Symposium on Theory of Machines and Mechanisms, (TMM' 05), Bucharest, Romania, pp: 141-146.

Petrescu, F.I. and R.V. Petrescu, 2013. Cinematics of the 3R Dyad. Engevista, 15: 118-124.

Petrescu, F.I.T. and R.V. Petrescu, 2012a. The Aviation History. Publisher: Books On Demand, ISBN-13: 978-3848230778.

Petrescu, F.I. and R.V. Petrescu, 2012b. MecatronicaSisteme Seriale si Paralele. Create Space Publisher, USA, ISBN-10: 978-1-4750-6613-5, pp: 128.

Petrescu, F.I. and R.V. Petrescu, 2011. Mechanical Systems, Serial and Parallel-Course (in Romanian). LULU Publisher, London, UK, ISBN-10: 978-1-4466-0039-9, pp: 124.

Petrescu, F.I. and R.V. Petrescu, 2016a. Parallel moving mechanical systems kinematics, ENGEVISTA, 18: 455-491.

Petrescu, F.I. and R.V. Petrescu, 2016b. Direct and inverse kinematics to the Anthropomorphic Robots, ENGEVISTA, 18: 109-124.

Petrescu, F. and R. Petrescu, 2016c. An otto engine dynamic model. IJM\&P, 7: 038-048.

Petrescu, F.I. and R.V. Petrescu, 2016d. Otto motor dynamics, GEINTEC, 6: 3392-3406.

Petrescu, F.I. and R.V. Petrescu, 2016e. Dynamic cinematic to a structure 2R. GEINTEC, 6: 3143-3154.

Petrescu, F.I., B. Grecu, A. Comanescu and R.V. Petrescu, 2009. Some mechanical design elements. Proceeding of the International Conference on Computational Mechanics and Virtual Engineering, (MEC' 09), Braşov, pp: 520-525.

Petrescu, R.V., R. Aversa, A. Apicella, M.M. Mirsayar and F.I.T. Petrescu, 2016a. About the gear efficiency to a simple planetary train. Am. J. Applied Sci., 13: 1428-1436. DOI: 10.3844/ajassp.2016.1428.1436

Petrescu, R.V., R. Aversa, A. Apicella, S. Li and G. Chen et al., 2016b. Something about electron dimension. Am. J. Applied Sci., 13: 1272-1276. DOI: 10.3844/ajassp.2016.1272.1276

Petrescu, F.I.T., A. Apicella, R. Aversa, R.V. Petrescu and J.K. Calautit et al., 2016c. Something about the mechanical moment of inertia. Am. J. Applied Sci., 13: 1085-1090. DOI: 10.3844/ajassp.2016.1085.1090 
Petrescu, R.V., R. Aversa, A. Apicella, F. Berto and S. Li et al., 2016d. Ecosphere protection through green energy. Am. J. Applied Sci., 13: 1027-1032. DOI: 10.3844/ajassp.2016.1027.1032

Petrescu, F.I.T., A. Apicella, R.V. Petrescu, S.P. Kozaitis and R.B. Bucinell et al., $2016 \mathrm{e}$. Environmental protection through nuclear energy. Am. J. Applied Sci., 13: 941-946. DOI: 10.3844 /ajassp.2016.941.946

Petrescu, F.I.T. and J.K. Calautit, 2016a. About nano fusion and dynamic fusion. Am. J. Applied Sci., 13: 261-266. DOI: 10.3844/ajassp.2016.261.266

Petrescu, F.I.T. and J.K. Calautit, 2016b. About the light dimensions. Am. J. Applied Sci., 13: 321-325. DOI: 10.3844/ajassp.2016.321.325

Petrescu, R.V., R. Aversa, B. Akash, R. Bucinell and J. Corchado et al., 2017a. Modern propulsions for aerospace-a review. J. Aircraft Spacecraft Technol., 1: 1-8. DOI: 10.3844 /jastsp.2017.1.8

Petrescu, R.V., R. Aversa, B. Akash, R. Bucinell and J. Corchado et al., 2017b. Modern propulsions for aerospace-part II. J. Aircraft Spacecraft Technol., 1: 9-17. DOI: 10.3844/jastsp.2017.9.17

Petrescu, R.V., R. Aversa, B. Akash, R. Bucinell and J. Corchado et al., 2017c. History of aviation-a short review. J. Aircraft Spacecraft Technol., 1: 30-49. DOI: 10.3844 jastsp.2017.30.49

Petrescu, R.V., R. Aversa, B. Akash, R. Bucinell and J. Corchado et al., 2017d. Lockheed martin-a short review. J. Aircraft Spacecraft Technol., 1: 50-68. DOI: 10.3844 jastsp.2017.50.68

Petrescu, R.V., R. Aversa, B. Akash, J. Corchado and F. Berto et al., 2017e. Our universe. J. Aircraft Spacecraft Technol., 1: 69-79. DOI: 10.3844 jastsp.2017.69.79

Petrescu, R.V., R. Aversa, B. Akash, J. Corchado and F. Berto et al., 2017f. What is a UFO? J. Aircraft Spacecraft Technol., 1: 80-90. DOI: 10.3844 /jastsp.2017.80.90

Petrescu, R.V., R. Aversa, B. Akash, J. Corchado and F. Berto et al., 2017g. About bell helicopter FCX-001 concept aircraft-a short review. J. Aircraft Spacecraft Technol., 1: 91-96. DOI: 10.3844/jastsp.2017.91.96

Petrescu, R.V., R. Aversa, B. Akash, J. Corchado and F. Berto et al., 2017h. Home at airbus. J. Aircraft Spacecraft Technol., 1: 97-118. DOI: $10.3844 /$ jastsp.2017.97.118

Petrescu, R.V., R. Aversa, B. Akash, J. Corchado and F. Berto et al., 2017i. Airlander. J. Aircraft Spacecraft Technol., 1: 119-148.

DOI: $10.3844 /$ jastsp.2017.119.148

Petrescu, R.V., R. Aversa, B. Akash, J. Corchado and F. Berto et al., 2017j. When boeing is dreaming-a review. J. Aircraft Spacecraft Technol., 1: 149-161. DOI: 10.3844 jastsp.2017.149.161
Petrescu, R.V., R. Aversa, B. Akash, J. Corchado and F. Berto et al., 2017k. About Northrop Grumman. J. Aircraft Spacecraft Technol., 1: 162-185. DOI: $10.3844 /$ jastsp.2017.162.185

Petrescu, R.V., R. Aversa, B. Akash, J. Corchado and F. Berto et al., 20171. Some special aircraft. J. Aircraft Spacecraft Technol., 1: 186-203. DOI: 10.3844 /jastsp.2017.186.203

Petrescu, R.V., R. Aversa, B. Akash, J. Corchado and F. Berto et al., 2017m. About helicopters. J. Aircraft Spacecraft Technol., 1: 204-223. DOI: 10.3844 /jastsp.2017.204.223

Petrescu, R.V., R. Aversa, B. Akash, F. Berto and A. Apicella et al., 2017n. The modern flight. J. Aircraft Spacecraft Technol., 1: 224-233. DOI: 10.3844 /jastsp.2017.224.233

Petrescu, R.V., R. Aversa, B. Akash, F. Berto and A. Apicella et al., 2017o. Sustainable energy for aerospace vessels. J. Aircraft Spacecraft Technol., 1: 234-240. DOI: 10.3844/jastsp.2017.234.240

Petrescu, R.V., R. Aversa, B. Akash, F. Berto and A. Apicella et al., 2017p. Unmanned helicopters. J. Aircraft Spacecraft Technol., 1: 241-248. DOI: $10.3844 /$ jastsp.2017.241.248

Petrescu, R.V., R. Aversa, B. Akash, F. Berto and A. Apicella et al., 2017q. Project HARP. J. Aircraft Spacecraft Technol., 1: 249-257. DOI: $10.3844 /$ jastsp.2017.249.257

Petrescu, R.V., R. Aversa, B. Akash, F. Berto and A. Apicella et al., 2017r. Presentation of romanian engineers who contributed to the development of global aeronautics-part I. J. Aircraft Spacecraft Technol., 1: 258-271. DOI: $10.3844 /$ jastsp.2017.258.271

Petrescu, R.V., R. Aversa, B. Akash, F. Berto and A. Apicella et al., 2017s. A first-class ticket to the planet mars, please. J. Aircraft Spacecraft Technol., 1: 272-281. DOI: 10.3844/jastsp.2017.272.281

Petrescu, R.V., R. Aversa, B. Akash, F. Berto and A. Apicella et al., 2017t. Forces of a 3R robot. J. Mechatron. Robot., 1: 1-14. DOI: $10.3844 /$ jmrsp.2017.1.14

Petrescu, R.V., R. Aversa, B. Akash, F. Berto and A. Apicella et al., 2017u. Direct geometry and cinematic to the MP-3R systems. J. Mechatron. Robot., 1: 15-23. DOI: 10.3844/jmrsp.2017.15.23

Petrescu, R.V., R. Aversa, B. Akash, F. Berto and A. Apicella et al., 2017v. Dynamic elements at MP3R. J. Mechatron. Robot., 1: 24-37. DOI: $10.3844 /$ jmrsp.2017.24.37

Petrescu, R.V., R. Aversa, B. Akash, F. Berto and A. Apicella et al., 2017w. Geometry and direct kinematics to MP3R with $4 \times 4$ operators. J. Mechatron. Robot., 1 : 38-46. DOI: $10.3844 / j m r s p .2017 .38 .46$ 
Petrescu, R.V., R. Aversa, A. Apicella, M.M. Mirsayar and S. Kozaitis et al., 2017x. Current stage in the field of mechanisms with gears and rods. J. Mechatron. Robot., 1: 47-57.

DOI: $10.3844 /$ jmrsp.2017.47.57

Petrescu, R.V., R. Aversa, A. Apicella, M.M. Mirsayar and S. Kozaitis et al., 2017y. Geometry and inverse kinematic at the MP3R mobile systems. J. Mechatron. Robot., 1: 58-65. DOI: 10.3844/jmrsp.2017.58.65

Petrescu, R.V., R. Aversa, A. Apicella, M.M. Mirsayar and S. Kozaitis et al., 2017z. Synthesis of optimal trajectories with functions control at the level of the kinematic drive couplings. J. Mechatron. Robot., 1: 66-74. DOI: $10.3844 /$ jmrsp.2017.66.74

Petrescu, R.V., R. Aversa, A. Apicella, M.M. Mirsayar and S. Kozaitis et al., 2017aa. The inverse kinematics of the plane system 2-3 in a mechatronic MP2R system, by a trigonometric method. J. Mechatron. Robot., 1: 75-87. DOI: $10.3844 /$ jmrsp.2017.75.87

Petrescu, R.V., R. Aversa, A. Apicella, M.M. Mirsayar and S. Kozaitis et al., 2017ab. Serial, anthropomorphic, spatial, mechatronic systems can be studied more simply in a plan. J. Mechatron. Robot., 1: 88-97. DOI: 10.3844/jmrsp.2017.88.97

Petrescu, R.V., R. Aversa, A. Apicella, M.M. Mirsayar and S. Kozaitis et al., 2017ac. Analysis and synthesis of mechanisms with bars and gears used in robots and manipulators. J. Mechatron. Robot., 1: 98-108. DOI: 10.3844/jmrsp.2017.98.108

Petrescu, R.V., R. Aversa, A. Apicella, M.M. Mirsayar and S. Kozaitis et al., 2017ad. Speeds and accelerations in direct kinematics to the MP3R systems. J. Mechatron. Robot., 1: 109-117. DOI: $10.3844 /$ jmrsp.2017.109.117

Petrescu, R.V., R. Aversa, A. Apicella, M.M. Mirsayar and S. Kozaitis et al., 2017ae. Geometry and determining the positions of a plan transporter manipulator. J. Mechatron. Robot., 1: 118-126. DOI: $10.3844 /$ jmrsp.2017.118.126

Reddy, P., K.V. Shihabudheen and J. Jacob, 2012. Precise non linear modeling of flexible link flexible joint manipulator. IReMoS, 5: 1368-1374.

Sevil, H.E. and A. Dogan, 2015. Fault diagnosis in air data sensors for receiver aircraft in aerial refueling. J. Guidance Control Dynam., 38: 1959-1975. DOI: $10.2514 / 1 . G 000527$
Sherson, J.F., H. Krauter, RK. Olsson, B. Julsgaard and K. Hammerer et al., 2006. Quantum teleportation between light and matter. Nature, 443: 557-560. DOI: 10.1038 /nature 05136

Sun, J.Z. and S.M. Joshi, 2009. An indirect adaptive control scheme in the presence of actuator and sensor failures. Proceedings of the AIAA Guidance, Navigation and Control Conference, Aug. 10-13, Chicago, Illinois. DOI: 10.2514/6.2009-5740

Tabaković, S., M. Zeljković, R. Gatalo and A. Zivković, 2013. Program suite for conceptual designing of parallel mechanism-based robots and machine tools. Int. J. Adv. Robot Syst. DOI: 10.5772/56633

Tang, X., D. Sun and Z. Shao, 2013. The structure and dimensional design of a reconfigurable PKM. IJARS. DOI: $10.5772 / 54696$

The Future of Aircraft Propulsion is Electric | NASA. https://www.nasa.gov/centers/armstrong/Features/le aptech.html

Tong, G., J. Gu and W. Xie, 2013. Virtual entity-based rapid prototype for design and simulation of humanoid robots. Int. J. Adv. Robot. Syst. DOI: $10.5772 / 55936$

Venkataraman, G., 1992. Chandrasekhar and his Limit. 1st Edn., Universities Press, ISBN-10: 817371035X, pp: 89.

Wang, K., M. Luo, T. Mei, J. Zhao and Y. Cao, 2013. Dynamics analysis of a three-DOF planar serialparallel mechanism for active dynamic balancing with respect to a given trajectory. Int. J. Adv. Robotic Syst. DOI: 10.5772/54201

Ward, T.A., 2010. Aerospace Propulsion Systems. 1st Edn., Wiley Publisher, ISBN-10: 9780470824979.

Williams, D.R., 1995. Saturnian satellite fact sheet. NASA.

Wen, S., J. Zhu, X. Li, A. Rad and X. Chen, 2012. Endpoint contact force control with quantitative feedback theory for mobile robots. IJARS. DOI: $10.5772 / 53742$

Source of Figures: Petrescu and Petrescu, 2012a

Figure 5a: Staelin, 2008 